\title{
SIMULATION OF BILINEAR FLOW IN SINGLE MATRIX BLOCK DRAINAGE
}

\author{
A Thesis \\ by \\ ROMI TRIAJI BRANAJAYA

\begin{abstract}
Submitted to the Office of Graduate Studies of
Texas A\&M University

in partial fulfillment of the requirements for the degree of

MASTER OF SCIENCE
\end{abstract}

December 2003

Major Subject: Petroleum Engineering 


\title{
SIMULATION OF BILINEAR FLOW IN SINGLE MATRIX BLOCK DRAINAGE
}

\author{
A Thesis \\ by \\ ROMI TRIAJI BRANAJAYA \\ Submitted to Texas A\&M University \\ in partial fulfillment of the requirements \\ for the degree of \\ MASTER OF SCIENCE
}

Approved as to style and content by:

Robert A. Wattenbarger

(Chair of Committee)

Robert R. Berg

(Member)

J. Bryan Maggard

(Member)
David S. Schechter

(Member)

Hans C. Juvkam-Wold

(Head of Department)

December 2003

Major Subject: Petroleum Engineering 


\begin{abstract}
Simulation of Bilinear Flow in Single Matrix Block Drainage. (December 2003)

Romi Triaji Branajaya, B.S., Trisakti University, Jakarta, Indonesia

Chair of Advisory Committee: Dr. Robert A. Wattenbarger
\end{abstract}

This thesis presents modeling of bilinear flow in tight gas wells and its behavior on single matrix block drainage.

The objectives of this research are to: simulate a tight gas well using matrix block drainage under constant production $p_{w f}$ and with a constant production rate; be able to predict the behavior of matrix block drainage; study the effect of natural fracture(s) near a well; examine the matrix block drainage in a natural fracture network; and to validate a matrix block drainage model with a hydraulic fracture analytical solution.

Two different production scenarios, constant $p_{w f}$ and constant rate, are assigned to a tight gas well in matrix block drainage. Matrix block drainage has two distinct permeabilities; a low permeability matrix serves as the tight gas reservoir with a high permeability streak surrounding the matrix. A well only produces from the high permeability fracture.

Models were run with different sensitivity cases toward fracture half length, $x_{f}$, and fracture permeability $k_{f}$. The fracture half-length reflects on $\mathrm{a} / \mathrm{b}$ aspect ratio. The analytical solution for hydraulic fracture developed by Cinco-Ley and Guppy serves as the validation of matrix block drainage.

Analysis on the flow regimes which occurred for different geometries and properties are provided. The log-log diagnostic plot of pseudo-pressure drop/gas rates and the log-log plot of dimensionless pressure derivatives and dimensionless reciprocal production rates are presented. Finally, an attempt to normalize the late time and early time of all geometries and properties is presented to obtain one analytical solution. 


\section{DEDICATION}

In the name of GOD, Most Gracious, Most Merciful

Dedicated to those whom I love with all my heart:

My parents Subandrio and Sunarti

My three sisters, Yuli, Sherly and Vani

Angel, rest peace in Heaven 


\section{ACKNOWLEDGMENTS}

The author wishes to express his sincere gratitude and appreciation to the following people who significantly contributed to this work.

Thank you to Dr. Robert A. Wattenbarger, Professor of Petroleum Engineering, who served as chair of my graduate committee. His dedication, devotion and enthusiasm guided the author with many ideas that led to the completion of this work. Dr. Wattenbarger diligently and meticulously reviewed and corrected every piece of the work and continuously added his fresh ideas and experience to the final product. I always felt that I was fortunate to work under his supervision.

Thank you to Dr. David Schechter, Dr.Robert Berg and Dr.Bryan Maggard, for serving as members of my graduate committee.

I wish to thank the faculty and staff at Harold Vance Department of Petroleum Engineering for sharing their knowledge, support, and encouragement during my studies at Texas A\&M University.

I wish to thank the Committee of Overseas Scholarship Program for Graduate Studies Pertamina-PSCs (Production Sharing Contractors) Educational Consortium and CNOOC Ltd for financial assistance.

Finally, I want to express my gratitude and appreciation to all my colleagues in the Reservoir Modeling Group of Texas A\&M University: Mazher Ibrahim, Deji Adeyeye, Mohamed El-Ahmady, Christian Huapaya, and Mariela Franquet. 
TABLE OF CONTENTS

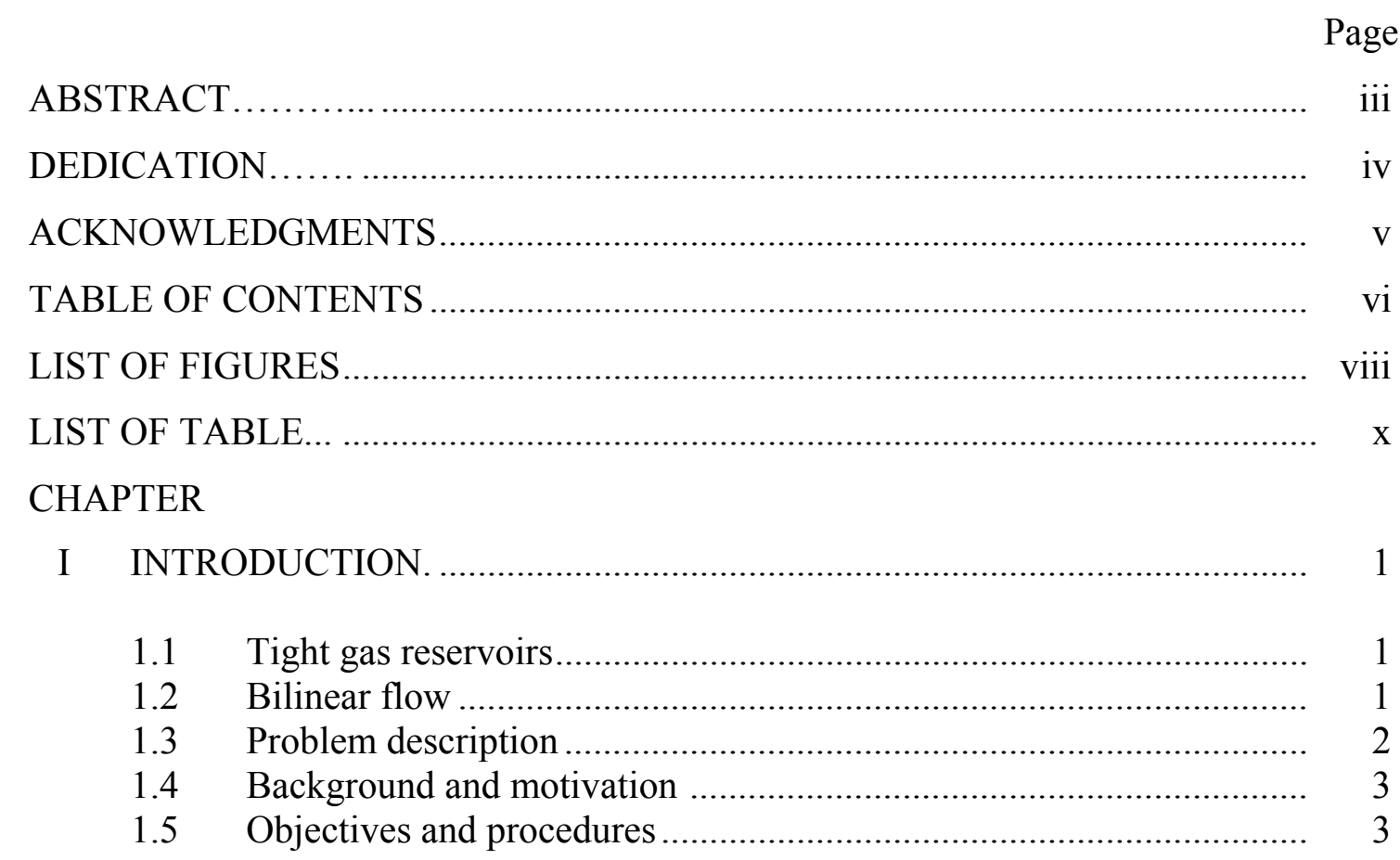

II LITERATURE REVIEW. ................................................................ 4

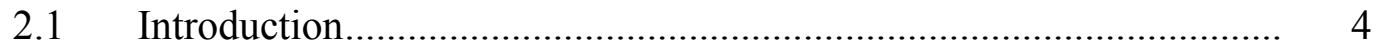

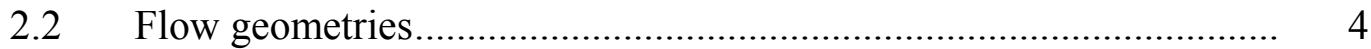

2.2.1 Bilinear flow ................................................................. 4

2.2.2 Linear flow................................................................... 6

2.3 Reservoir geometries and associated flow regimes ........................ 9

2.3.1 Hydraulic fractured wells ...................................................... 9

2.3.2 Naturally fractured reservoirs ............................................ 11

III SIMULATION OF BILINEAR FLOW IN THE SINGLE MATRIX BLOCK 15

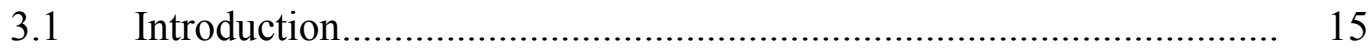

3.2 Flow pattern in fractured well.................................................... 15

3.3 Single matrix block model ......................................................... 16

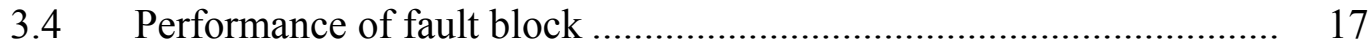

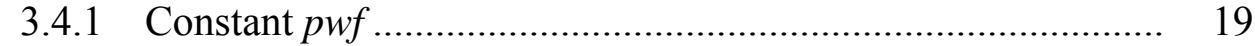

3.4.2 Constant rate ............................................................... 22

3.5 Dimensionless variables ........................................................... 25 
CHAPTER $\quad$ Page

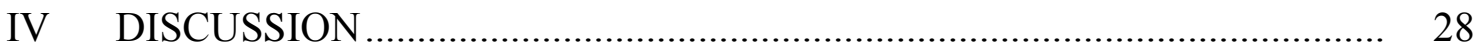

4.1 Introduction......................................................................... 28

4.2 General discussion ............................................................... 28

$4.3 \quad$ Future work................................................................................ 41

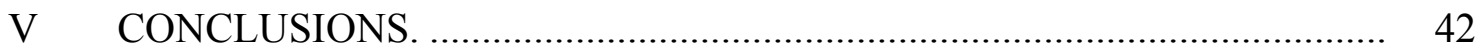

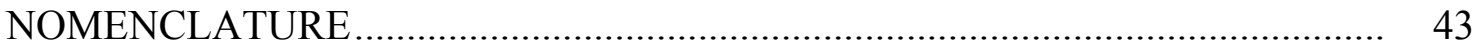

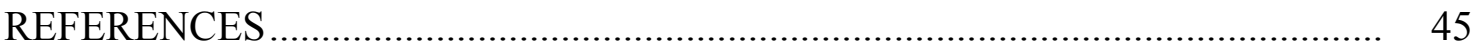

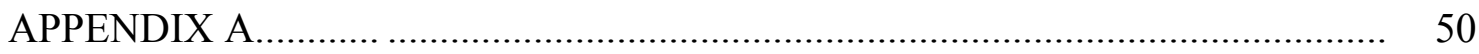

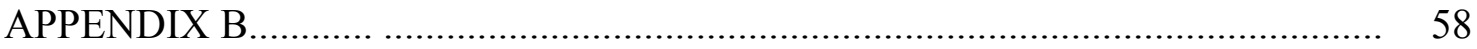

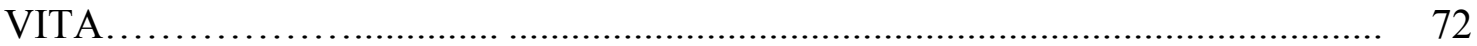




\section{LIST OF FIGURES}

FIGURE Page

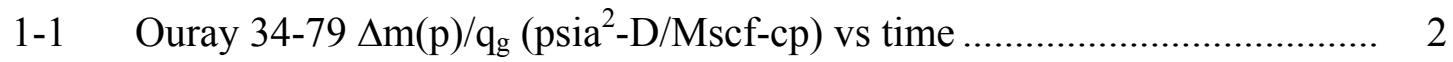

3-1 Fault block drainage model …........................................................ 17

3-2 Model equivalent of hydraulic fracture and fault block ......................... 17

3-3 Constant $p_{w f}$ solution for various $x_{f}\left(\right.$ all a/b ratio), $k_{f}=100 \mathrm{md} \ldots \ldots \ldots \ldots \ldots \ldots . . . . . . .19$

3-4 Simulation result and analytical solution under constant $p_{w f}$ solution for

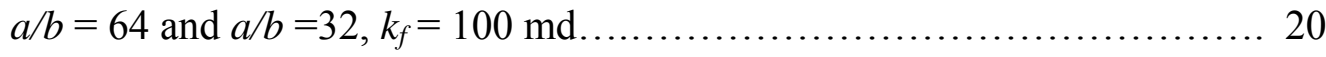

3-5 Slope under constant $p_{w f}$ solution for case $a / b=1, k_{f}=100 \mathrm{md} \ldots \ldots \ldots \ldots \ldots \ldots . . . . .21$

3-6 Slope under constant $p_{w f}$ solution for case $a / b=8, k_{f}=100 \mathrm{md} \ldots \ldots \ldots \ldots \ldots \ldots . . . . . .21$

3-7 Slope under constant $p_{w f}$ solution for case $a / b=64, k_{f}=100 \mathrm{md} \ldots \ldots \ldots \ldots \ldots . . . .22$

3-8 Constant rate solution for various $x_{f}$ (all a/b ratio), $k_{f}=100 \mathrm{md} \ldots \ldots \ldots \ldots \ldots \ldots . . . . .23$

3-9 Simulation result and analytical solution under constant rate solution

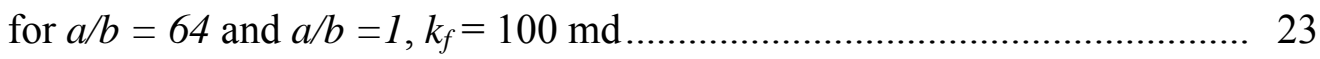

3-10 Slope under constant rate solution for case $a / b=1, k_{f}=100 \mathrm{md}$................ 24

3-11 Slope under constant rate solution for case $a / b=8, k_{f}=100 \mathrm{md} \ldots \ldots \ldots \ldots \ldots \ldots . . . . .24$

3-12 Slope under constant rate solution for case $a / b=64, k_{f}=100 \mathrm{md} \ldots \ldots \ldots . .25$

4-1 Normalized early time for all $a / b$ under constant $p_{w f}$ production, $k_{f}=100 \mathrm{md}$

4-2 $\left(1 / q_{D}\right)$ and $\left(1 / q_{D}{ }^{\prime}\right)$ versus $t_{D x f}, a / b=64$ under constant $p_{w f}$ production, $k_{f}=100 \mathrm{md}$. 
4-3 $\left(1 / q_{D}\right)$ and $\left(1 / q_{D}^{\prime}\right)$ versus $t_{D x f}, a / b=1$ under constant $p_{w f}$ production, $k_{f}=100 \mathrm{md}$

4-4 $\left(1 / q_{D}\right)$ and $\left(1 / q_{D}^{\prime}\right)$ versus $t_{D x f}$, all $a / b$ under constant $p_{w f}$ production, $k_{f}=100 \mathrm{md}$.

4-5 Normalized early time for all $a / b$ under constant rate production, $k_{f}=100 \mathrm{md}$.

4-6 $\left(p_{W D}\right)$ and $\left(p_{W D}\right)$ versus $t_{D x f}, a / b=64$ under constant rate production, $k_{f}=100 \mathrm{md}$.

4-7 $\left(p_{W D}\right)$ and $\left(p_{W D}\right)$ versus $t_{D x f}, a / b=1$ under constant rate production,

$k_{f}=100 \mathrm{md}$.

4-8 $\quad\left(p_{W D}\right)$ and $\left(p_{W D}\right)$ versus $t_{D x f}$, all $a / b$ under constant rate production, $k f=100 \mathrm{md}$.

4-9 Bilinear flow for $a / b=64$ at $t_{D x f}=10^{-11}$ under constant $p_{w f}$ production, $k_{f}=100 \mathrm{md}, F_{C D}=1$

4-10 Linear flow for $a / b=64$ at $t_{D x f}=510^{-5}$ under constant $p_{w f}$ production, $k_{f}=100 \mathrm{md}, F_{C D}=1$

4-11 Bilinear flow for $a / b=1$ at $t_{D x f}=210^{-8}$ under constant $p_{w f}$ production, $k_{f}=100 \mathrm{md}, F_{C D}=35$ 38

4-12 Linear flow for $a / b=1$ at $t_{D x f}=210^{-4}$ under constant $p_{w f}$ production, $k_{f}=100 \mathrm{md}, F_{C D}=35$

4-13 Change of dimensionless variables for $a / b=64$ and $F_{C D}=200$ 40

4-14 Normalized late time for all $a / b$ under constant rate production, $k f=100 \mathrm{md}$. 


\section{LIST OF TABLES}

TABLE Page

3-1 Simulation data input f.............................................................. 18

3-2 Simulation cases of bilinear flow ................................................... 18

3-3 Dimensionless variables for constant $p_{w f}$ production, matrix block

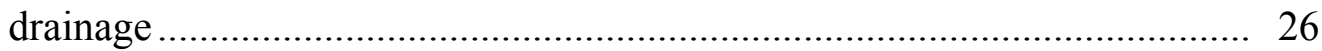

3-4 Dimensionless variables for constant rate production, matrix block

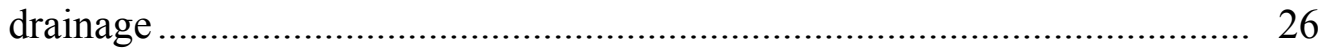

4-1 Dimensionless variables changed for $a / b=64, F_{C D}=200 \ldots \ldots \ldots \ldots \ldots \ldots \ldots \ldots . . . . . . . . .39$ 


\section{CHAPTER I \\ INTRODUCTION}

In this chapter we explain the scope of our work. We start with the problem description and objective of the research. Previous works done by many authors are presented in chapter two as literature review. Chapter three will focus on the research result. Discussion of the result will follow in chapter four, finally, some conclusion in the last chapter.

\subsection{Tight gas reservoirs}

Tight gas reservoirs are defined as a gas reservoir, which cannot produce commercial quantity of gas at economical rate unless massive stimulation and/or fracturing treatments are successfully designed and implemented. Usually tight gas reservoirs have matrix permeability less than $0.1 \mathrm{md}$.

The U.S. Energy Information Administration estimates that overall energy consumption will rise $60 \%$ during 1997-2020 with natural gas being the fastest growing component of the primary world energy. Currently many countries use natural gas as the primary source of imported energy, while at the same time gas exporting countries have developed gas reserves and transportation infrastructure to meet the demand for natural gas.

\subsection{Bilinear flow}

Bilinear flow is flow regime resulting from combined simultaneous linear flow from matrix to fracture in perpendicular direction and in the fracture. Bilinear flow is characterized by quarter slope line when pressure or reciprocal of production data are plotted versus time on a log-log plot. Several authors have discussed the occurrence of bilinear flow. This flow regime encountered in hydraulic fracture and naturally fractured well, it is especially an important flow regime associated with production from tight gas reservoirs.

This thesis follows the style and format of Journal of Petroleum Technology. 


\subsection{Problem description}

The emphasis will be placed on long-term bilinear flow. Field examples of bilinear flow encountered at Ouray 34-79 well, Castelgate, Utah. The well shows longterm bilinear flow more than a year as shown by $m=1 / 4$ in Fig. 1-1. Ouray 34-79 is producing from a tight gas well with permeability of $0.0193 \mathrm{md}$. Questions arise when we try to predict the long-term behavior of the well with simulation. The reservoir is suspected producing form natural fractures throughout production time. This research project is intended to simulate bilinear flow with single low permeability matrix block model surrounded by high permeability fracture and how it can be fitted in to the whole reservoir behavior.

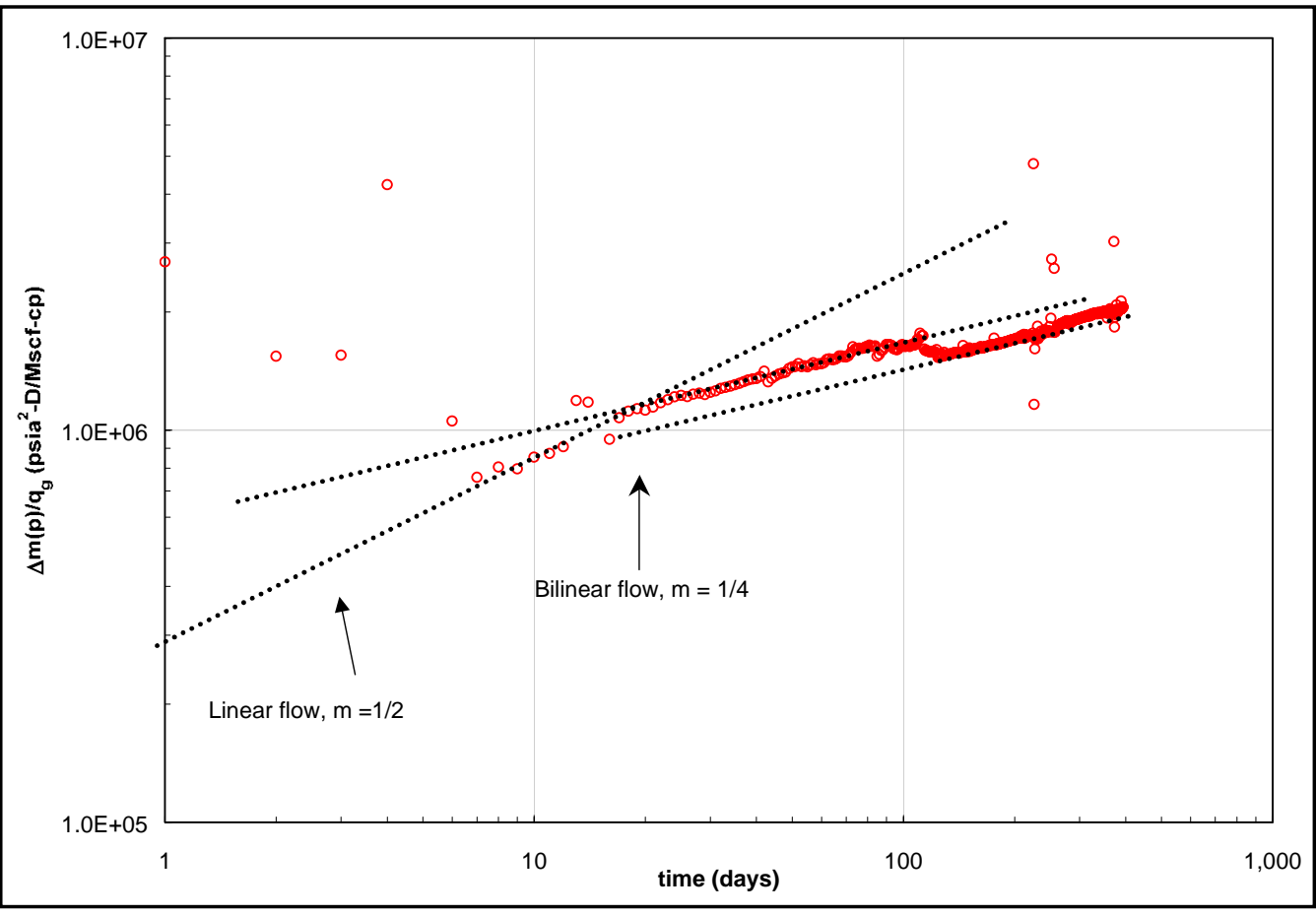

Fig. 1-1 - Ouray 34-79 $\Delta \mathrm{m}(\mathrm{p}) / \mathrm{q}_{\mathrm{g}}\left(\mathrm{psia}^{2}-\mathrm{D} / \mathrm{Mscf}-\mathrm{cp}\right)$ vs time 


\subsection{Background and motivation}

Predicting the flow regimes from a tight gas well require total information or reservoir definition and fluid-rock properties among other parameters.

Cinco-Ley and Samaniego ${ }^{1}$ first introduce the idea of bilinear flow in hydraulic fractured well. They showed analytical solution to describe bilinear flow. To best of our knowledge not much too much has been written concerning what causes the long-term transient performance and production analysis of tight gas wells. The subject and the purpose of this research is to investigate long-term bilinear flow in tight gas wells using simulation and verify the behavior of the model with Cinco-Ley's analytical solution. Discussion about physical scenarios that cause bilinear flow under either constant flowing bottom hole pressure or constant rate production is presented.

Wattenbarger $^{2}$ presented linear analytical solutions for fractured wells rectangular reservoir geometry. Type curves and equations to analyze long-term linear flow performance of tight gas wells under either constant flowing bottom hole pressure or constant rate production is developed.

A model similar to dual porosity Warren and Root $^{3}$ is developed. We use matrix block drainage with low permeability surrounded by high permeability fracture and the well only producing from the fracture.

\subsection{Objectives and procedures}

The objectives of this research are:

(1) Study the long-term behavior of tight gas well

(2) Simulate flow behavior in naturally fracture reservoir with matrix block drainage model

(3) Be able to predict matrix block drainage behavior

(4) Validate the simulation result with the analytical solution 


\section{CHAPTER II}

\section{LITERATURE REVIEW}

\subsection{Introduction}

This chapter deals with literature review on several different areas of flow dynamic studied and documented in the past. It serves as the basic fundamentals to the current research. We shall start with the occurrence of the bilinear flow and linear flow. These will present also the analytical solution and the graphical analysis. We shall then discuss reservoir and well geometries and flow regimes associated. Finally the last section focuses on the miscellaneous references relevant to petroleum engineering.

\subsection{Flow geometries}

Several flow regimes occur in different reservoir models and sometime in a given model but at different times depending on reservoir and well characteristics. Each flow regime gives distinctive shape to a pressure and pressure derivative response. Log-log diagnostic plot first presented by Bourdet et $a l^{4}$ is used to identify the data for straightline analysis of various flow regimes and then appropriate plotting procedure for straight-line analysis is used.

\subsubsection{Bilinear flow}

Bilinear flow is detected in hydraulically fracture and natural fractured reservoirs. Long-term bilinear flow has been discussed widely in petroleum literature ${ }^{1,5,6}$. Long-term bilinear behavior has been recognized in some tight basins that produce $\operatorname{gas}^{7,8,9}$.

Some conditions causing bilinear flow are: a vertical well between two parallel leaky boundaries due to faulting or sedimentary process, a vertical well near a high conductivity infinite fault, a vertical well with a finite conductivity fracture ${ }^{10,11}$,a horizontal well in a fractured reservoir with transient dual porosity behavior during the intermediate linear flow period, a horizontal well in a layered, with transient dual 
porosity behavior during the intermediate linear flow period and linear reservoir with transient dual porosity behavior.

Some authors discussed the occurrence of bilinear flow regime in reservoirs. Some of them presented models, solutions, and type curves under different conditions for both homogeneous and dual porosity reservoirs ${ }^{1,5,12,13}$. Among these, the following sources from the literature report the occurrence of bilinear flow regime in some reservoirs.

Cinco-Ley and Samaniego ${ }^{1}$ introduced the idea of bilinear flow in petroleum reservoirs. They found that a plot of $p_{w f}$ vs $\sqrt[4]{t}$ yields a straight line whose slope depends upon the group $h_{f} \sqrt{w k_{f}}$ where $h_{f}, w$ and $k_{f}$ are the height, width and permeability of the fracture respectively. This was introduced as part of graphical method provided to analyze pressure data, for cases of well intersecting a vertical fracture of low and intermediate conductivities at early times. The author concluded that bilinear flow model is appropriate for analyzing pressure data whenever the formation permeability is too low and the fracture length is large, because under these conditions, the dimensionless fracture conductivity and the dimensionless time corresponding to practical values of real time are within the range of application of this technique.

Cinco-Ley and Meng ${ }^{5}$ studied a well with finite conductivity vertical fracture in a dual porosity reservoir. They found that in the transient matrix flow model the pressure behavior exhibits a $1 / 8$ slope in a log-log plot during the bilinear flow dominated by transition period of the fluid transfer. Hence, a graph of pressure vs $\mathrm{t}^{1 / 8}$ yields a straight line passing trough the origin. During pseduolinear flow, and if the fluid transfer is in the transition period, a log-log graph of the pressure versus time exhibits $1 / 4$ slope straight line. This proves that a graph of $\mathrm{t}$ versus $\mathrm{t}^{1 / 4}$ yields a straight line. Hence, it is concluded that bilinear flow is not the only type of flow that exhibits the one-quarter-slope type of behavior.

Cinco-Ley et al. ${ }^{6}$ showed that the transient pressure behavior for a well with a low conductivity vertical fracture $\left(F_{c d} \leq 0.1\right)$ exhibits three flow periods bilinear flow, transient period, and pseudo-radial period. 
Spivey and Lee ${ }^{14}$ outlined the technique for identifying flow regimes from their characteristic pressure and pressure derivative responses, and provide methods for selecting data and the appropriate plotting procedure for straight line analysis of each flow regime. Each flow regime causes a pressure and pressure derivative response with a characteristic shape. The shape of the pressure derivative response is determined bye the current flow regime, while the pressure response is also affected by all preceding flow regimes. Because of this, the presence of particular flow regime is often inferred from the shape of the pressure derivative.

England et al. ${ }^{15}$ focused on the comparison of the performance of conventionally fractured wells and those that have not been completed with the treated water and low propane concentration ("waterfrac") technique. A new evaluation technique for comparing the effectiveness of the treatments utilizing production data is introduced. Specialized diagnostic, performance history matching with analytic solution and specialized type curve analyses have been used for several areas to estimate the fracture and formation properties of bilinear, formation linear and pseduoradial flow regimes.

Kern et al. ${ }^{16}$ presented semi-analytic solution unsteady state flow behavior of a well intersecting a vertical fracture for case of constant pressure well. Analytic solutions are also presented for defining certain portions of the early time data for various types of fracture conductivity. A graphical technique is provided to analyze rate data by plotting a graph of $1 / \mathrm{q}$ versus $\mathrm{t}^{1 / 4}$ to yield straight line with a slope, which is proportional to the fracture conductivity.

\subsubsection{Linear flow}

Linear flow behavior has been detected in almost all tight basins that produce gas in low permeability reservoirs ${ }^{7,17,18,19,20,21}$. Linear reservoirs are those reservoirs which show predominantly linear flow because of the shape of the reservoir. This situation may occur in vertically fractured vertical wells whose fractures extend literally to the reservoir boundaries. It may also occur in horizontal natural fractures and high permeability streaks. In this case, the linear flow will develop in the vertical direction. Such reservoir may develop linear flow from the start of production. 
Stright and Gordon ${ }^{7}$ described long-term linear performance on tight gas wells in the Picenace basin, which did not have particularly large fracture treatments. They observed that this linear flow behavior for many years indicated that fracture lengths are much longer than would be expected from hydraulic fracturing treatments. They discussed that if a $\log -\log$ diagnostic plot $q_{g}$ versus $t$ for the first or two years of production has a half slope, and then a $\sqrt{t}$ extrapolating technique would be used for $q_{g}$ forecasting. They suggested that boundary dominated effects can be represented by an exponential decline curve.

Kohlhaas and $\mathrm{Abbot}^{17}$ explained that linear flow conditions develop early in the life of the well, which has been hydraulically fractured. After, this early linear flow regime is followed by early radial flow. Then, late linear flow may develop due to certain configurations of reservoir geometry. Some conditions in which a late flow regime would develop are channel sands, bar sands, edge or bottom-water-drive reservoirs. Wells between parallel faults, horst, and stratified reservoirs in which lowpermeability layers drain into high permeability layers then radial to well bore. They developed techniques for analyzing spherical and linear flow. They also suggested that the pressure data should be graphed in different plots to help identify and recognize the different flow regimes.

El-Banbi and Wattenbarger ${ }^{19}$ presented a practical approach to analyze both pressure (well testing) and production (decline curve analysis) data, which are influenced by linear flow. They pointed out that constant rate solutions are different from the constant pressure solution and the use of wrong equations in the analysis of tight gas wells may result in errors as highs as $60 \%$. They also showed the application of techniques in analyzing actual production data.

Arévalo and Wattenbarge ${ }^{21}$ reported recent results of an ongoing study of the daily production rates and wellhead pressure of six fractured tight gas wells in Utah. Through production analysis, they identified and interpreted the flow periods by using diagnostic and specialized plots of pressure and production data. Then, they evaluated reservoir properties in function of observed transient performance. They would expect that these wells would show the following transient period: early linear, then bilinear, 
and then late linear flow. They concluded that in low permeability reservoirs there are natural paths of higher permeability/conductivity. These may be natural streaks of higher permeability or maybe natural fractures. The authors would expect that a number of such higher permeability streaks are present in the vicinity of any well but may not be connected to the well bore.

Muskat $^{22}$ discussed steady-state single phase and multiphase linear flow systems and their pressure distribution. He also shows linear flow geometries in terms of core analysis and line-derivative networks applied to secondary recovery.

Miller $^{23}$ presented the theory of unsteady state influx water in linear systems of oil reservoirs and fluid connected aquifers. His work is considered the classical paper in linear flow theory. He presented the analytical solutions for both infinite and finite aquifers. Constant-rate and constant pressure cases were defined and solved analytically. The solution results were plotted in a usable graphical form. The author also explained the concept of superposition and worked some numerical example to illustrate the use of his results. The constant pressure solutions were presented in a form to calculate cumulative water influx as a function of time.

Nabor and Barham ${ }^{24}$ generalized Miller's solutions in dimensionless variables and derived solutions for constant pressure outer boundary case. Dimensionless time transformation is presented to reduce the analytical solutions to only three working curves corresponding to closed outer boundary, infinite acting, and constant pressure outer boundary. By the use of these curves and the appropriate equations, the water influx or the pressure drop at the aquifer reservoir boundary can be easily calculated for linear reservoir.

Wattenbarger et al. ${ }^{25}$ and Wattenbarger ${ }^{18}$ found that some literature author did not use correct equations in analyzing data under constant flowing bottom hole pressure. They noticed that analytical solutions for constant bottom hole flowing pressure production and constant rate production are not the same. They mentioned that only a constant rate production equation in gas well is well known. Then, they adapted linear solution of Miller $^{23}$ and Nabor and Barham ${ }^{24}$ for fractured wells in rectangular geometry for both constant rate and constant pressure cases for linear flow in rectangle. The author 
developed correct transient and stabilized linear equations plus infinite series. Similarly, a methodology for estimating $\sqrt{k} A_{c}$ product and original gas in place, OGIP, for tight gas reservoir was developed.

Economides et $a^{26}$ used a parallelpiped model with no-flow boundaries on five sides and a constant pressure boundary at the bottom to analyze pressure transient data of fractured geothermal steam wells. They modeled the fracture system as a rectangular shaped source. They used type curve matching technique to illustrate the use of the model in analyzing field data.

Wagner et $a l .{ }^{27}$ used source and Green's functions to develop type curves for fractured wells in linear reservoirs. They looked at the case where the fracture is parallel to the reservoir linear boundaries. They showed that linear flow develops in such reservoirs.

Ammer et $a l .^{28}$ used log-log plot of cumulative gas produced versus time to analyze the production mechanisms of 284 producing wells in the Clinton formation of eastern Ohio. The production characteristics signified that the sandstone exhibits linear flow (1/2) slope in $48 \%$ of the wells. Nearly all of the intermediate slopes were closelinear slopes. The authors explained that a correlation of slope with the environment of deposition was established. They mentioned that an intermediate flow is indicative of a well draining multiple layers with different flow characteristic.

\subsection{Reservoir geometries and associated flow regimes}

\subsubsection{Hydraulic fractured wells}

Prats et.al ${ }^{29}$ presented analytical solution for constant pressure and constant rate cases for a cylindrical, homogeneous, isotropic reservoir with a vertical well intersected by an infinite conductivity vertical fracture that fully penetrates the formation. It was found that both constant rate and constant pressure case can be modeled by an elliptical reservoir with larger effective well bore radius of about one fourth of the total fracture length or one half the fracture wing 
Prats and Levine ${ }^{30}$ investigated the possibility of using numerical technique to study the two space variable flow behavior resulting from a vertical fracture. Results are discussed first in terms of specific reservoir and crude properties and geometries. Later dimensionless parameters are introduced in order to extend results to different values of some of the reservoir and fracture properties.

Russel and Truitt $^{31}$ presented numerical solution to a vertical fractured well with an infinite conductivity fracture, in the center of a square, homogeneous, isotropic, uniform thickness reservoir filled with a low, constant compressibility fluid is presented. The diffusivity equation was discretized and solved numerically with no flow boundaries for the edges of the reservoir and a constant rate at the well bore with no pressure drops along the fracture. The transient flow regime is characterized by region near the fracture where flow is linear and region away from the fracture where flow is pseduo radial.

Wattenbargber and Ramey ${ }^{32}$ found that the drawdown testing method for vertically fractured wells can be extended to the real gas case by using the pseduopressure function. They also showed that the calculated $k h$ will tend to be too high in the absence of turbulence. They also developed rules to identify the end of linear flow and start of radial flow. A two dimensional simulator is developed that used pseduo-pressure as solution variable.

Morse and Von Goten ${ }^{33}$ studied the productivity index ratio between the fractured cases and the unfractured pseduo steady state cases, it showed a decrease with time till stabilization (pseduo steady state productivity index). The productivity index ratio increases very rapidly as the fracture penetration $\mathrm{x}_{\mathrm{f}} / \mathrm{x}_{\mathrm{e}}$ increases. For constant pressure cases a $2 \mathrm{D}$ numerical simulation was run. The result show again that the larger the $\mathrm{x}_{\mathrm{f}} / \mathrm{x}_{\mathrm{e}}$ the larger the increase in the productivity index ratio.

Agarwal $^{34}$ introduced a time transformation function to account for the variation of gas viscosity and compressibility as a function of pressure, which in turn is a function of time. Unlike the real pseduopressure, this transformation is approximate. However, it is useful in analyzing pressure buildup tests in massive hydraulic fractured wells. The author suggested the use of initial pressure at the start of the buildup test as a reference point. He also showed that with the use of the pseduo pressure pseduo time analysis, one 
can analyze buildup test for gas wells more efficiently than with the use of pseduopressure alone.

Raghavan et al. $^{35}$ presented new correlations to determine the long-time performance of a multiply-fractured, horizontal system. They presented the result based on the purpose of fracturing horizontal well is to create a system such that the long-time performance of the horizontal well will be equivalent to that of a fractured well with a specific conductivity and fracture length equal to distance between the two outermost fractures.

\subsubsection{Naturally fractured reservoirs}

Naturally fractured reservoirs are often encountered in petroleum reservoirs especially tight gas reservoirs. They are usually modeled with anisotropic models or dual porosity models. Dual porosity models are used to describe the behavior of reservoirs that are composed of two media with distinctive properties. One medium is the fracture system. The fracture system has to be formed of a network of connected fractures, which are responsible for the flow capacity of the formation. In the mean time, the fracture system is characterized by a very low storage capacity. The other medium is matrix system. It is assumed that the matrix system does not contribute to the flow capacity of the formation but contains most of the fluid stored in the formation.

Warren and $\operatorname{Root}^{3}$ developed solutions for naturally fractured reservoirs based on idealized model of matrix cubes intersected by fractures. They assumed that naturally fractured reservoirs could be characterized by two different system: low storage high permeability fractures and high storage low permeability matrix. They assumed that the flow occurs only in the fractured system and the matrix feeds the fractures with a slightly compressible fluid. The interporosity flow (flow from matrix blocks to fractured system) is pseduo-steady-state flow. Their model is characterized by two parameters in addition to the parameters characterizing the homogeneous model. They used Laplace transform technique to solve the resulting partial differential equation.

Arnold et $a l^{36}$ presented a method to estimate the effective directional permeability ratio and the direction of maximum and minimum permeability in 
anisotropic reservoirs. Their method is based on a steady-state equation for homogeneous fluid flow and uses elliptical flow equations. The method requires bottom hole pressure to be recorded from three wells while a fourth well is being produced. The authors also cited examples from the literature that showed directional permeability at different magnitude.

Parsons $^{37}$ studied the effect of fractures on overall permeability of the porous medium. He used two models in his study: a regular fracture-matrix model and a heterogeneous fracture system, which he solved numerically. He concluded that the gross single-phase flow behavior in naturally fractured porous rock is equivalent to that of an anisotropic permeability medium.

Prats $^{38}$ studied analytically the effect of thin impermeable shale streaks and infinitely conductive fractures on permeability anisotropy of the reservoir. He showed that the anisotropy ratio can be correlated with fracture length and density of fractures. The solutions for impermeable streaks results in $90^{\circ}$ oriented results of anisotropy compared with finite conductivity fracture use.

Locke and Sawyer ${ }^{39}$ used pressure transient testing in a naturally fractured reservoir to determine the direction of anisotropy. The test lasted for 32 days and no reservoir boundaries were observed. The authors developed a type curve for constant pressure case. They used superposition of the inverse of infinite conductivity vertical fracture solution for infinite acting reservoirs and numerical solutions for bounded reservoirs.

Odeh $^{40}$ studied the behavior of naturally fractured reservoirs for infinite acting reservoirs. He assumed quasi-steady-state flow in the matrix. He used Laplace Transform technique to solve the problem. His solution is in the form of the Ei-solution with average properties. The results he obtained are similar to that of Warren and Root although the models are different. However, he concluded that for all practical purpose, one distinguishes between fractured and homogenous reservoirs from pressure build up and /or draw-down data.

Kazemi $^{41}$ presented a model for naturally fractured reservoir based on transient interporosity flow in the matrix system. He solved the problem using numerical 
techniques. He concluded that the two semi-log straight lines formed for the early time and late time regions were parallel. The difference between his model and that of Warren and Root is only in the transition period between fracture flow to total system flow. Kazemi also realized that the behavior of a fractured reservoir, as described by his mode was identical with the behavior of multi-layer reservoirs with cross-flow.

de Swaan ${ }^{42}$ presented a model for transient interporosity flow. He presented analytical solutions for both early time and the late time regions for infinite action reservoirs. The early time flow is governed by fracture flow and the late time flow is governed by the total system flow. He did not present the solution for the intermediate time which is the transition from fracture system flow to total system flow.

Aguilera $^{43}$ presented equations for evaluation of linear flow in naturally fractured reservoirs. This situation might occur in the case of dual porosity systems, which are hydraulically fractured. He assumed that only fractures were flowing to the hydraulic fracture at constant rate an matrix block were feeding fluid to the fracture system. The hydraulic fracture was infinite conductivity. His solutions can be used for any interporosity flow model and for any matrix block shape.

Aguilera $^{44}$ also presented methods for matching observed pressure data during draw-down or build up tests. He concluded that the transition period is difficult to handle. He reported that the half-slope line, indicative of linear flow, might be seen in the transition period if $\omega<0.0099$, for the stratum model. He concludes, however, that the differences between the different models are difficult to be seen on the actual data for most practical purposes.

Da Prat et al. ${ }^{45}$ developed solutions and type curves for decline curve analysis in naturally fractured reservoirs. The used the model of Warren and Root which assumed pseduo-steady-state interporosity flow. They solutions were presented for both infinite and finite reservoirs and were inverted from Laplace space numerically. For closed outer boundary reservoirs, they showed that the log-log plot of dimensionless cumulative rate versus dimensionless time would give unit slope line. The flow rate showed a rapid decline initially, became nearly constant for a period of time, and then a final decline in rate took a place. 
Gringarten ${ }^{46}$ presented a review of the methods of analysis of fractured reservoirs and aquifers in the geotechnical, ground-water and petroleum literature. He studied that there were two main approaches used for analyzing flow problems in fissured rocks. One based on representing the fracture formation as discontinuous medium, and considered individual fracture behavior and the exact geometry of the fissured system; the other assumed continuity and statically homogeneous rock and fluid properties. The models discussed included homogeneous, anisotropic, vertical fracture, horizontal fracture, and heterogeneous models. Heterogeneous included double porosity, multi layer and composite model.

Gringarten ${ }^{47}$ discussed different double porosity models and presented different type curves that were used in analyzing pressure transient data for those reservoirs. He concluded that fissured reservoirs and multi-layered reservoirs exhibited the same double porosity behavior. He showed that the two parallel semi-log straight line feature did not always exist. The author experience suggested that non-damaged in double porosity reservoirs exhibited a pseduo-skin factor of negative 3, and zero skin usually indicated a damaged well. He also concluded that fissured reservoirs could be distinguished from multi-layered reservoirs only if the well is not damaged nor acidized. He also showed that the two parameters used for characterizing double porosity behavior ( $\lambda$ and $\omega$ ) might change with time for the same well because they depend on reservoirs and fluid properties. 


\section{CHAPTER III \\ SIMULATION OF BILINEAR FLOW IN THE SINGLE MATRIX BLOCK}

\subsection{Introduction}

Bilinear flow regimes have been discussed and reported in numbers of gas wells and is recognized by $\sqrt[4]{t}$ during transient flow. Some conditions causing bilinear flow are: a vertical well between two parallel leaky boundaries due to faulting or sedimentary process, a vertical well near a high conductivity infinite fault, a vertical well with a finite conductivity fracture ${ }^{8,9}$, a horizontal well in a fractured reservoir with transient dual porosity behavior during the intermediate linear flow period, a horizontal well in a layered with transient dual porosity behavior during the intermediate linear flow period and linear reservoir with transient dual porosity behavior. With all these various causes of long-term bilinear flow misinterpretation of production and pressure data may originate.

In the first section of this chapter, we are going to show how we model the fracture network and how it different from Cinco-Ley hydraulic fracture model.

In the second section of this chapter we show the behavior of the matrix block drainage under constant bottom hole pressure and constant rate production. Several sensitivity cases are made analysis toward fracture conductivity. Generally, changes are only made to fracture half-length and fracture permeability.

Finally in the last section we show dimensionless variables used to characterized the behavior of the matrix block drainage.

\subsection{Flow pattern in fractured wells}

Five different flow regimes occur in the fractions and formation around a hydraulic fractured well ${ }^{1}$. These flow patterns include fracture linear, bilinear, formation linear, elliptical and pseudo-radial flow. Fracture linear flow happens in very short time and may not be seen because veiled by wellbore-storage effects. During this flow period, most of the fluid coming to the wellbore comes mainly from fluid expansion in the fracture and the flow is linear. During the bilinear flow periods most of the fluid entering 
to the wellbore comes from the fracture and the formation, this flow period is going to last as long as the effect of the tip of the fracture has not been felt. Once the tip of the fracture is felt, bilinear flow is end followed by linear formation linear flow, indicates the end of the transient period.

\subsection{Single matrix block model}

Experience shown that naturally fracture reservoir may behave according to a variety of reservoir flow models: (1) homogenous reservoir, (2) multi region or composite reservoir, (3) Anisotropic medium, (4) single fracture system and (5) Double porosity medium. The fault block model is similar to double porosity system, where it has high permeability streak surrounding the matrix block. Fig. 3-1 is a Cartesian grid model is generated using $2 \mathrm{D}$ numerical simulator to simulate a matrix block surrounded by fracture network. The model geometry is specified by the length a and width $b$. Simulation cases (runs) were carried out for various aspect ratio $(a / b)$ of $1,2,4,8,16,32$, 64 and various dimensionless fracture conductivity $F_{C D}$ of 2, 20, 100 and 200. The various aspect ratio are obtained by changing the value of $a$ and keep value $b$ remain the same.

Hydraulic fracture has the fracture half-length of $x_{f}$ and the width of $w_{f}$. The flow is coming from two perpendicular direction for hydraulic fracture model while the fault block only has one flow coming also perpendicular, consequently, fault block model will have rate of $q / 2$ and fracture width of $w / 2$. The fault block model has the same fracture half length of $x_{f}$ yet is defined as a + b. Fig. 3-2 illustrates the differences 


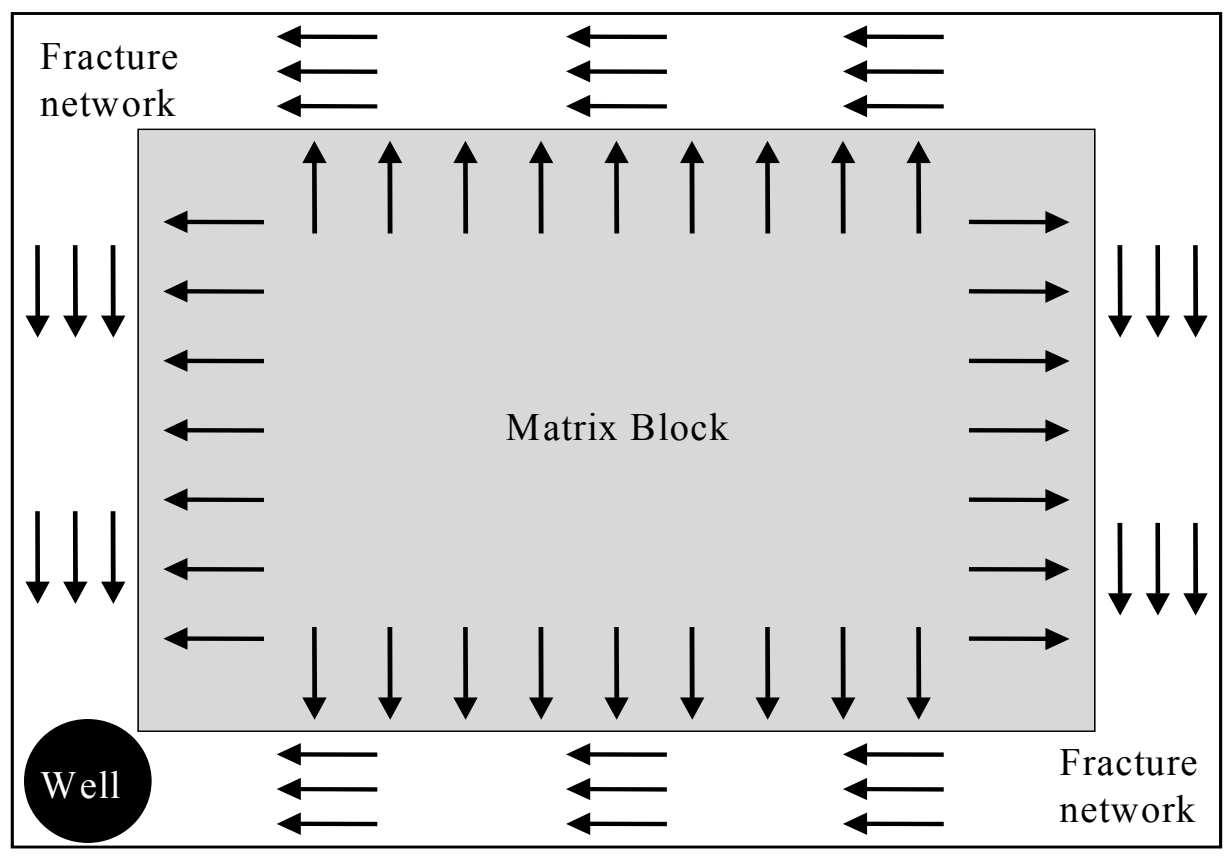

Fig. 3-1 - Fault block drainage model
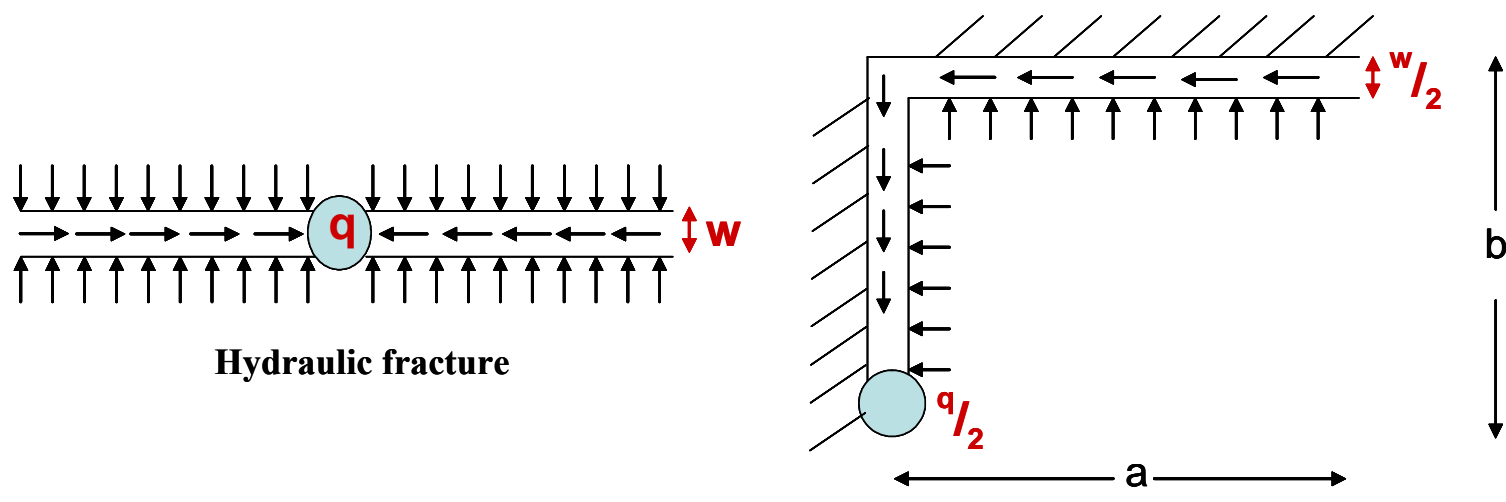

Fault block

Fig. 3-2 - Model equivalent of hydraulic fracture and fault block

\subsection{Performance of fault block.}

Several simulation cases are designed to validate analytical solution. Two parameters are changed for each case; fracture half-length $x_{f}$ and fracture permeability $k_{f}$. Changes made to fracture half-length will reflect to aspect ratio $(a / b)$. 
Table 3-1 - Simulation data input

\begin{tabular}{|c|c|c|c|}
\hline Fluid type & Gas-water & $\mathbf{k}_{\mathbf{z}}$ & - \\
\hline Gas gravity & 0.8 & $\mathbf{k}_{\mathbf{f}}$ & $100 \mathrm{md}$ \\
\hline Initial pressure & $\mathbf{8 0 0 0} \mathrm{psi}$ & $\phi_{\text {matrix }}$ & 0.01 \\
\hline Temperature & $610 \mathrm{R}$ & $\phi_{\text {fracture }}$ & 0.0001 \\
\hline Rock compressibility & $410^{-6} 1_{\mathrm{psi}}$ & $\mathbf{S w}$ & 0.5 \\
\hline Thickness & $200 \mathrm{ft}$ & Constant rate & $10,0000 \mathrm{scf} / \mathrm{d}$ \\
\hline $\mathbf{k}_{\mathrm{x}}$ & $0.001 \mathrm{md}$ & Constant pwf & $7,000 \mathrm{psi}$ \\
\hline $\mathrm{k}_{\mathrm{y}}$ & $0.001 \mathrm{md}$ & Fracture Width & 0.35 \\
\hline
\end{tabular}

Table 3-1 displays data input for the simulation run. Initial pressure is set to 8000 psi and gas rates are 10,000 scf/d.

Table 3-2 present several simulation cases in order to verify with analytical solution. Starting with various $x_{f}$ for $a / b=1,8,64$ and constant $k_{f}=100 \mathrm{md}$ for constant bottom hole case. Next simulation cases investigating sensitivity on fracture permeability while $\mathrm{xf}$ is constant.

Table 3-2 - Simulation cases of bilinear flow

\begin{tabular}{|c|c|c|c|c|c|}
\hline \multicolumn{4}{|c|}{ Constant $p_{w f}$} & \multicolumn{2}{|c|}{ Constant rate } \\
\hline$k_{f}(m d)$ & $X_{f}$ (feet) & $X_{f}$ (feet) & $k_{f}(m d)$ & $k_{f}(m d)$ & $X_{f}$ (feet) \\
\hline \multirow{4}{*}{100} & $\begin{array}{c}2003 \\
(a / b=1) \\
\left(f_{C D}=35\right)\end{array}$ & \multirow{2}{*}{$\begin{array}{l}2003 \\
(a / b=1)\end{array}$} & $\begin{array}{c}5.27 \\
\left(f_{C D}=2\right)\end{array}$ & \multirow{4}{*}{100} & $\begin{array}{c}2003 \\
(a / b=1) \\
\left(f_{C D}=35\right) \\
\end{array}$ \\
\hline & $\begin{array}{c}9016 \\
(\mathrm{a} / \mathrm{b}=8) \\
\left(\mathrm{f}_{\mathrm{CD}}=7\right)\end{array}$ & & $\begin{array}{c}527 \\
\left(f_{C D}=200\right)\end{array}$ & & $\begin{array}{c}9016 \\
(a / b=8) \\
\left(f_{C D}=7\right)\end{array}$ \\
\hline & \multirow{2}{*}{$\begin{array}{l}65087 \\
(a / b=64) \\
\left(f_{C D}=1\right)\end{array}$} & \multirow{2}{*}{$\begin{array}{l}65087 \\
(a / b=64)\end{array}$} & $\begin{array}{c}186.59 \\
\left(f_{C D}=2\right)\end{array}$ & & \multirow{2}{*}{$\begin{array}{l}65087 \\
(a / b=64) \\
\left(f_{C D}=1\right)\end{array}$} \\
\hline & & & $\begin{array}{c}18659 \\
\left(f_{C D}=200\right)\end{array}$ & & \\
\hline
\end{tabular}


For constant production rate, simulation conducted only for fixed fracture permeability and various fracture half length, because this research work emphasizes constant bottomhole pressure.

\subsubsection{Constant $p_{w f}$}

Fig 3-3 displays all the cases under constant bottom-hole pressure for $\mathrm{kf}=100$ md and $\mathrm{a} / \mathrm{b}=1,2,4,8,16,32,64$. At the beginning all aspect ratio show bilinear flow due to finite conductivity of the fracture. At later times bilinear flow develops into linear flow for some of the aspect ratio.

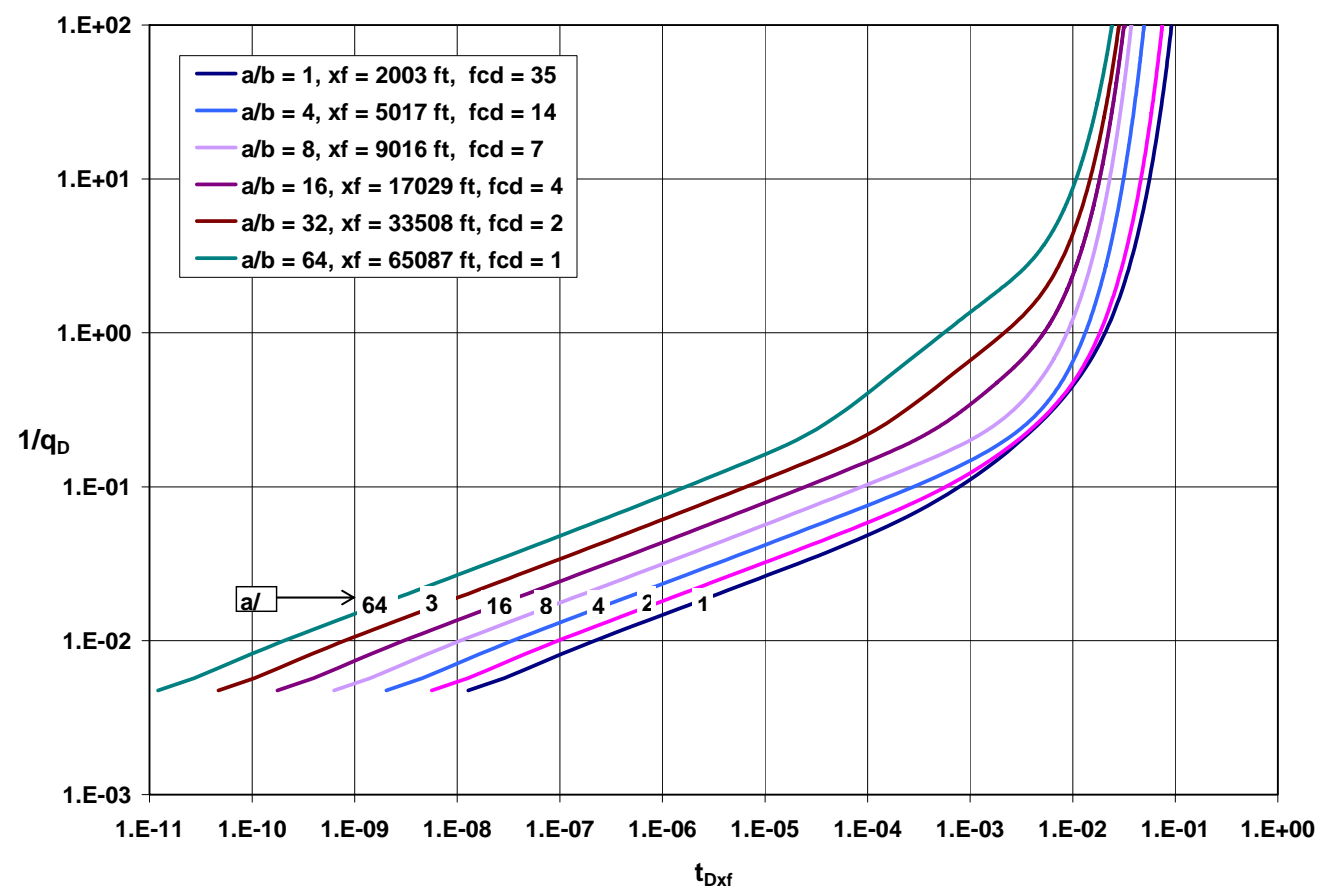

Fig 3-3 - Constant $p_{w f}$ solution for various $x_{f}\left(\right.$ all a/b ratio), $k_{f}=100 \mathrm{md}$

Fig 3-4 shows flow patterns developing for case $a / b=1$ and $a / b=64$. Both cases show good agreement with analytical solution for bilinear flow. Linear flow only develops in case $\mathrm{a} / \mathrm{b}=64$ due the long fracture, then followed by constant pressure resulting into exponential rise in $1 / q_{D}$. 


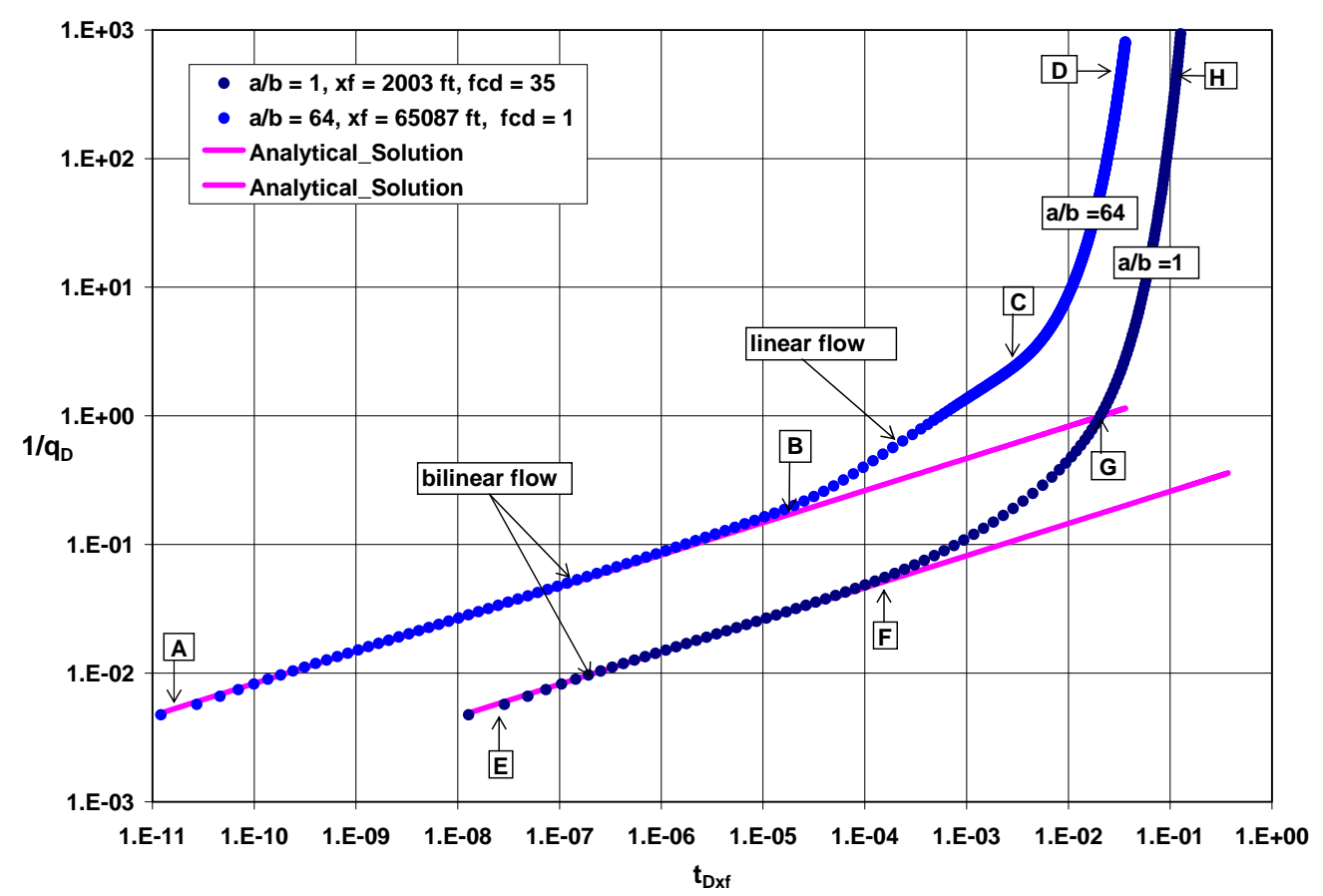

Fig 3-4 - Simulation result and analytical solution under constant $p_{w f}$ solution for $a / b=$ 64 and $a / b=1, k_{f}=100 \mathrm{md}$

Fig. 3-5 through 3-7 display plot for case $a / b=1,8,64$, they confirm that bilinear flow from simulation results are in good agreement with analytical solution. The figure are $\Delta \mathrm{m}(\mathrm{p}) / \mathrm{q}_{\mathrm{g}}$ versus $\mathrm{t}^{1 / 4}$ which reflect the slope of the bilinear flow. At later times some points from simulation start to depart from the analytical solution, indicates that the bilinear flow is ended. 


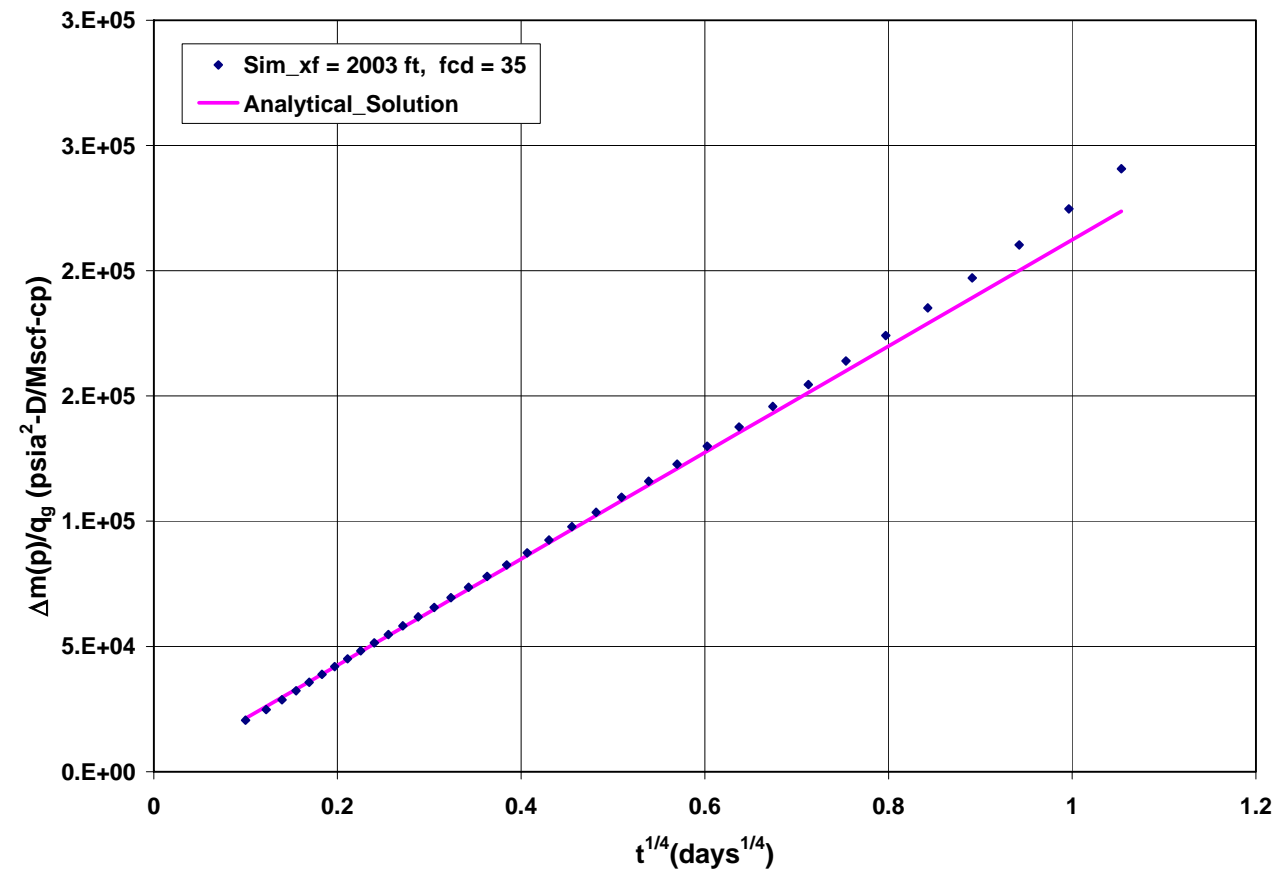

Fig 3-5 - Slope under constant $p_{w f}$ solution for case $a / b=1, k_{f}=100 \mathrm{md}$

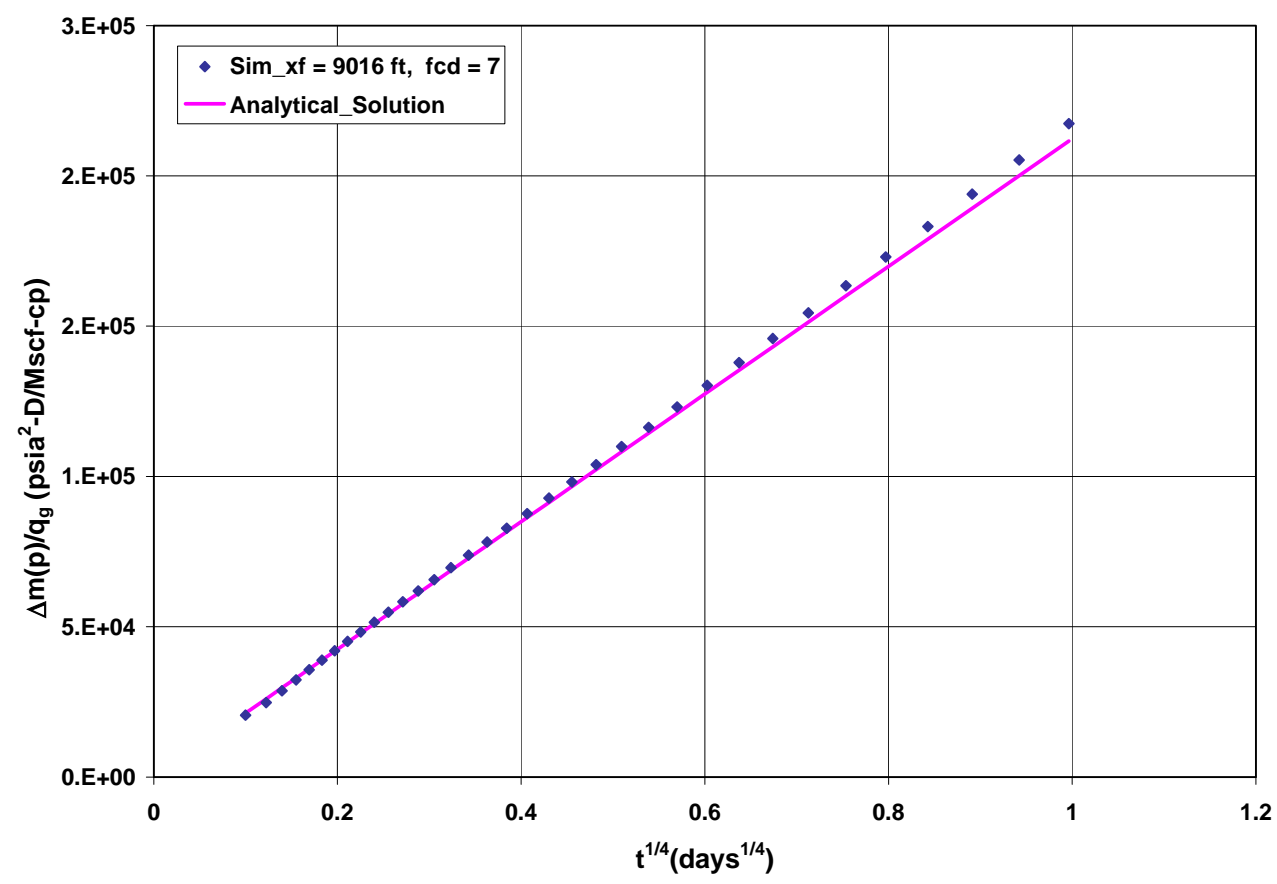

Fig 3-6 - Slope under constant $p_{w f}$ solution for case $a / b=8, k_{f}=100 \mathrm{md}$ 


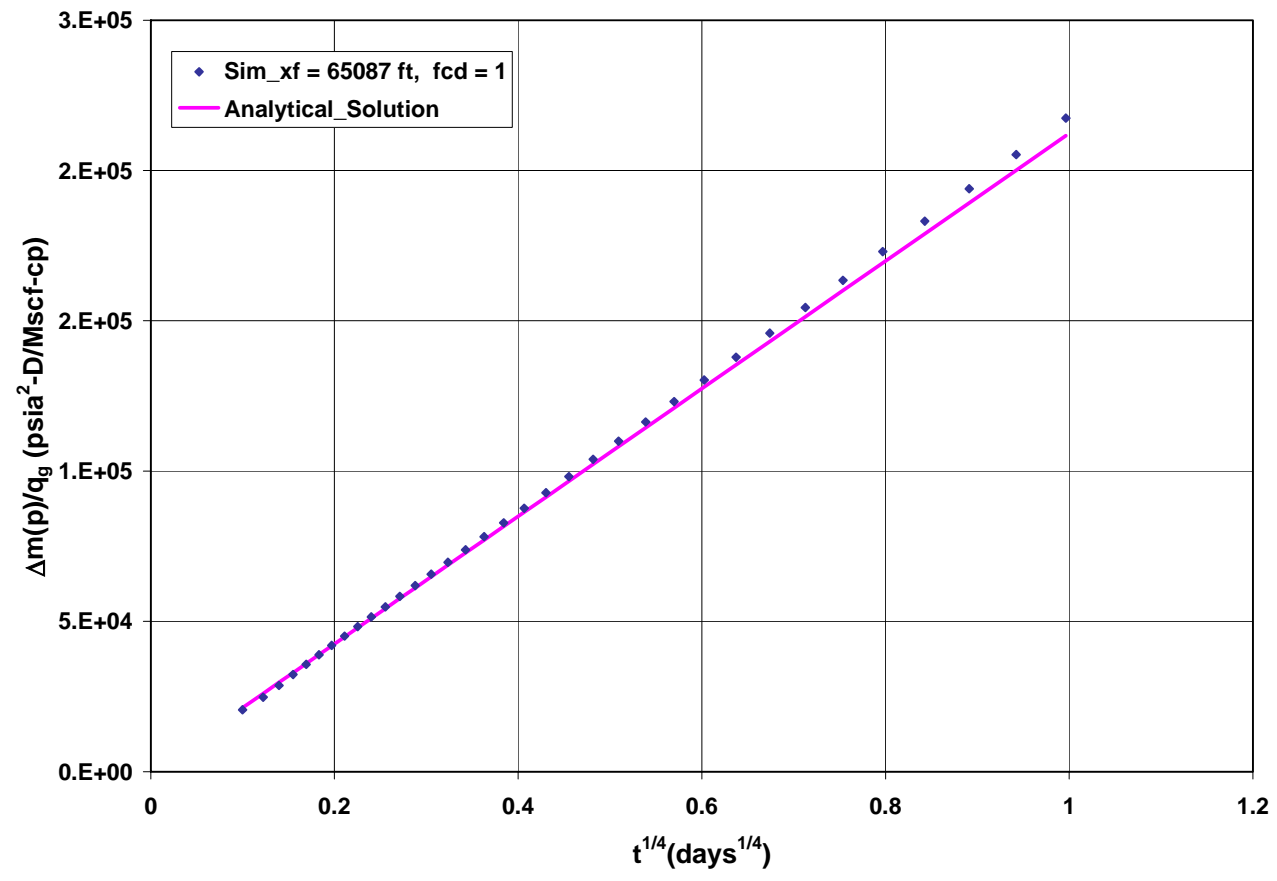

Fig 3-7 - Slope under constant $p_{w f}$ solution for case $a / b=64, k_{f}=100 \mathrm{md}$

\subsubsection{Constant rate}

Fig 3-8 displays all the cases under constant rate production for $\mathrm{kf}=100 \mathrm{md}$ and $\mathrm{a} / \mathrm{b}=1,2,4,8,16,32,64$. At the beginning all aspect ratio show bilinear flow due to finite conductivity of the fracture.

Fig 3-9 shows flow patterns developing for case $a / b=1$ and $a / b=64$. Both cases show good agreement with analytical solution for bilinear flow. At later time bilinear flow is followed by boundary dominated flow.

Figs. 3-10 through 3-12 display plot for case $a / b=1,8,64$, they confirm that bilinear flow from simulation results are in good agreement with analytical solution. The figure are $\Delta \mathrm{m}(\mathrm{p}) / \mathrm{q}_{\mathrm{g}}$ versus $\mathrm{t}^{1 / 4}$ which reflect the slope of the bilinear flow. At later times some points from simulation start to depart from the analytical solution, indicates that the bilinear flow is ended. 


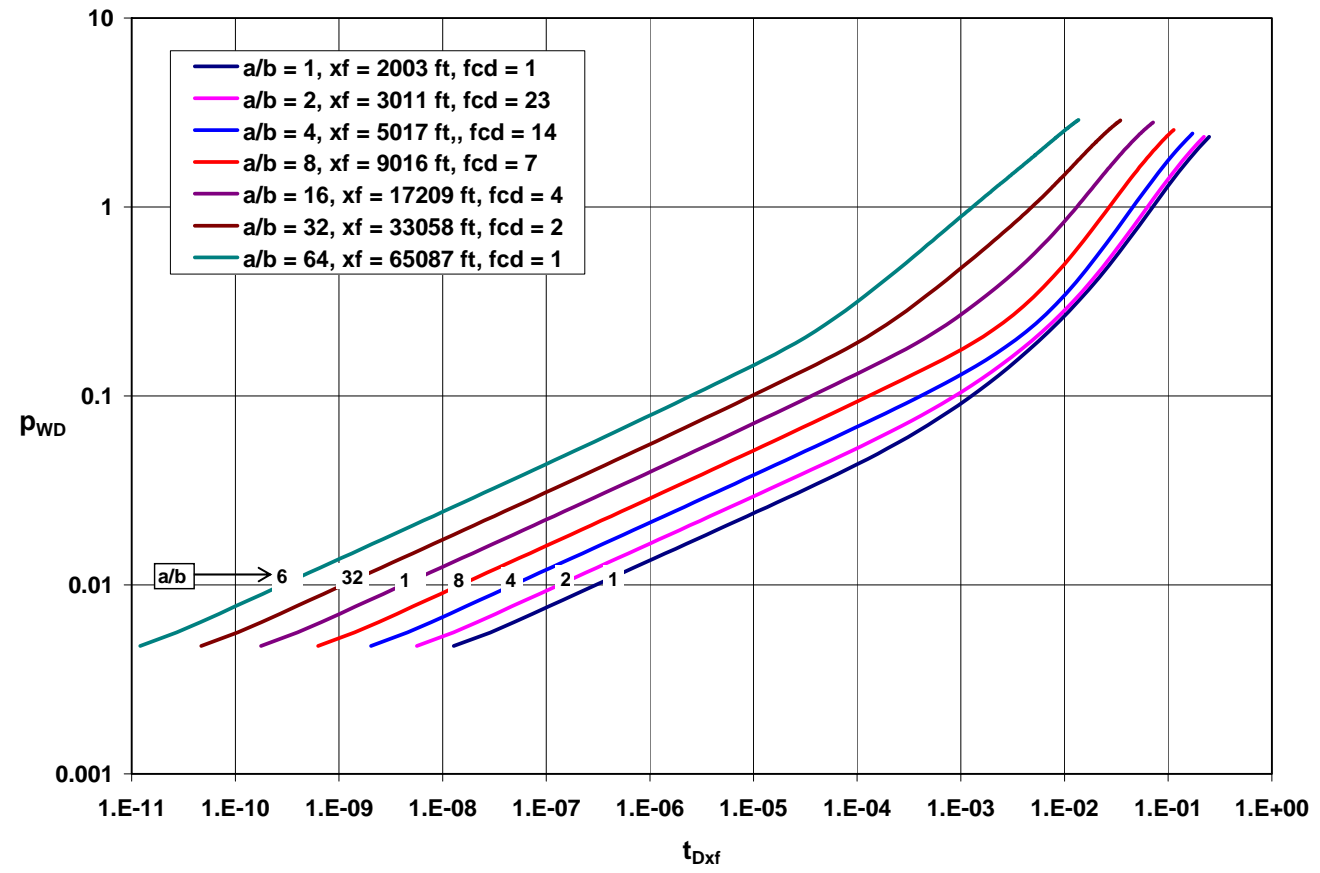

Fig 3-8 - Constant rate solution for various $x_{f}$ (all $a / b$ ratio), $k_{f}=100 \mathrm{md}$

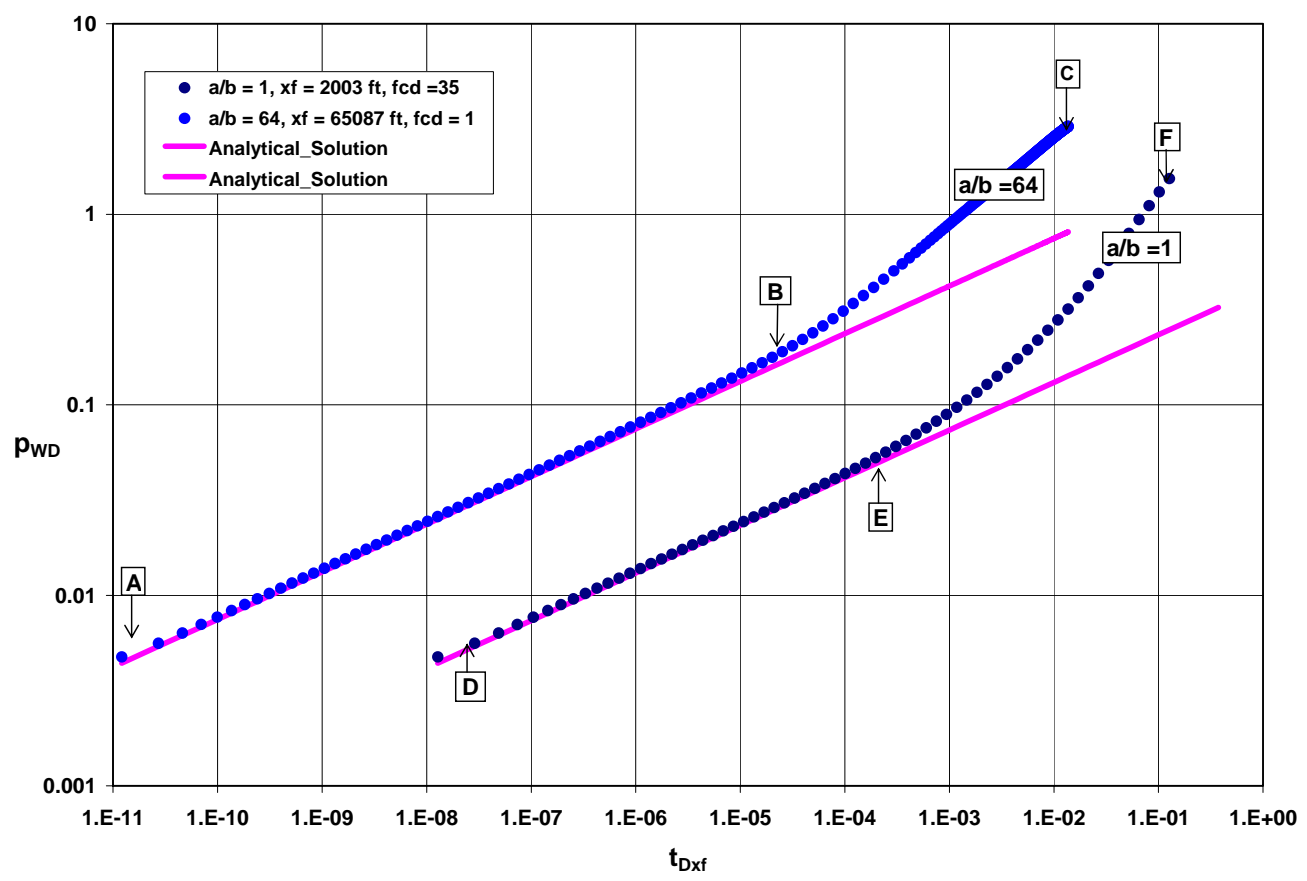

Fig 3-9 - Simulation result and analytical solution under constant rate solution for $a / b=64$ and $a / b=1, k_{f}=100 \mathrm{md}$ 


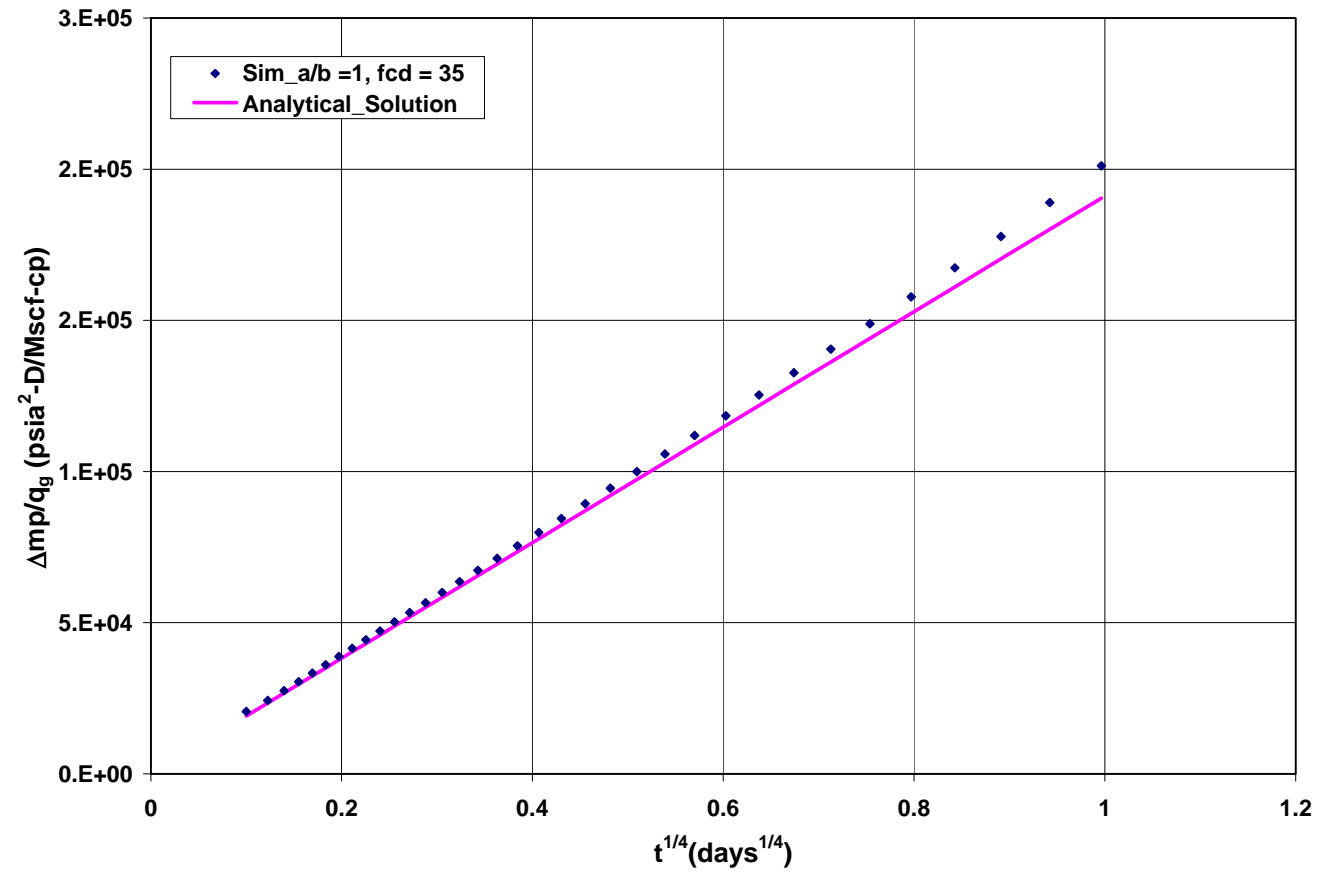

Fig 3-10 - Slope under constant rate solution for case $a / b=1, k_{f}=100 \mathrm{md}$

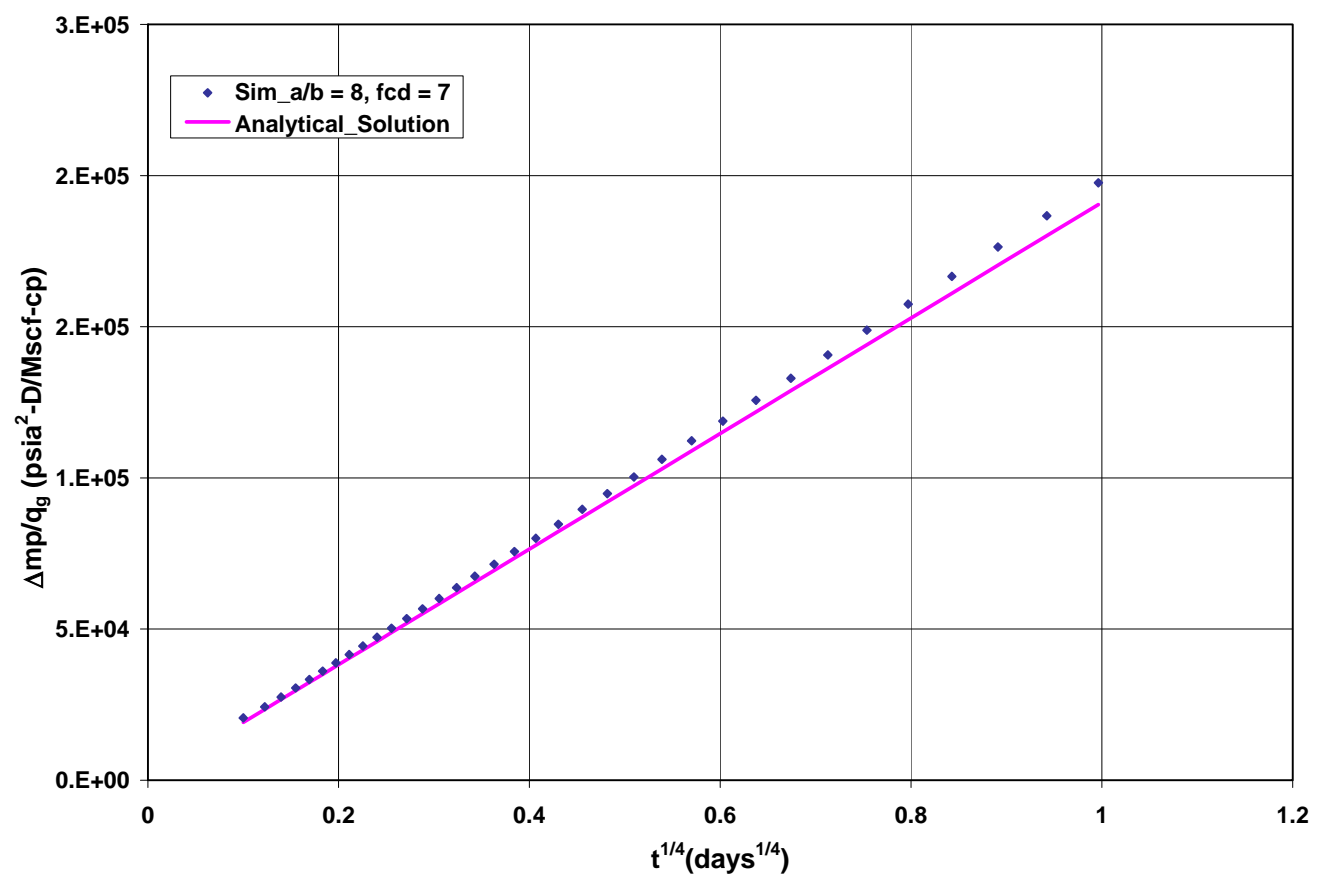

Fig 3-11 - Slope under constant rate solution for case $a / b=8, k_{f}=100 \mathrm{md}$ 


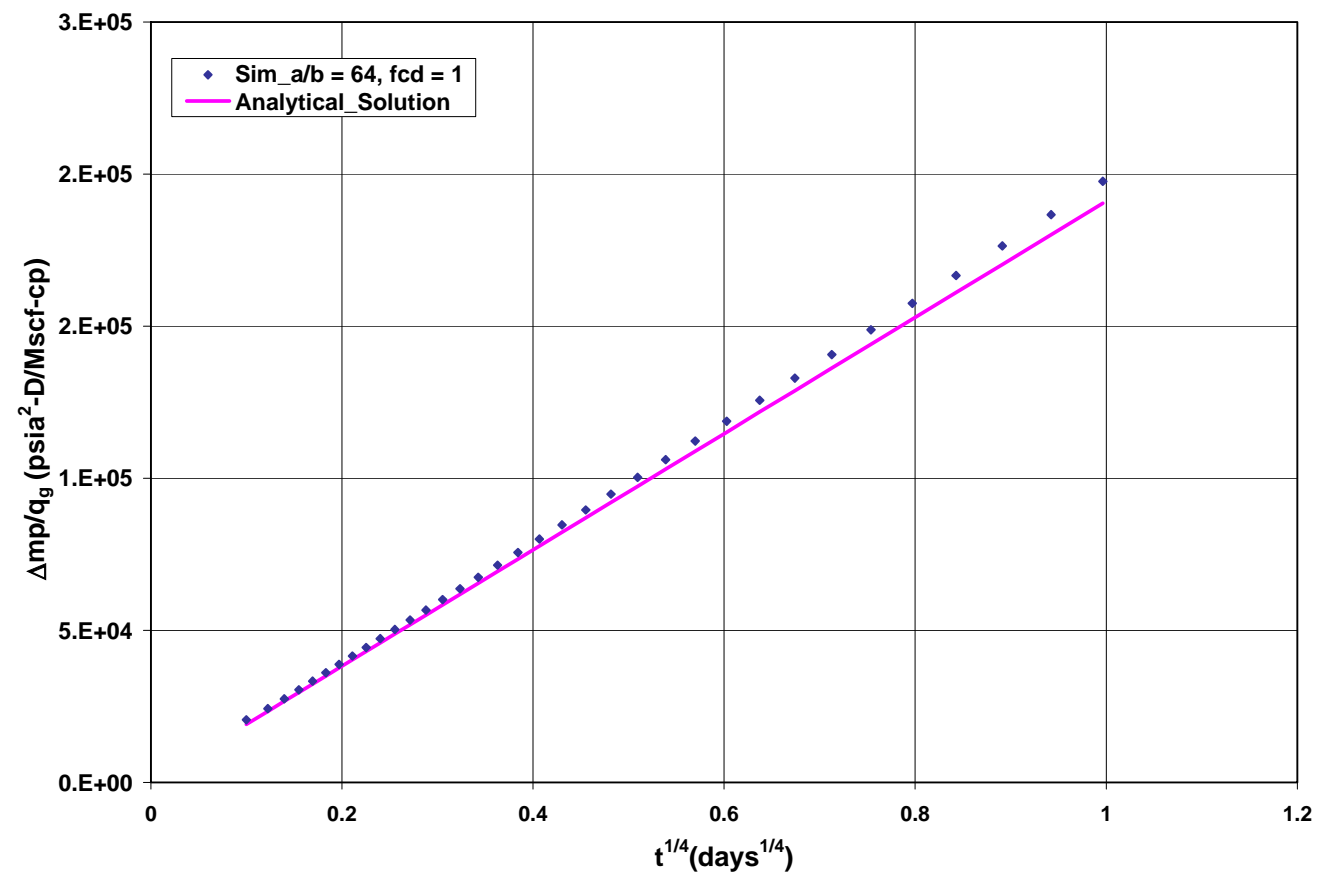

Fig 3-12 - Slope under constant rate solution for case $a / b=64, k_{f}=100 \mathrm{md}$

\subsection{Dimensionless variables}

In this section we discuss the dimensionless variables used to characterize the flow regime and analytical solution developed by Cinco-Ley and Guppy. The dimensionless variables for bilinear flow under constant $p w f$ production are shown in Table 3-3 and dimensionless variables for bilinear flow under constant rate production are shown in Table 3-4. These dimensionless variables for gas bilinear flow are represented in function of the fracture half length, $x_{f}$, for single block matrix $x_{f}$ is represented by total length of $a+b$.

We examine, Table 3-3 and Table 3-4, the definitions of $1 / q_{D}$ and $p_{W D}$ seem to be equal. However, both definitions are different, in $1 / q_{D}$ case $p w f$ varies, while in $p_{W D}$ case $q_{g}$ varies. In Table 3-3 and Table 3-4, the real gas pseudo-pressure, $m(p)$, is defined as follows

$$
m(p)=2 \int_{p_{o}}^{p} \frac{p}{\mu_{g} z} d p
$$




\begin{tabular}{|c|c|}
\hline $\begin{array}{c}\text { Table 3-3 - Dimensionless variables for constant } p_{w f} \text { production, matrix block } \\
\text { drainage }\end{array}$ \\
\hline Oil & $\frac{1}{q_{D}}=\frac{k_{m} h\left[m\left(p_{i}\right)-m\left(p_{w f}\right)\right]}{1422 q_{g} T}$ \\
\hline$\frac{1}{q_{D}}=\frac{k_{m} h\left(p_{i}-p_{w f}\right)}{141.2 q_{o} B \mu}$ & $t_{D \times f}=\frac{0.00633 k_{m} t}{\left(\phi \mu c_{t}\right)_{i}\left(x_{f}\right)^{2}}$ \\
\hline$t_{D \times f}=\frac{0.00633 k_{m} t}{\phi \mu c_{t}\left(x_{f}\right)^{2}}$ & \\
\hline
\end{tabular}

Table 3-4 - Dimensionless variables for constant rate production, matrix block

\begin{tabular}{|c|c|}
\hline \multicolumn{2}{|c|}{ drainage } \\
\hline Oil & Gas \\
\hline$p_{W D}=\frac{k_{m} h\left(p_{i}-p_{w f}\right)}{141.2 q_{o} B \mu}$ & $p_{W D}=\frac{k_{m} h\left[m\left(p_{i}\right)-m\left(p_{w f}\right)\right]}{1422 q_{g} T}$ \\
\hline$t_{D \times f}=\frac{0.00633 k_{m} t}{\phi \mu c_{t}\left(x_{f}\right)^{2}}$ & $t_{D \times f}=\frac{0.00633 k_{m} t}{\left(\phi \mu c_{t}\right)_{i}\left(x_{f}\right)^{2}}$ \\
\hline
\end{tabular}

Analytical solution. The analytical solutions presented in Eq. 3-2 and Eq. 3-3 are applied with excellent accuray for bilinear flow into a fracture tight gas well for both conditions constant $p w f$ production and constant $q_{g}$ production, respectively. Both analytical solution based on the fracture half-length.

Constant rate solution

$$
p_{W D}=\frac{k h\left[m\left(p_{i}\right)-m\left(p_{w f}\right)\right]}{1422 q_{g} T}=\frac{2.45}{\sqrt{\left(F_{C D}\right)}} t_{D \times f}^{1 / 4}
$$


Constant $p w f$ solution

$$
\frac{1}{q_{D}}=\frac{k h\left[m\left(p_{i}\right)-m\left(p_{w f}\right)\right]}{1422 q_{g} T}=\frac{2.722}{\sqrt{\left(F_{C D}\right)}} t_{D x f}^{1 / 4}
$$

fracture conductivity

$$
\left(F_{C D}\right)=\frac{k_{f} w_{f}}{k x_{f}}
$$

and where the slope is

$$
\frac{\Delta m}{q}=C \frac{1}{\sqrt{k}} \frac{T 1422}{\sqrt{k_{f} w_{f}} h}\left(\frac{0.00633 k}{\phi \mu c_{t}}\right)^{1 / 4}
$$




\section{CHAPTER IV \\ DISCUSSION}

\subsection{Introduction}

In this chapter, several aspect and results from this research work are discussed. Review of occurrence of each flow geometry and its background is discussed.

\subsection{General discussion}

It is critical to understand and recognize the flow geometry from production data analysis due to reservoir interpretation. Flow geometry from production data can be recognized using graphical interpretation of log-log diagnostic plot. Each flow geometry in diagnostic plot has a characteristic slope in the same period of production time.

Type curves can help identify the appropriate reservoir model, identify the appropriate flow regimes for analysis, and estimate reservoir properties. They are helpful especially for analyzing gas well.

The log-log diagnostic plot of pseudo pressure drop divided by gas rate, $\Delta \mathrm{m}(\mathrm{p}) / \mathrm{qg}$, versus time is useful to identify when a flow regimes start to depart from its slope for either constant $p_{w f}$ production or constant rate production. In addition, we can verify simulation result with the analytical solution.

Specialized derivative log-log plot is recommended either for constant pwf production and constant rate production. Dimensionless pressure drop, $p_{W D}$, or reciprocal dimensionless production rate, $1 / q_{D}$, versus dimensionless time, $t_{D}$, together with derivative of dimensionless pressure drop, $p_{W D}$, or derivative of reciprocal dimensionless production rate, $1 / q_{D^{\prime}}$, characterize clearly successive flow regime and transition period.

We would expect that matrix block drainage would show the following period: formation bilinear flow, late linear flow, and boundary dominated flow. Fig. 3-2 shows the equivalent matrix block model to hydraulic fracture model, when applying analytical solution, only half production rate and half width of the fracture are calculated since most of the fluid entering the wellbore comes only from one side of the fracture. 
Establishing normalized variable helping to determine which reservoir properties or reservoir geometry affected one of the several flow regimes and its time of occurrence.

Constant pwf production. Fig. 4-1 shows log-log diagnostic plot of normalized dimensionless time for all aspect ratio $(a / b)$ form Fig. 3-3. This plot displays dimensionless reciprocal production rate $1 / q_{D}{ }^{\prime}$ versus normalized dimensionless time $t_{D x f} f\left(F_{C D}\right)^{2}$. Three consecutive flow regimes occur as follows: formation bilinear flow, linear flow and boundary dominated flow resulting in exponential rise in $1 / q_{D}$. This plot is also confirmed that bilinear flow is still in transient period since the effect of fracture tip has not been felt. In fact, for some aspect which has linear flow regime, it is also confirmed that linear flow is still in transient period since all the linear flow fall in one line.

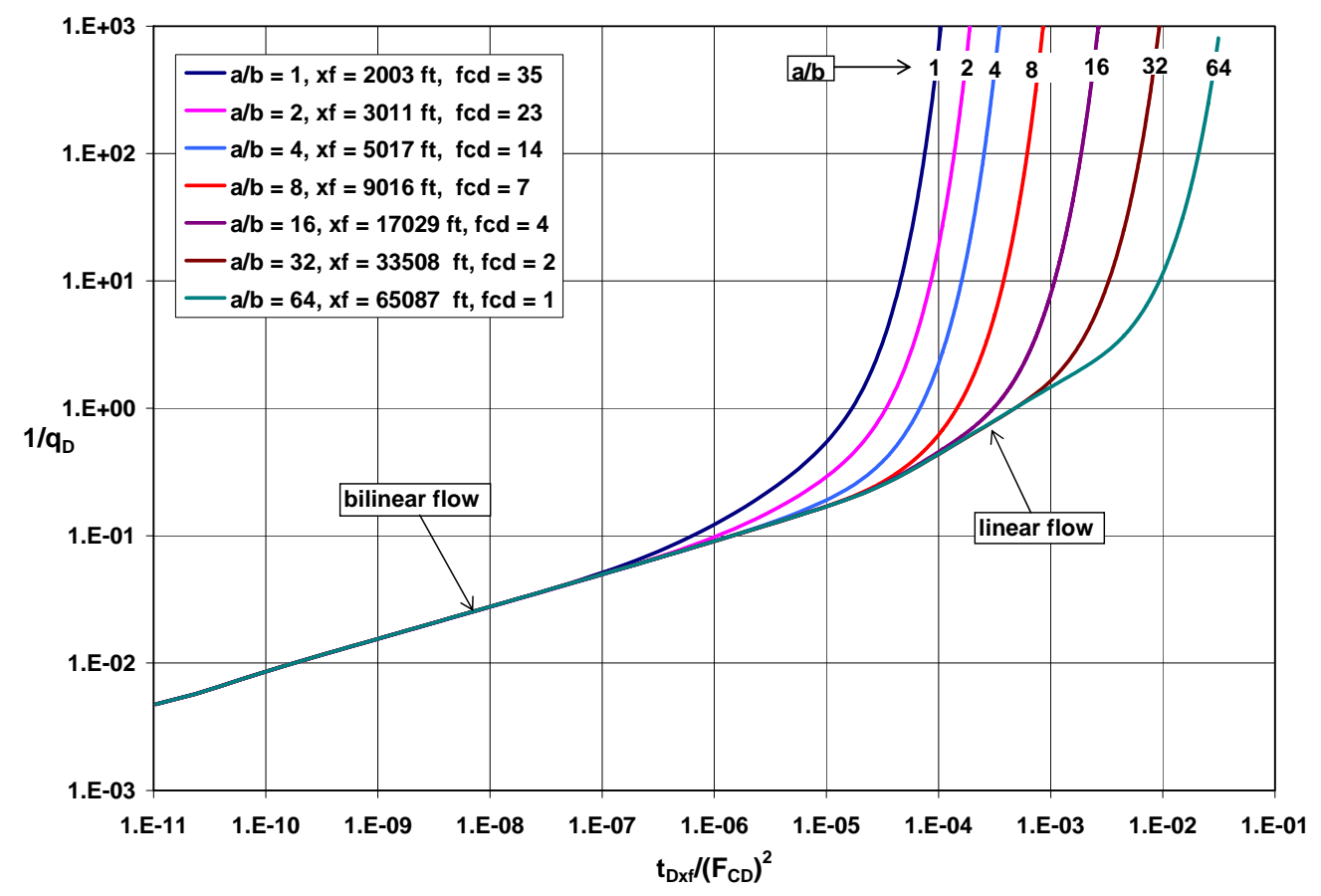

Fig 4-1 - Normalized early time for all $a / b$ under constant $p_{w f}$ production, $k_{f}=100 \mathrm{md}$ 
Fig. 4-2 display dimensionless reciprocal production rate and its derivative, $1 / q_{D}{ }^{\prime}$ $\& 1 / q_{D}$, versus dimensionless time $t_{D x f}$ for case $\mathrm{a} / \mathrm{b}=64$. Different from dimensionless reciprocal production rate, its derivative shows more complete flow regimes. Starting from $A-B$, this period has slope of $1 / 2$ describing like fracture linear flow, yet, it is originally caused by numerical error, Fig A-14 describes smaller time step. Formation bilinear flow develops between point B and C, recognized by slope of $1 / 4$. Point C and D is the transition period from formation bilinear flow to linear flow. Linear flow developed between point $\mathrm{D}$ and $\mathrm{E}$, at point $\mathrm{E}$ the outer closed boundary starts affecting the flow, resulting into an exponential rise in $1 / q_{D}$.

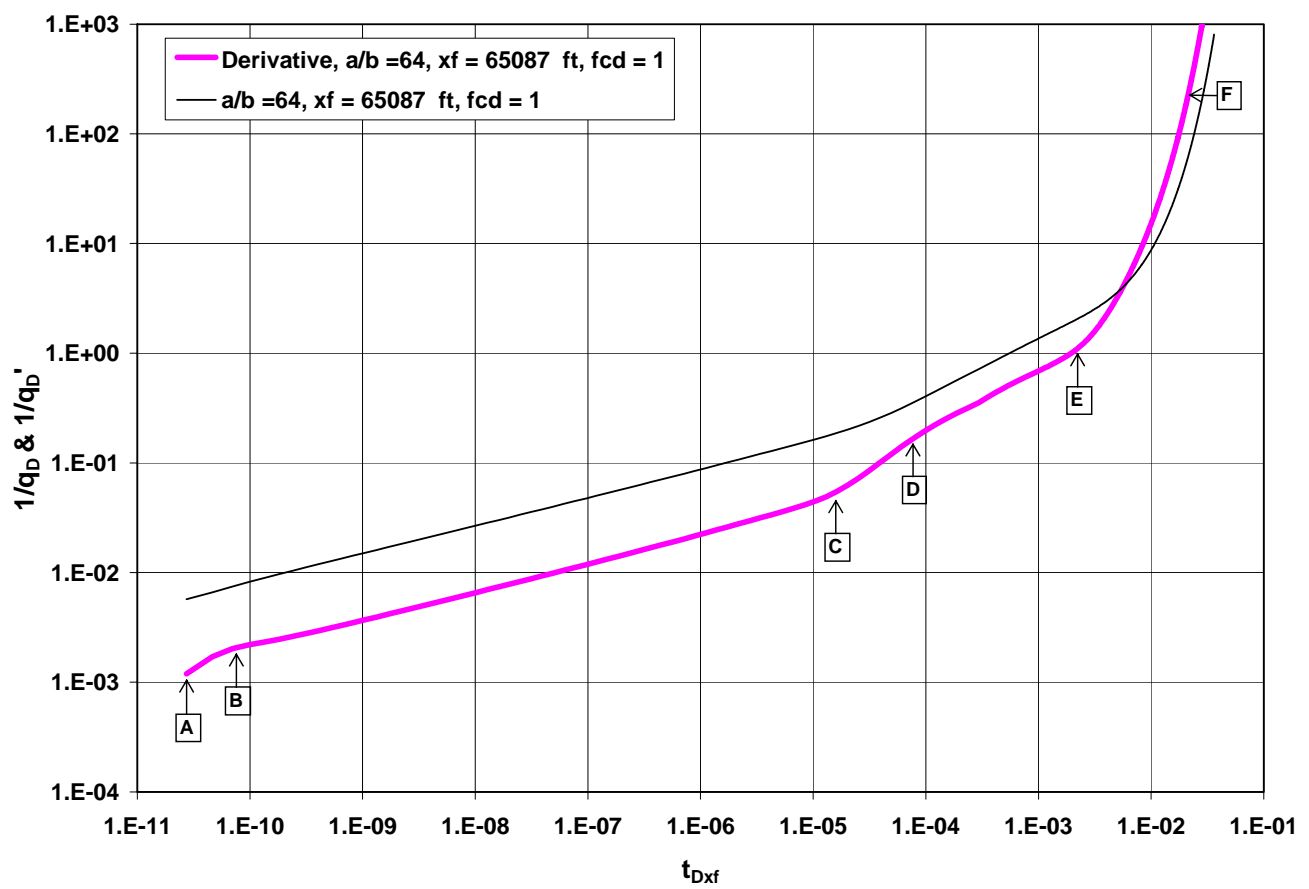

Fig 4-2 $-\left(1 / q_{D}\right)$ and $\left(1 / q_{D}^{\prime}\right)$ versus $t_{D x f}, a / b=64$ under constant $p_{w f}$ production, $k_{f}=100$ md

Fig. 4-3 display dimensionless reciprocal production rate and its derivative, $1 / q_{D}{ }^{\prime}$ $\& 1 / q_{D}$, versus dimensionless time $t_{D x f}$ for case $\mathrm{a} / \mathrm{b}=1$. Point $\mathrm{A}$ and $\mathrm{B}$ displays numerical error and it possesses $1 / 2$ slopes similar to fracture linear flow. Followed by formation bilinear described between point $\mathrm{B}$ and $\mathrm{C}$, recognized by slope of $1 / 4$. Unlike case $\mathrm{a} / \mathrm{b}=$ 
64 linear flow does not develop, whereas transition period, (C-D), before reservoir boundary felt occur. Between point D and E the outer closed boundary starts affecting the flow, resulting into an exponential rise in $1 / q_{D}$.

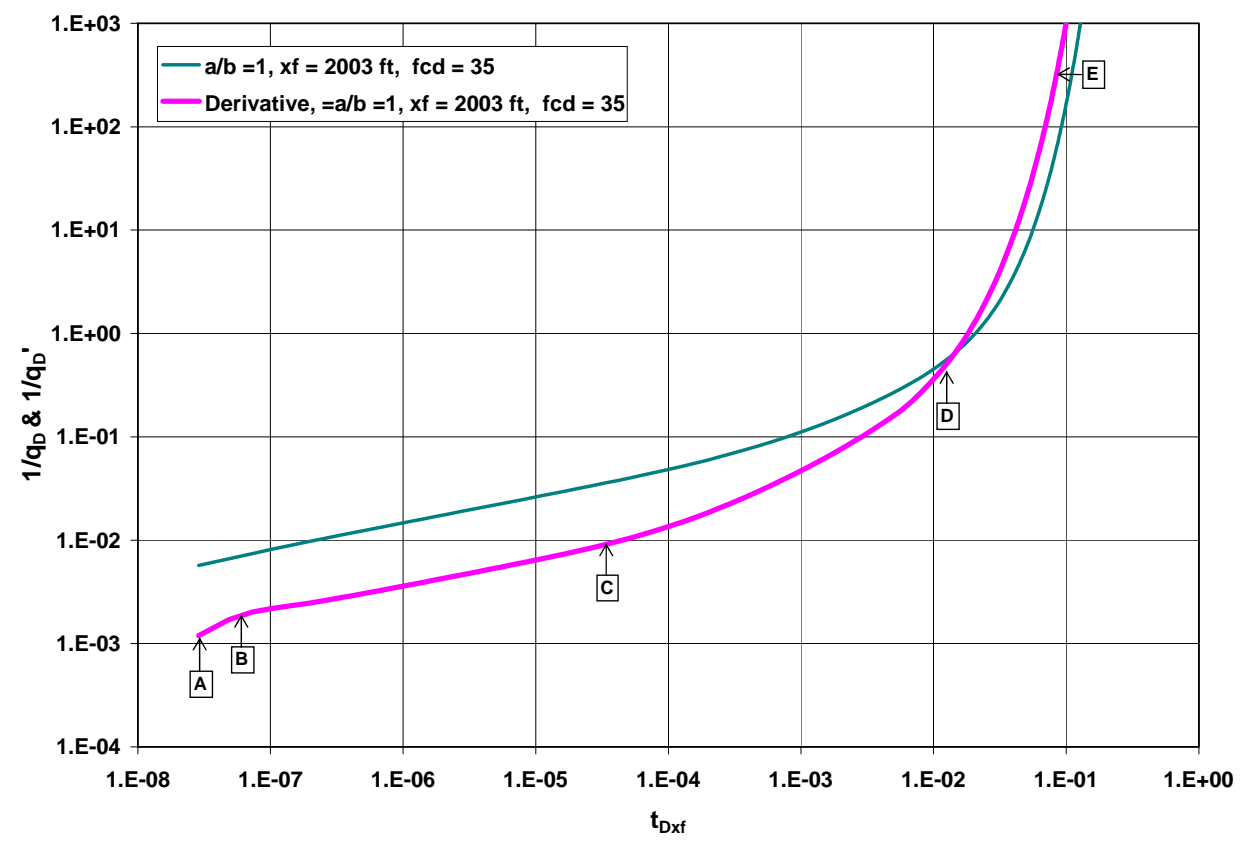

Fig 4-3 $-\left(1 / q_{D}\right)$ and $\left(1 / q_{D}^{\prime}\right)$ versus $t_{D x}, a / b=1$ under constant $p_{w f}$ production, $k_{f}=100$ md

Fig. 4-4 displays dimensionless reciprocal production rate and its derivative, $1 / q_{D}{ }^{\prime} \& 1 / q_{D}$, versus dimensionless normalized time $t_{D x} f\left(F_{C D}\right)^{2}$. The plot shows that for $a / b<32$, linear flow does not develop, yet for $a / b=16$ transition period occurs instead linear flow period followed by boundary dominated flow. Point A and B displays numerical error and it possesses $1 / 2$ slopes similar to fracture linear flow. Followed by formation bilinear described between point $B$ and $C$, recognized by slope of $1 / 4$. Unlike case $\mathrm{a} / \mathrm{b}=64$ linear flow does not develop, whereas transition period, (C-D), before reservoir boundary felt occur. Between point $\mathrm{D}$ and $\mathrm{E}$ the outer closed boundary starts affecting the flow, resulting into an exponential rise in $1 / q_{D}$. 


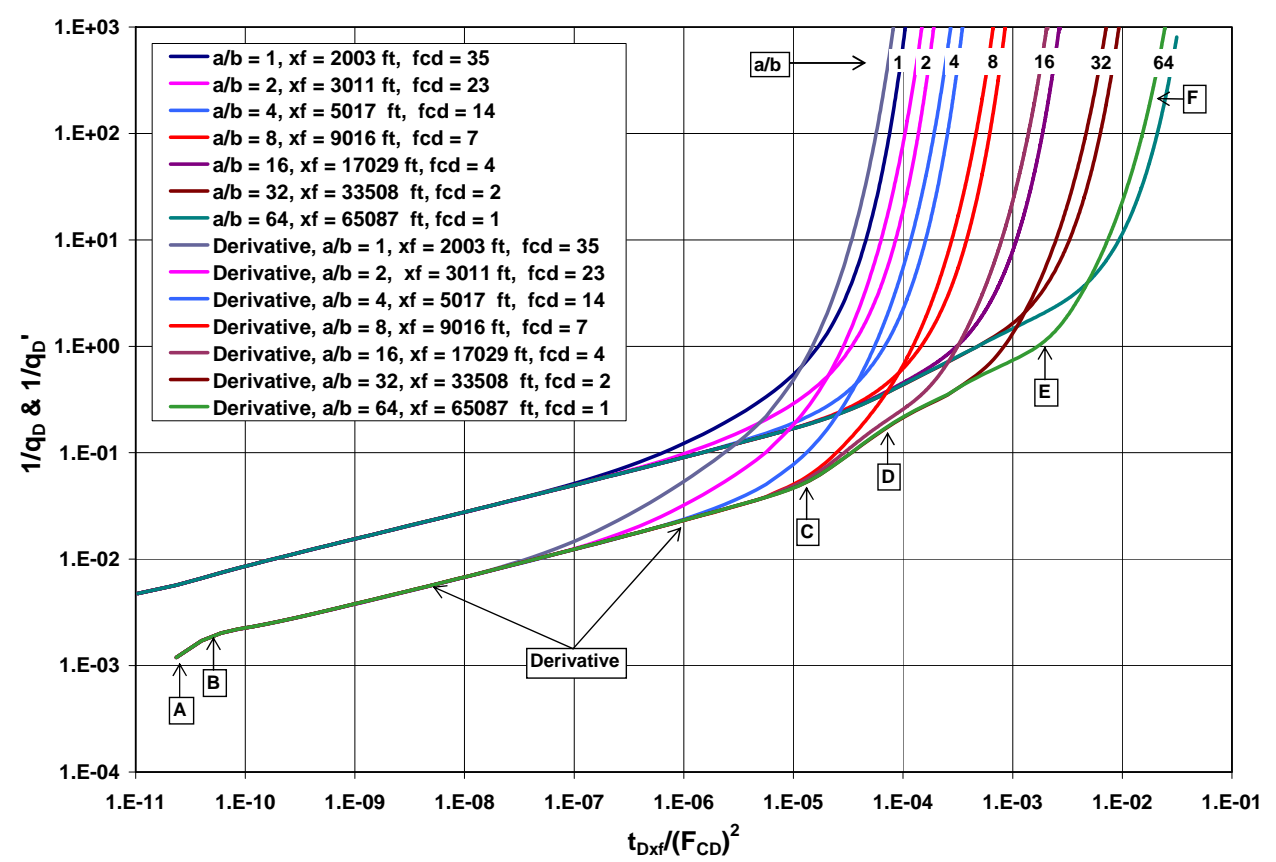

Fig 4-4 $-\left(1 / q_{D}\right)$ and $\left(1 / q_{D}{ }^{\prime}\right)$ versus $t_{D x f}$, all $a / b$ under constant $p_{w f}$ production, $k_{f}=100 \mathrm{md}$

Constant rate production. Fig. 4-5 shows log-log diagnostic plot of normalized dimensionless time for all aspect ratio $(a / b)$ form Fig. 3-8. This plot displays dimensionless pressure drop $p_{W D}$ versus normalized dimensionless time $t_{D x} f\left(F_{C D}\right)^{2}$. Two consecutive flow regimes occur as follows: formation bilinear flow, linear flow. This plot is also confirmed that bilinear flow is still in transient period since the effect of fracture tip has not been felt. In fact, for some aspect which has linear flow regime, it is also confirmed that linear flow is still in transient period since all the linear flow fall in one line. 


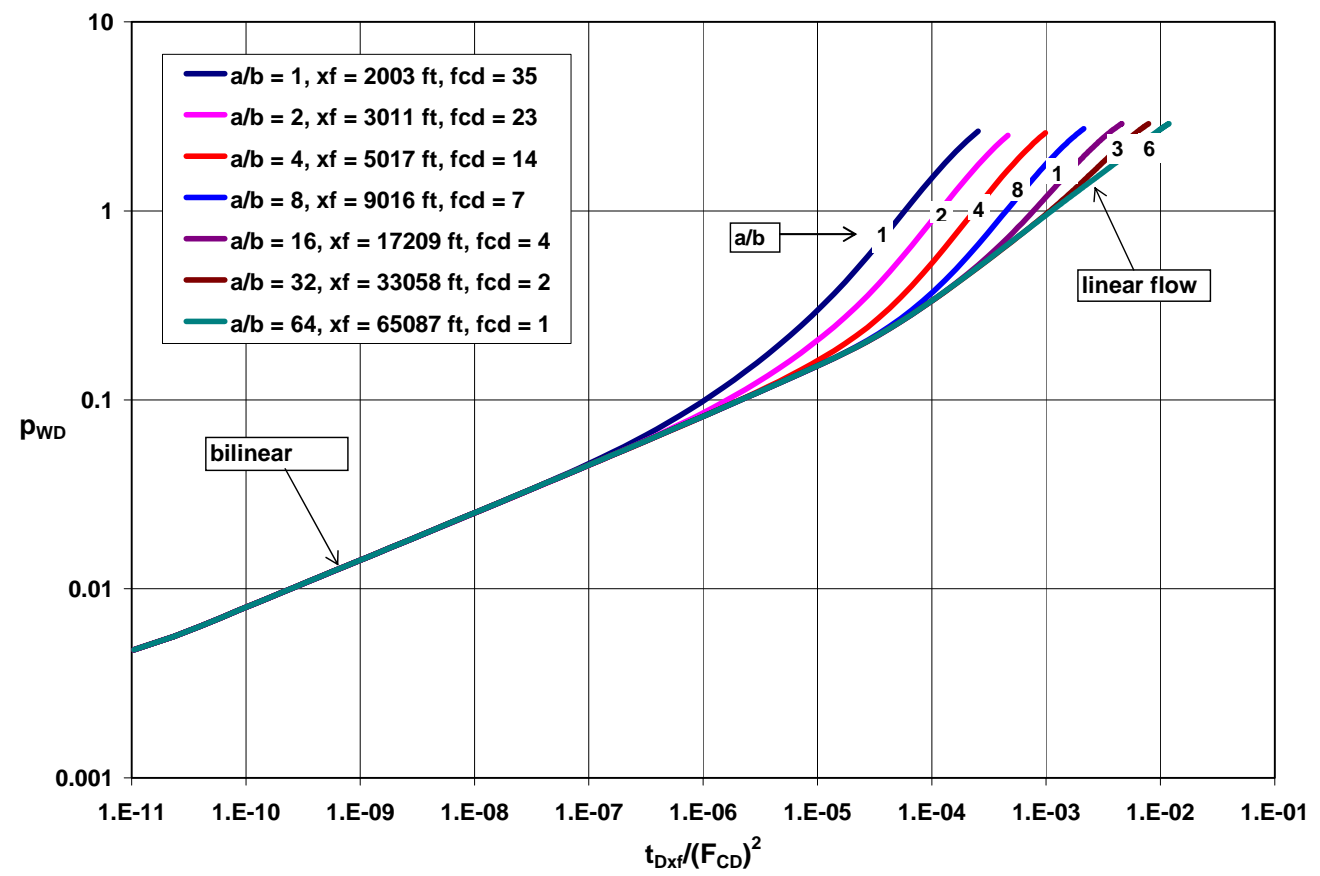

Fig 4-5 - Normalized early time for all a/b under constant rate production, $k_{f}=100 \mathrm{md}$

Fig. 4-6 display dimensionless pressure drop and its derivative, $p_{W D} \& p_{W D}$, versus dimensionless time $t_{D x f}$ for case $\mathrm{a} / \mathrm{b}=64$. Different from dimensionless production rate, its derivative shows more complete flow regimes. Starting from A-B, this period has slope of $1 / 2$ describing like fracture linear flow, yet, it is originally caused by numerical error. Formation bilinear flow develops between point $\mathrm{B}$ and $\mathrm{C}$, recognized by slope of $1 / 4$. Point $C$ and $D$ is the transition period from formation bilinear flow to linear flow. Linear flow developed between point D and E, at point $\mathrm{E}$ the constant pressure boundary starts affecting the flow. 


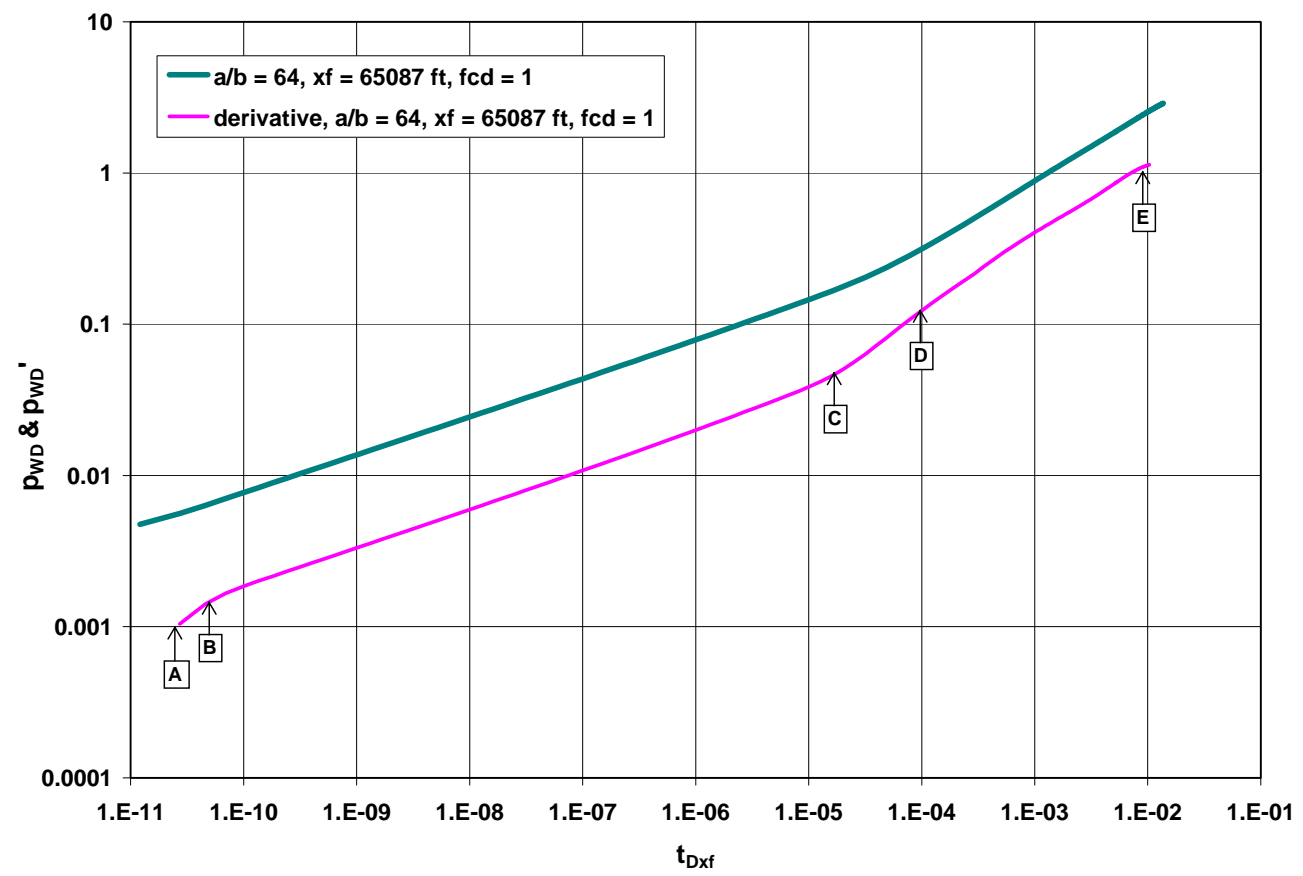

Fig 4-6 $-\left(p_{W D}\right)$ and $\left(p_{W D}\right)$ versus $t_{D x f}, a / b=64$ under constant rate production, $k_{f}=100$ md

Fig. 4-7 display dimensionless pressure drop and its derivative, $p_{W D} \& p_{W D}$, versus dimensionless time $t_{D x f}$ for case $\mathrm{a} / \mathrm{b}=1$. Point $\mathrm{A}$ and $\mathrm{B}$ displays numerical error and it possesses $1 / 2$ slope similar to fracture linear flow. Followed by formation bilinear described between point $B$ and $C$, recognized by slope of $1 / 4$. Unlike case $a / b=64$ linear flow does not develop, whereas transition period, (C-D), before reservoir boundary felt in point $\mathrm{D}$. 


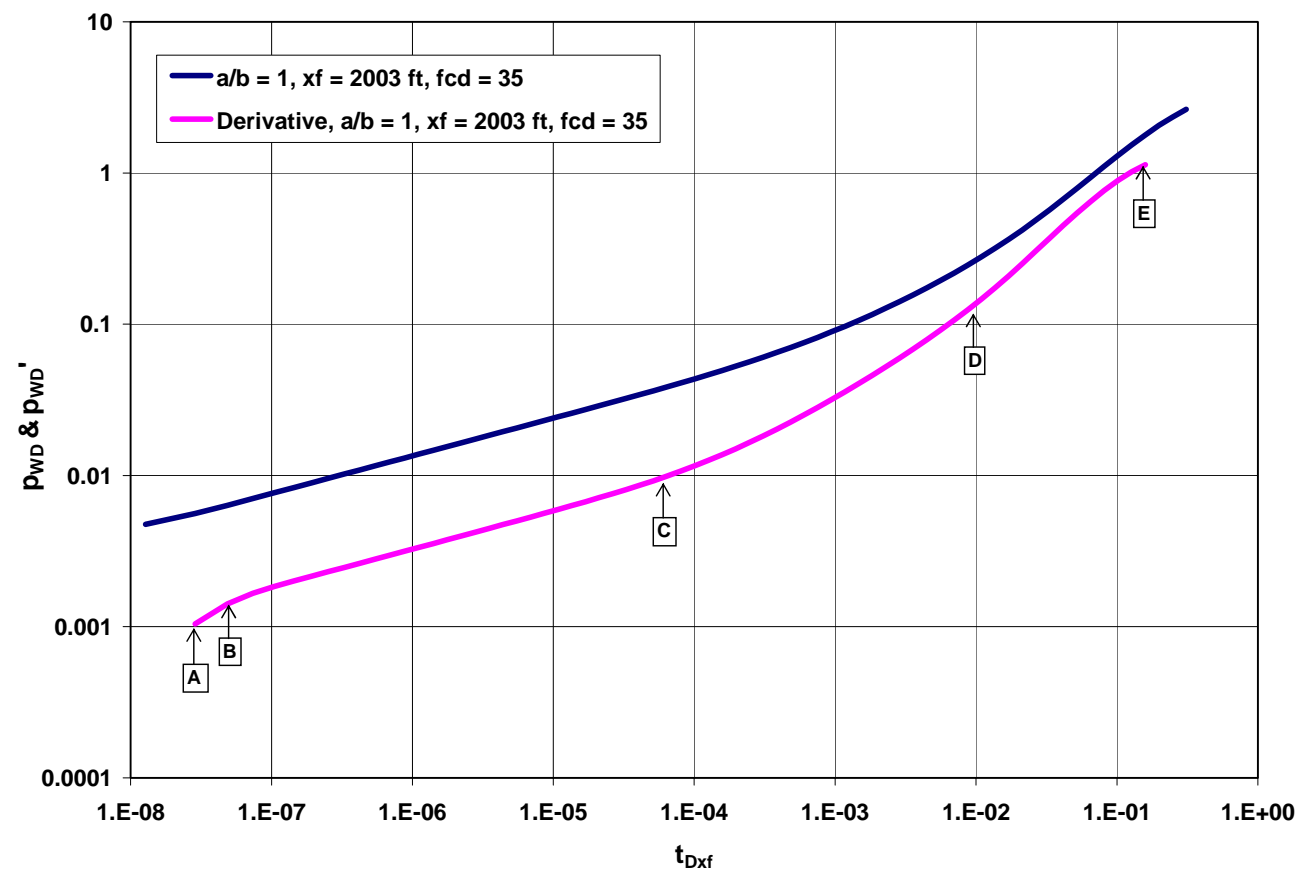

Fig 4-7 $-\left(p_{W D}\right)$ and $\left(p_{W D}\right)$ versus $t_{D x}, a / b=1$ under constant rate production, $k_{f}=100$ md

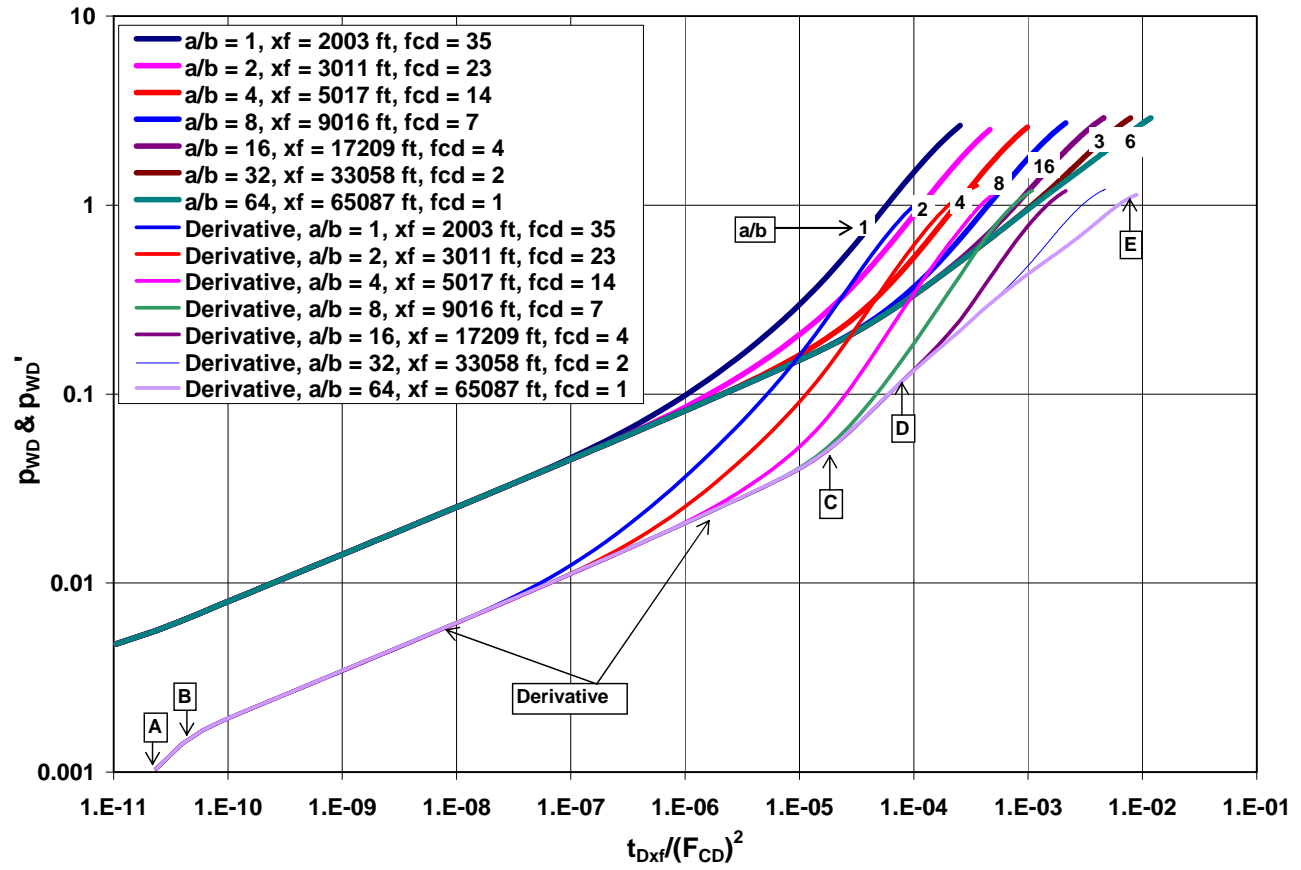

Fig 4-8 $-\left(p_{W D}\right)$ and $\left(p_{W D}\right)$ versus $t_{D x f}$, all $a / b$ under constant rate production, $k_{f}=100 \mathrm{md}$ 
Fig. 4-8 displays dimensionless pressure drop and its derivative, $p_{W D} \& p_{W D}$, versus dimensionless normalized time $t_{D x} f\left(F_{C D}\right)^{2}$. The plot shows that for $a / b<32$, linear flow does not develop, yet for $a / b=16$ transition period occurs instead linear flow period followed by boundary dominated flow.

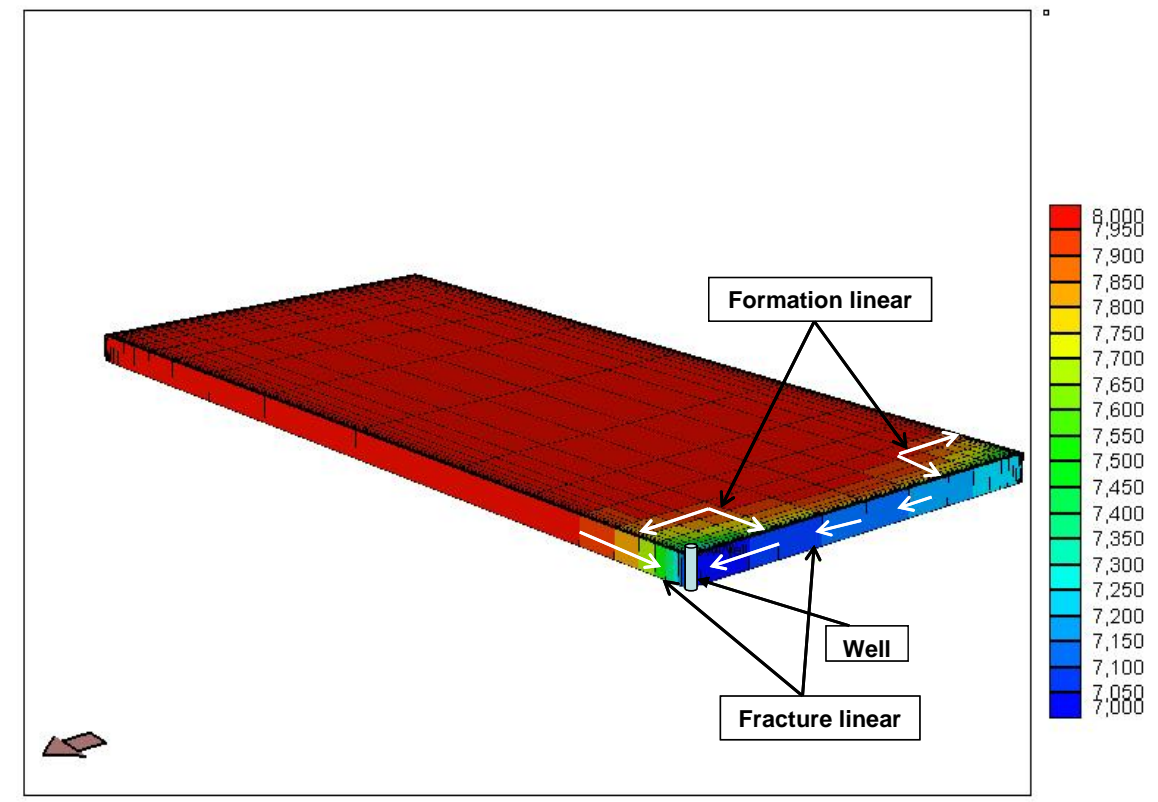

Fig. 4-9 - Bilinear flow for $a / b=64$ at $t_{D x f}=10^{-11}$ under constant $p_{w f}$ production, $k f=$ $100 \mathrm{md}, F_{C D}=1$.

Linear flow period. Not all the reservoir geometry experiences the linear flow. Linear flow only developed for $a / b>16$, whereas $a / b<16$ exhibits bilinear flow followed by boundary dominated flow. First hypothesis is that linear flow developed when the bilinear flow reach fracture tip and pressure drop exhibit from matrix to all direction to the well bore. Fig. 4-9 shows graphical explanation of the occurrence of bilinear flow for $a / b=64$, it displays pressure drop in matrix and also in the fracture. Fig. 4.10 shows how the linear flow developed, instead of reaching the fracture tip, the pressure in the two adjacent fractures and the matrix are stabilized creating pressure drop only in one direction. 


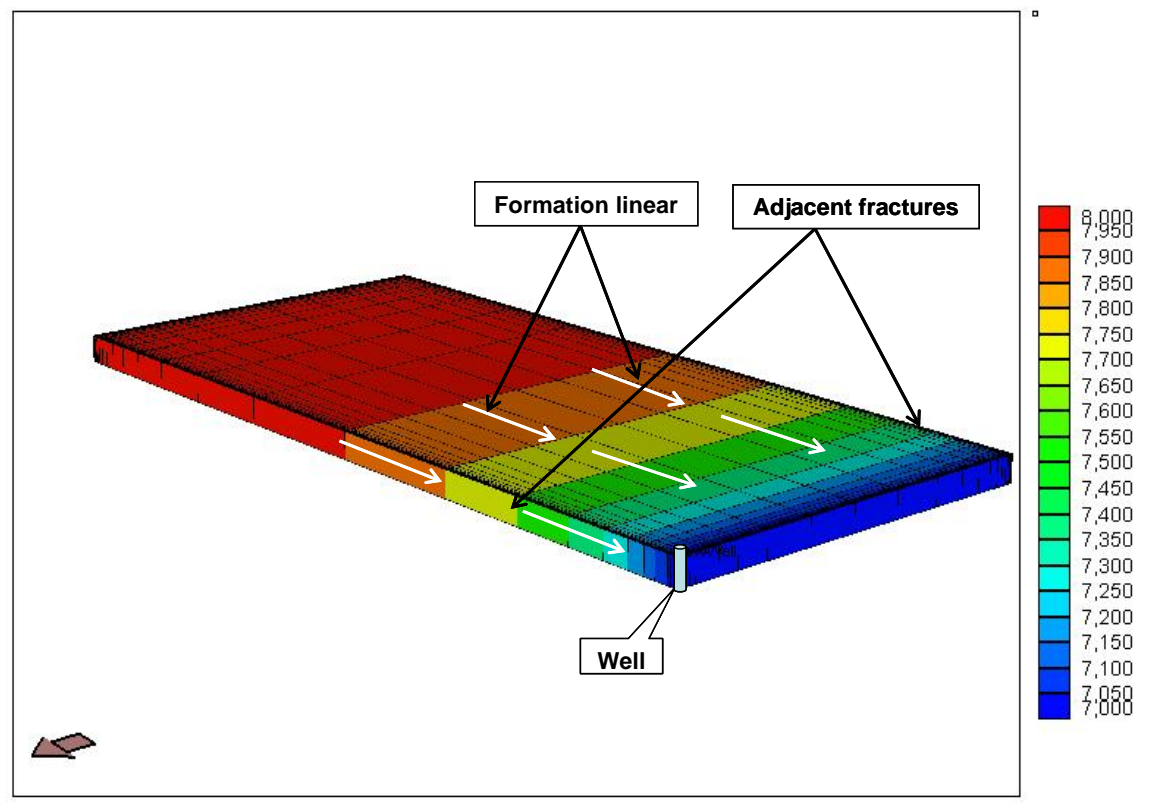

Fig. 4-10- Linear flow for $a / b=64$ at $t_{D x f}=510^{-5}$ under constant $p_{w f}$ production, $k f=$ $100 \mathrm{md} F_{C D}=1$.

Case $a / b=1$ does not demonstrate linear flow due to small reservoir size. At early time it exhibit bilinear flow just like case $a / b=64$. Later time, when the bilinear flow hits the fracture tips, start to exhibit boundary dominated flow. Fig. 4-11 and Fig. 4-12 show graphical explanation. 


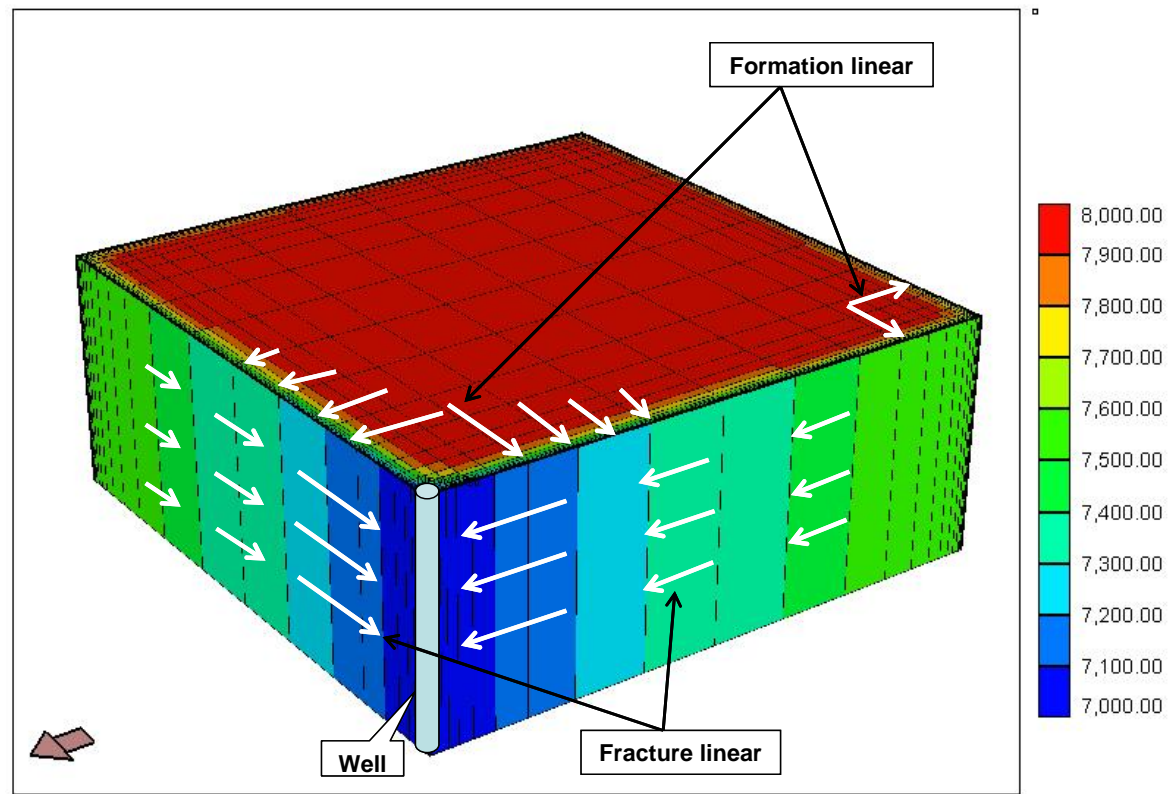

Fig. 4-11- Bilinear flow for $a / b=1$ at $t_{D x f}=210^{-8}$ under constant $p_{w f}$ production, $k f$ $=100 \mathrm{md}, F_{C D}=35$.

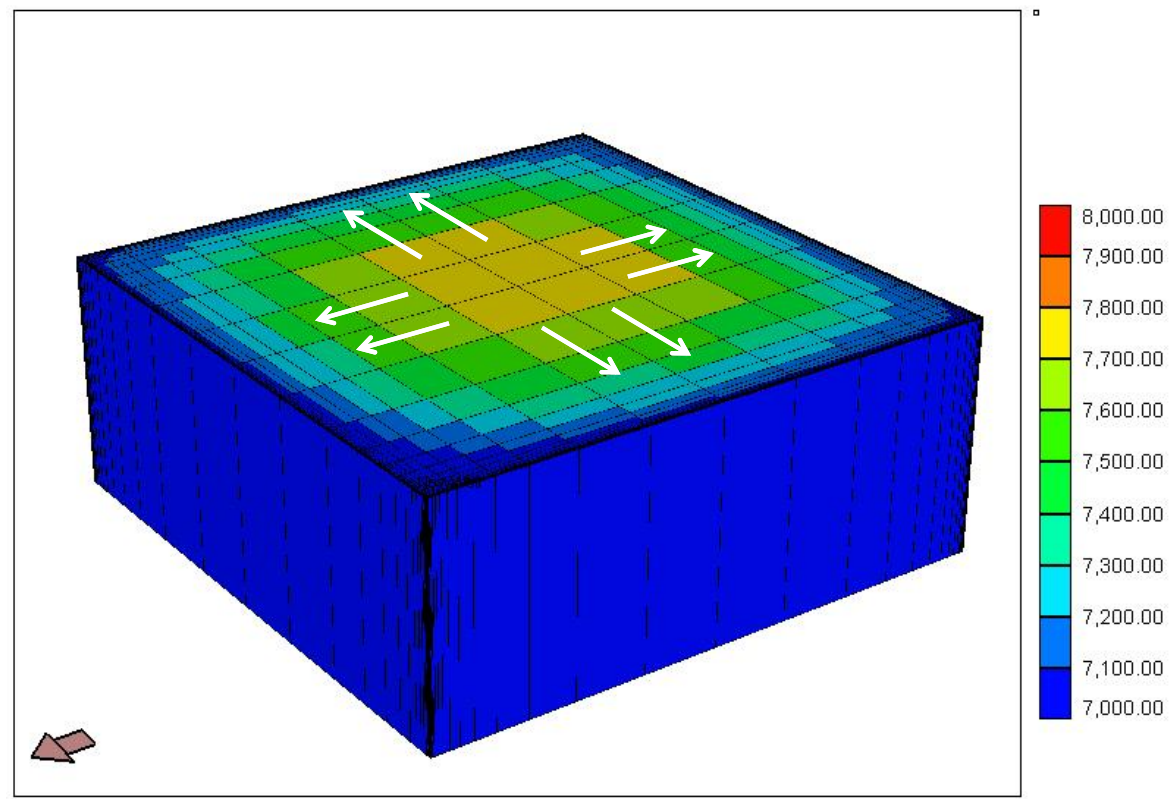

Fig. 4-12- Linear flow for $a / b=1$ at $t_{D x f}=210^{-4}$ under constant $p_{w f}$ production, $k f=100$ $\mathrm{md}, F_{C D}=35$. 
Dimensionless variables. Dimensionless variables defined in Table 3-3 are common for practical used. . So far, the results present constant value for each dimensionless variable. To assure that defined dimensionless variables are adequate enough to characterize the problem, one case where $\frac{a}{b}=64$ and $F_{C D}=200$ is chosen. Table 4-1 shows dimensionless variables changed.

Table 4-1 - Dimensionless variables changed for $a / b=64, F_{C D}=200$

\begin{tabular}{|c|c|c|c|c|c|c|}
\hline Variables & base & $\mathrm{k}_{\text {matrix }}$ & $\mathrm{p}_{\mathrm{i}} \& \mathrm{p}_{\mathrm{wf}}$ & $\phi_{\text {matrix }}$ & Temp & $\mathrm{x}_{\mathrm{f}}$ \\
\hline $\mathrm{k}_{\text {matrix }}(\mathrm{md})$ & 0.001 & 0.01 & & & & \\
Temp (R) & 610 & & & & 660 & \\
$\phi_{\text {matrix }}$ & 0.01 & & & 0.1 & & \\
$\mathrm{p}_{\mathrm{i}}(\mathrm{psi})$ & 8000 & & 6000 & & & \\
$\mathrm{p}_{\mathrm{wf}}(\mathrm{psi})$ & 7000 & & 5000 & & & \\
$\mathrm{k}_{\text {fracture }}(\mathrm{md})$ & 18596.56 & 185965.59 & & & & 36327.709 \\
$\mathrm{x}_{\text {fracture }}(\mathrm{ft})$ & 65087 & & & & & 127146.98 \\
$\mathrm{c}_{\mathrm{t}}\left(\mathrm{psi} \mathrm{i}^{-1}\right)$ & $5.38110^{-5}$ & & $9.07210^{-5}$ & & $6.10910^{-5}$ & \\
$\mu_{\mathrm{g}}(\mathrm{cp})$ & 0.03436 & & 0.02917 & & 0.03206 & \\
\hline
\end{tabular}

Column base shows original data and the rest of the columns show the changed variables. $k_{\text {matrix }}$ column explains that permeability of the matrix changed from original value, consequently fracture permeability also changed since $a / b$ and $F_{C D}$ is constant. Similar process occur when change fracture half length, $x_{f}$, consequently permeability is also changed. Altering initial pressure and wellbore-pressure will change total compressibility, $c_{t}$, and gas viscosity, $\mu_{g}$, because simulator (GASSIM) calculates these two dependent pressure variables using correlation, similar procedure occur when altering temperature. Fig. 4-13 shows the result of variables changed. 


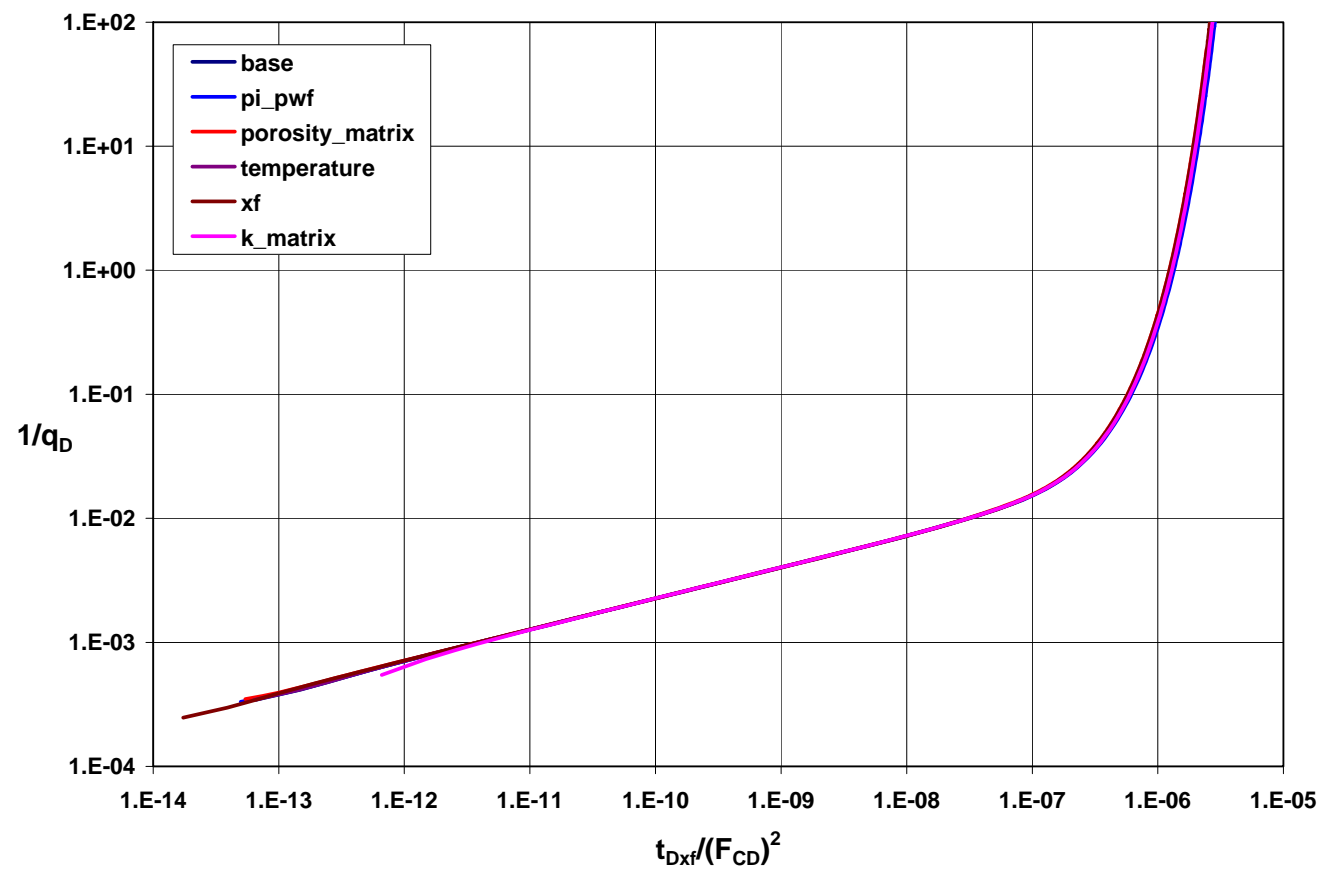

Fig. 4-13 - Change of dimensionless variables for $a / b=64$ and $F_{C D}=200$

Late time. As well as early time, we can also normalize the late time. Fig. 4-14 shows graphical plot of $p_{W D}$ versus $t_{D A}$ in log-log scale. At early time, we observed numerical error for all $a / b$ before the bilinear flow develop. Case where $a / b=64$, linear flow was observed after bilinear flow. At late time, all cases start to develop unit slope of one and merge into one line. 


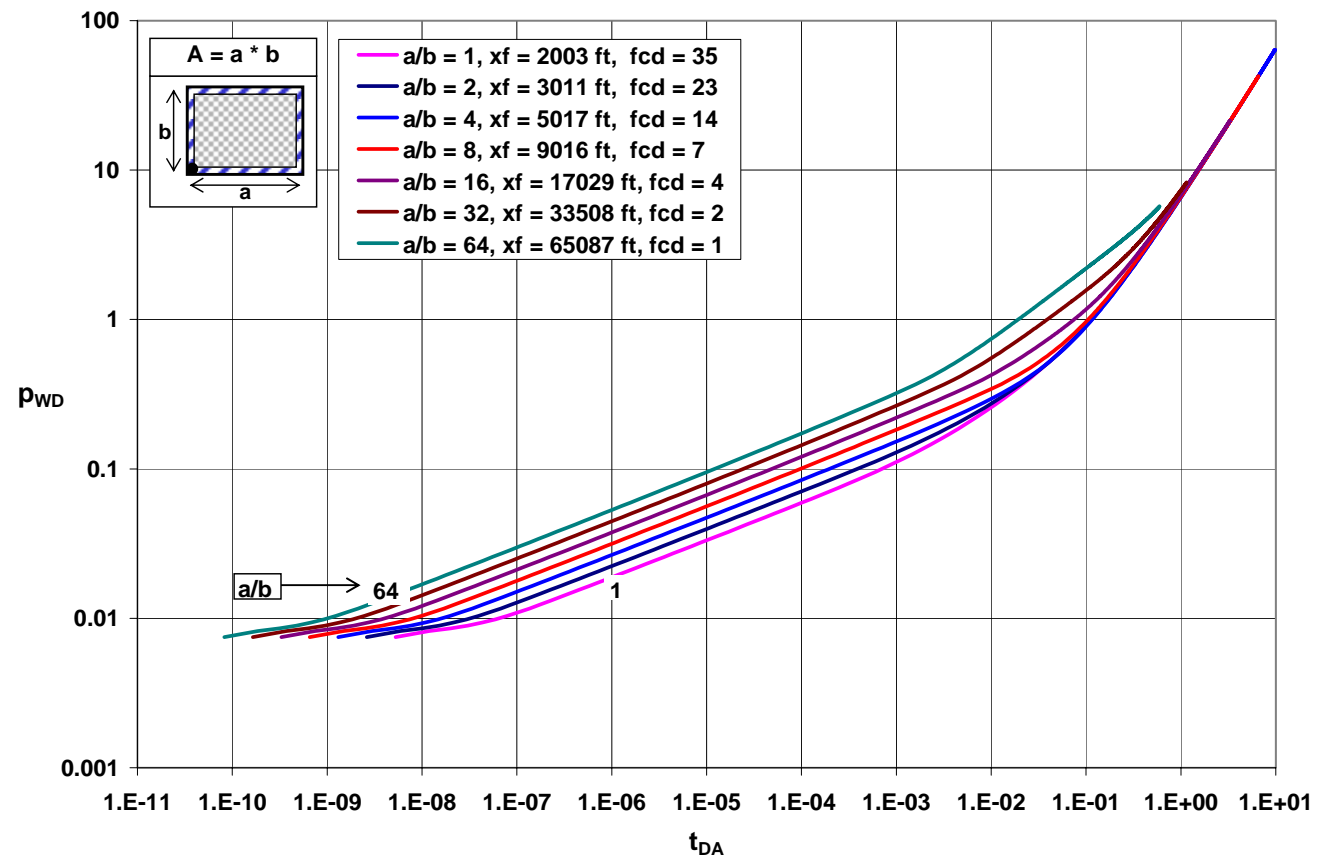

Fig 4-14 - Normalized late time for all $a / b$ under constant rate production, $k_{f}=100 \mathrm{md}$

\subsection{Future work}

In function of the research topic, the following recommendations and future research work are made to improve the research.

1. Investigate simulation case under constant rate production.

2. Incorporating single matrix block drainage into warren-root naturally fracture model.

3. And applying this single matrix block to well performance. 


\section{CHAPTER V CONCLUSIONS}

This work presents the result of performance of bilinear flow in single matrix block drainage. From this work, the following conclusions have been reached.

1. The single matrix block drainage model has early bilinear flow period which is equivalent to the analytical solution developed by Cinco-Ley et. al ${ }^{2}$ and Guppy et. $a l^{14}$.

2. Linear flow was observed after bilinear flow for cases which has $a / b$ greater than 16 and dimensionless fracture conductivity $\left(F_{C D}\right)$ less than 2 .

3. When linear flow was observed for constant $p w f$ case, it was for flow in the longitudinal direction, not perpendicular to fracture faces.

4. The variables and parameters $t_{D x}, 1 / q_{D}$ or $p_{W D}, F_{C D}$, and aspect ratio $(a / b)$ seem to completely define behavior of matrix block drainage for case of constant $p_{w f}$.

5. Linear flow does not develop earlier than bilinear flow, as suggesting in the literature, rather, bilinear flow behavior begins at time $=0$ for case of constant $p_{w f}$. 


\section{NOMENCLATURE}

\section{Variables}

$$
\begin{aligned}
& \text { A }=\text { Drainage area, } \mathrm{L}^{2}\left[\mathrm{ft}^{2}\right] \\
& a \quad=\text { length of matrix block, L [ft] } \\
& b \quad=\text { width of matrix block, } \mathrm{L}[\mathrm{ft}] \\
& B_{g i}=\text { initial gas formation volume factor, } \mathrm{L}^{3} / \mathrm{L}^{3}[\mathrm{rcf} / \mathrm{scf}] \\
& c_{f} \quad=\text { formation (rock) compressibility, } \mathrm{Lt}^{2} / \mathrm{m},[\mathrm{psia}-1] \\
& c_{g} \quad=\text { gas compressibility, } \mathrm{Lt}^{2} / \mathrm{m},\left[\mathrm{psia}^{-1}\right] \\
& c_{t} \quad=\text { total system compressibility, } \mathrm{Lt}^{2} / \mathrm{m},\left[\mathrm{psia}^{-1}\right],\left[=c_{g} S_{g}+c_{o} S_{o}+c_{w} S_{w i}+c_{f}\right] \\
& c_{w} \quad=\text { water compressibility, } \mathrm{Lt}^{2} / \mathrm{m}\left[\mathrm{psia}^{-1}\right] \\
& d p / d L=\text { potential gradient in the flow direction, } \mathrm{psi} / \mathrm{in}, \mathrm{atm} / \mathrm{cm} \\
& F_{C D}=\text { dimensionless fracture conductivity }\left[=k_{f} w / k x_{f}\right] \\
& h \quad=\text { net reservoir thickness, }\left(h_{n e t}\right), \mathrm{L},[\mathrm{ft}] \\
& k=\text { permeability of the reservoir, } \mathrm{L}^{2},[\mathrm{md}] \\
& k_{f} \quad=\text { fracture permeability (fracture referred to bulk volume), } \mathrm{L}^{2}, \text { [md] } \\
& k_{m} \quad=\text { matrix permeability of a homogeneous rock, } \mathrm{L}^{2},[\mathrm{md}] \\
& m_{D} \quad=\text { dimensionless pseudo-pressure } \\
& m_{D L}=\text { dimensionless gas real pseudo-pressure }\left[=\sqrt{k} A_{c} \Delta m(p) / 1424 q_{g} T\right] \\
& m(p)=\text { real gas pseudo-pressure, } \mathrm{m} / \mathrm{Lt}^{3},\left[\mathrm{psia}^{2} / \mathrm{cp}\right] \\
& m(\bar{p})=\text { real gas pseudo-pressure at average reservoir pressure, } \mathrm{m} / \mathrm{Lt}^{3},\left[\mathrm{psia}^{2} / \mathrm{cp}\right] \\
& m\left(p_{i}\right)=\text { real gas pseudo-pressure at initial pressure, } \mathrm{m} / \mathrm{Lt}^{3},\left[\mathrm{psia}^{2} / \mathrm{cp}\right] \\
& m\left(p_{w f}\right)=\text { real gas pseudo-pressure at flowing bottomhole pressure, } \mathrm{m} / \mathrm{Lt}^{3},\left[\mathrm{psia}^{2} / \mathrm{cp}\right] \\
& p=\text { absolute pressure, } \mathrm{m} / \mathrm{Lt}^{2},[\mathrm{psia}] \\
& \bar{p} \quad=\text { average reservoir pressure, } \mathrm{m} / \mathrm{Lt}^{2},[\mathrm{psia}] \\
& p_{D} \quad=\text { dimensionless pressure } \\
& p_{i}=\text { initial reservoir pressure, } \mathrm{m} / \mathrm{Lt}^{2},[\mathrm{psia}] \\
& p_{O} \quad=\text { reference pressure, } \mathrm{m} / \mathrm{Lt}^{2},[\mathrm{psia}] \\
& p_{w D}=\text { dimensionless pressure at the wellbore }
\end{aligned}
$$




$$
\begin{array}{ll}
p_{w f} & =\text { flowing bottomhole pressure, }(\mathrm{BHFP}), \mathrm{m} / \mathrm{Lt}^{2},[\mathrm{psia}] \\
q & =\text { production rate, } \mathrm{L}^{3} / \mathrm{t},[\mathrm{stb} / \mathrm{D}] \\
q_{D} & =\text { dimensionless rate at the wellbore } \\
q_{g} & =\text { gas production, } \mathrm{L}^{3} / \mathrm{t},[\mathrm{Mscf} / \mathrm{D}] \\
t & =\text { time, } t,[\text { days }] \\
t_{D} & =\text { dimensionless time }\left[=0.00633 \mathrm{kt} / \phi \mu_{g} C_{t} r^{2}{ }_{w}\right] \\
t_{D A} & =\text { dimensionless time }\left[=0.00633 \mathrm{kt} / \phi \mu_{g} c_{t} A\right] \\
t_{D x f} & =\text { dimensionless time }\left[=0.00633 \mathrm{kt} / \phi \mu_{g} c_{t} x_{f}{ }^{2}\right] \\
T & =\text { reservoir temperature, } \mathrm{T},\left[{ }^{\circ} \mathrm{R}\right] \\
V_{p} & =\text { pore volume of the reservoir, } \mathrm{L}^{3},[\mathrm{rcf}] \\
w & =\text { width of the fracture, }(w), \mathrm{L},[\mathrm{ft}] \\
x_{f} & =\text { fracture half-length, } \mathrm{L},[\mathrm{ft}] \\
z & =\text { gas compressibility factor }
\end{array}
$$

$$
\begin{aligned}
& \text { Greek Symbols } \\
& \phi \quad=\text { porosity, [fraction] } \\
& \gamma_{g} \quad=\text { gas specific gravity }(\text { air }=1) \\
& \mu \quad=\text { viscosity, } \mathrm{m} / \mathrm{Lt} \text {, [cp] } \\
& \mu_{g} \quad=\text { gas viscosity, } \mathrm{m} / \mathrm{Lt} \text {, [cp] } \\
& \rho=\text { fluid density, }\left[\mathrm{lbm} / \mathrm{ft}^{3}, \mathrm{gm} / \mathrm{cm}^{3}\right](\text { water }=1) \\
& \Delta m(p)=\text { drop of pseudo pressure, }\left[\mathrm{psia}^{2} / \mathrm{cp}\right],\left[=m\left(p_{i}\right)-m\left(p_{w f}\right)\right] \\
& \Delta p \quad=\text { drop of pressure }\left[=p_{i}-p_{w f}\right],[\mathrm{psi}] \\
& \pi \quad=\text { constant }
\end{aligned}
$$




\section{REFERENCES}

1. Cinco-Ley, H. and Samaniego, F.V.: "Transient Pressure Analysis for Fractured Wells,” JPT (September 1981) 1749; paper SPE 7490.

2. Wattenbarger, R.A.: “Analysis of Linear Flow into Fractured Wells," report, Dept. of Petroleum Engineering, Texas A\&M University, College Station, TX (1996).

3. Warren, J.E. and Root, P.J.: "The Behavior of Naturally Fractured Reservoirs," SPEJ (September 1963) 245-55; Trans., AIME, 228.

4. Bourdet, D., Whittle, T.M., Douglas, A.A., and Pirard, Y.M.: "A New Set of Type Curves Simplifies Well Test Analysis," World Oil (May 1983) 95-106.

5. Cinco-Ley, H. and Meng, H.Z.: "Pressure Transient Analysis of Wells with Finite Conductivity Vertical Fractures in Double Porosity Reservoirs," paper SPE 18172 presented at the 1988 Annual Technical Conference and Exhibition, Houston, TX, 25 October.

6. Cinco-Ley, H., Ramey, H.J., Jr., Samaniego-V., F., and Rodriguez, F.: "Behavior of Wells with Low-Conductivity Vertical Fractures," paper SPE 16776 presented at the 1987 Annual Technical Conference and Exhibition, Dallas, TX, 27-30 September.

7. Stright, D.H. and Gordon, J.I.: "Decline Curve Analysis in Fractured Low Permeability Gas Wells in the Piceance Basin," paper SPE/DOE 11640 presented at the 1983 SPE/DOE Symposium on Low Permeability held in Denver, Colorado, 1416 March.

8. Ammer, J.R., Sawyer, W.K., and Drophin, M.J.: "Practical Methods for Detecting Production Mechanisms in Tight Gas Reservoirs," paper SPE/DOE/GRI 12864 presented at the 1984 SPE/DOE/GRI Unconventional Gas Recovery Symposium, Pittsburgh, PA, 13-15 May.

9. Arévalo-Villagrán, J.A. and Wattenbarger, R.A.: "Interpretation of Flow Behavior from Production Analysis of Castlegate Tight Gas Wells," quarterly reports for the Hydraulic Fracture Effectiveness Project, Dept. of Petroleum Engineering, Texas A\&M University, College Station, TX, February (2001). 
10. Cinco-Ley, H., Samaniego, F.V, and Dominguez, N.: "Transient Pressure Behavior for a Well With a Finite-Conductivity Vertically Fracture," SPEJ (Aug. 1978) 253; paper SPE 6014.

11. Agarwal, R.G., Carter, R.D., and Pollock, C.B.: "Evaluation and Performance Prediction of Low-Permeability Gas Wells Stimulated by Massive Hydraulic Fracturing," JPT (March 1979) 362; Trans., AIME, 267.

12. Cinco-Ley, H. and Samaniego, V.F.: "Transient Pressure Analysis: Finite Conductivity Fracture Case Versus Damaged Fracture Case," paper SPE 10179 presented at the 1981 Annual Fall Technical Conference and Exhibition, San Antonio, TX, 5-7 October.

13. Wong, D.W., Mothersele, C.D., Harrington, A.G., and Cinco-Ley, H.: "Pressure Transient Analysis in Finite Linear Reservoirs Using Derivative and Conventional Techniques: Field Examples," paper SPE 15421 presented at the 1986 Annual Technical Conference and Exhibition, New Orleans, LA, 5-8 October.

14. Spivey, J.P. , and Lee, W.J.,: "Identifying Flow Regimes in Pressure Transient Tests" Pet.Eng.Intl. (October 1997), 70, No.10, 66-70.

15. England, K.W., Poe, B.D., and Conger, J.G.,: "Comprehensive Evaluations of Fractured Gas Wells Utilizing Production Data”, SPE 60285, presented at the SPE Rocky Mountain Regional Meeting, Denver, Colorado, March 12-15.

16. Guppy, K., Cinco-Ley, H., Ramey, H.,: "Transient Flow Behavior of Vertically Fractured Well Producing at Constant Pressure," paper SPE 9963.

17. Kohlhaas, C.A. and Abbot, W.A.: "Application of Linear and Spherical Flow Analysis Techniques to Field Problems - Case Studies," paper SPE 11088 presented at the 1982 Annual Fall Conference and Exhibition held in New Orleans, LA, 26-29 September.

18. Wattenbarger, R.A.: “Analysis of Linear Flow into Fractured Wells,” report, Dept. of Petroleum Engineering, Texas A\&M University, College Station, TX (1996).

19. El-Banbi, A.H. and Wattenbarger, R.A.: "Analysis of Linear Flow in Gas Well Production," paper SPE 39972 presented at the 1998 SPE Gas Technology Symposium, Calgary, Alberta, 15-18 March. 
20. Arévalo-Villagrán, J.A., Wattenbarger, R.A., Samaniego-Verduzco, F., and Pham, T.T.: "Production Analysis of Long-Term Linear Flow in Tight Gas Reservoirs: Case Histories," paper SPE 71516 to be presented at the 2001 Annual Technical Conference and Exhibition, New Orleans, LA, 30 September-3 October.

21. Arévalo-Villagrán, J.A. and Wattenbarger, R.A.: "Interpretation of Flow Behavior from Production Analysis of Tight Gas Wells," quarterly reports for the Hydraulic Fracture Effectiveness Project, Dept. of Petroleum Engineering, Texas A\&M University, College Station, TX, February (2001).

22. Muskat, M.: Physical Principles of Oil Production, McGraw Hill Book Company, Inc., New York, (1949).

23. Miller, F.G.: "Theory of Unsteady-State Influx of Water in Linear Reservoirs," Journal of the Institute of Petroleum, Volume 48, No. 467 (November 1956) 365-79.

24. Nabor, G.W. and Barham, R.H.: "Linear Aquifer Behavior,” JPT (May 1964) 561563.

25. Wattenbarger, R.A., El-Banbi, A.H., Villegas, M.E. and Maggard, J.B.: "Production Analysis of Linear Flow Into Fractured Tight Gas Wells," paper SPE 39931 presented at the 1998 SPE Rocky Mountain Regional/Low-Permeability Reservoirs Symposium and Exhibition held in Denver, CO, 5-8 April.

26. Economides, M.J., Ogbe, D., Miller, F., Cinco-Lwy, H., and Fehlberg, E.L.: “ Pressure Buildup Analysis of Geothermal Steam well With Pararellpiped Model," JPT (April 1982) 925.

27. Wagner, P.B., Ehlig-Economides, C.A., and Economides, M.J.: "Custom TypeCurve Generation for Pressure Transient Analysis of Elongated Linear Flow Systems," paper SPE 13341 (May 1984).

28. Ammer, J.R., Sawyer, W.K., and Drophin, M.J.: "Practical Methods for Detecting Production Mechanisms in Tight Gas Reservoirs," paper SPE/DOE/GRI 12864 presented at the 1984 SPE/DOE/GRI Unconventional Gas Recovery Symposium, Pittsburgh, PA, 13-15 May.

29. Prats, M., Hazebroek, P. and Strickler, W.R.: "Effect of Vertical Fractures on Reservoir Behavior-Compressible-Fluid Case,” paper SPEJ (June 1962), 87-94. 
30. Prats, M. and Levine, J.S.: "Effects of Vertical Fractures on Reservoir BehaviorResults on Oil and Gas Flow” Paper SPE 593.

31. Russel, D.G. and Truitt, N.E.: “Transient Pressure Behavior in Vertically Fractured Reservoirs," JPT (October 1964), 1159-1170.

32. Wattenbarger, R.A. and Ramey, H.J., Jr.: "Well Test Interpretation of Vertically Fractured Gas Wells,” JPT (May 1969) 625; Trans., AIME, 246.

33. Morse, R.A. and Von Gonten, D.: "Productivity of Vertically Fractured Wells Prior to Stabilized Flow," paper SPE 3631 presented at the 1971 Annual Technical Conference and Exhibition, New Orleans, LA, 3-6 October.

34. Agarwal, R.G.: "Real Gas Pseduo-Time - A New Function for Pressure Buildup Analysis of MHF Gas Wells," paper SPE 8279 presented at the $54^{\text {th }}$ Annual Conference and Exhibition held in Las Vegas, Sept. 23-26, 1979

35. Raghavan, R., Chen, C., Agarwal, B.: “An Analysis of Horizontal Wells Intercepted by Multiple Fractures" Paper SPE 27652, SPE Permian Basin Oil and Gas Recovery Conference held in Midland, Texas, 16-18 March 1994.

36. Arnold, M.D., Gonzalez, H.J., and Crawford, P.B.: "Estimation of Reservoir Anisotropy from Production Data," JPT (August 1962) 909.

37. Parsons, R.W.: "Permeability of Idealized Fractured Rock," SPEJ (June 1966) 126.

38. Prats, M.: "The Influence of Oriented Arrays of Thin Impermeable Shale Lenses or of Higly Conductive Natural Fractures on Apparent Permeability Anisotropy," JPT (Oct. 1972) 1219.

39. Locke, C.D. and Sawyer, W.K.: "Constant Pressure Injection Test in a Fractured Reservoirs-History Match Using Numerical Simulation and Type Curve Analysis," paper SPE 5594 presented at the 1975 Annual Fall Meeting, Dallas, Sept. 28-Oct. 1.

40. Odeh, A.S.: "Unsteady State Behavior of Naturally Fractured Reservoirs," SPEJ (Sept. 1963) 245.

41. Kazemi, H.: "Pressure Transient Analysis of Naturally Fractured Reservoirs with Uniform Fracture Distribution," SPEJ (December 1969) 451-462; Trans., AIME, 246. 
42. de Swaan, O.A.: "Analytic Solutions for Determining Naturally Fractured Reservoir Properties by Well Testing," SPEJ (June 1976) 117-122; Trans., AIME, 261.

43. Aguilera, R.: "An Approximate Solution of Linear Flow in Naturally Fractured Reservoirs,” paper SPE 16442, (1987).

44. Aguilera, R.:'Well Test Analysis of Naturally Fractured Reservoirs," SPEFE (Sept. 1987) 239.

45. Da Prat, G., Cinco-Ley, H., and Ramey, H.J., Jr.: “Decline Curve Análisis Using Type Curves for Two-Porosity Systems," SPEJ (June 1982) 354.

46. Gringarten, A.C.: "Flow Test Evaluation of Fractured Reservoir," paper presented at the 1979 Symposium on Recent Trends in Hydrology, Berkeley, Feb. 8-9.

47. Gringarten, A.C.: "Interpretation of Test in Fissured and Multilayered Reservoirs with Double Porosity Behavior: Theory and Practice," JPT (April 1984) 549. 
APPENDIX A

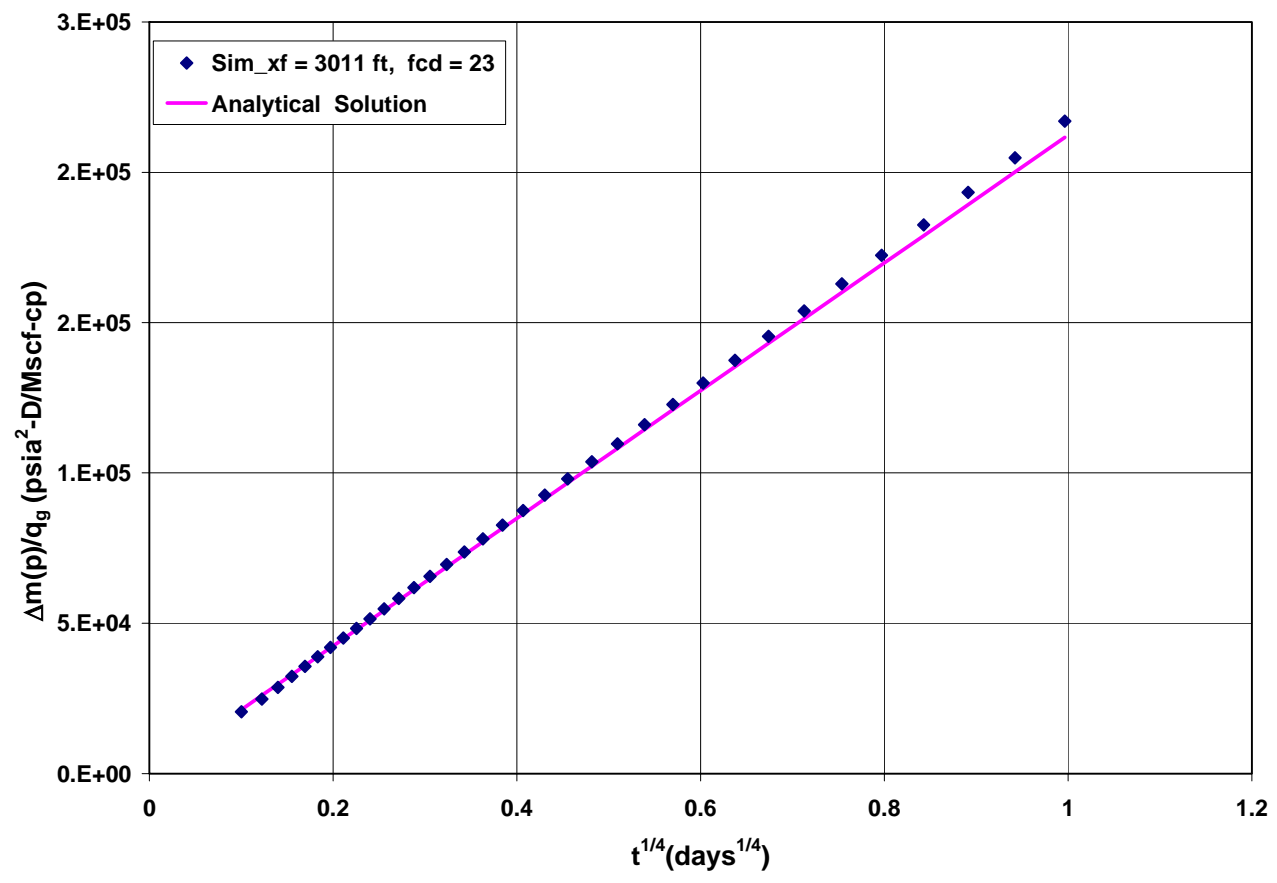

Fig A-1 - Slope under constant $p_{w f}$ solution for case $a / b=2, k_{f}=100 \mathrm{md}$

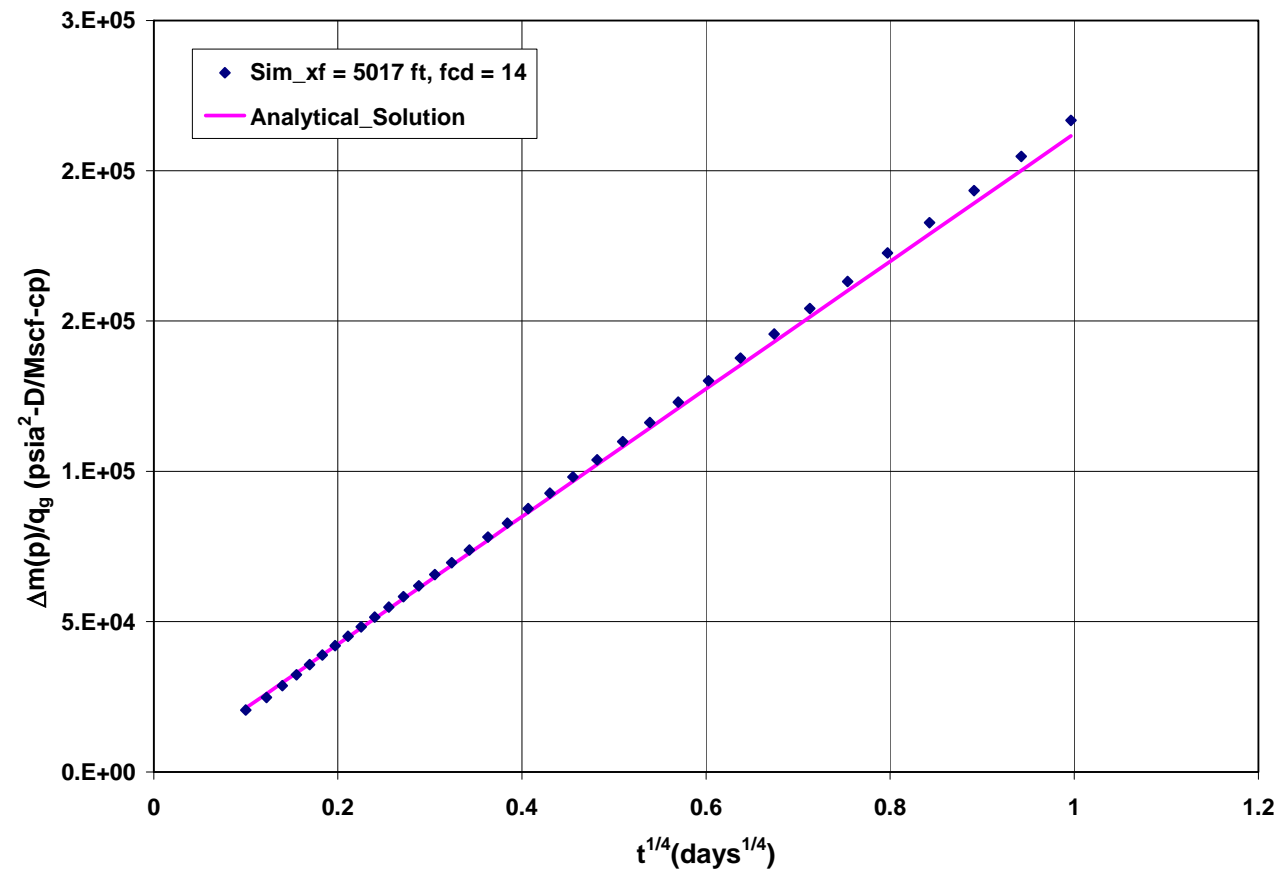

Fig A-2 - Slope under constant $p_{w f}$ solution for case $a / b=4, k_{f}=100 \mathrm{md}$ 


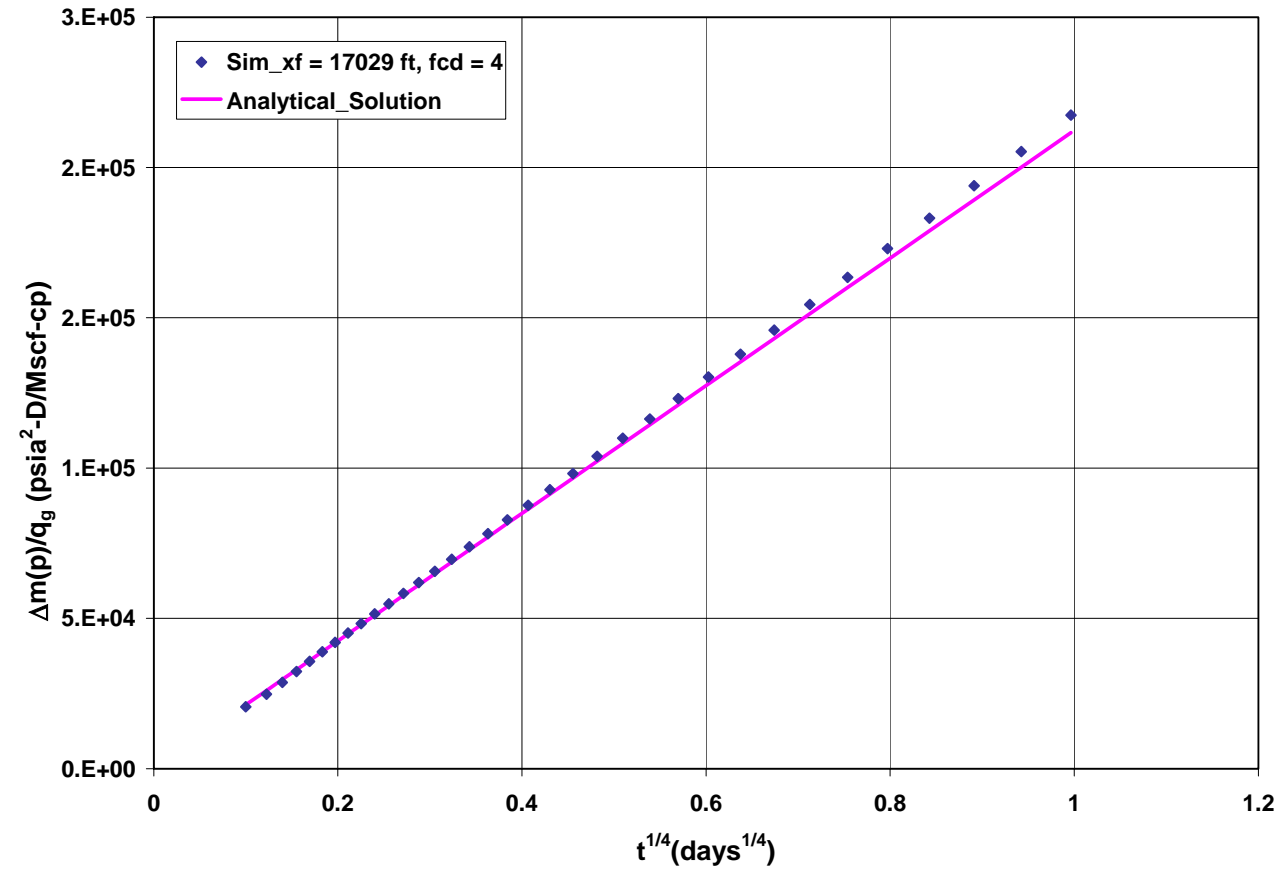

Fig A-3 - Slope under constant $p_{w f}$ solution for case $a / b=16, k_{f}=100 \mathrm{md}$

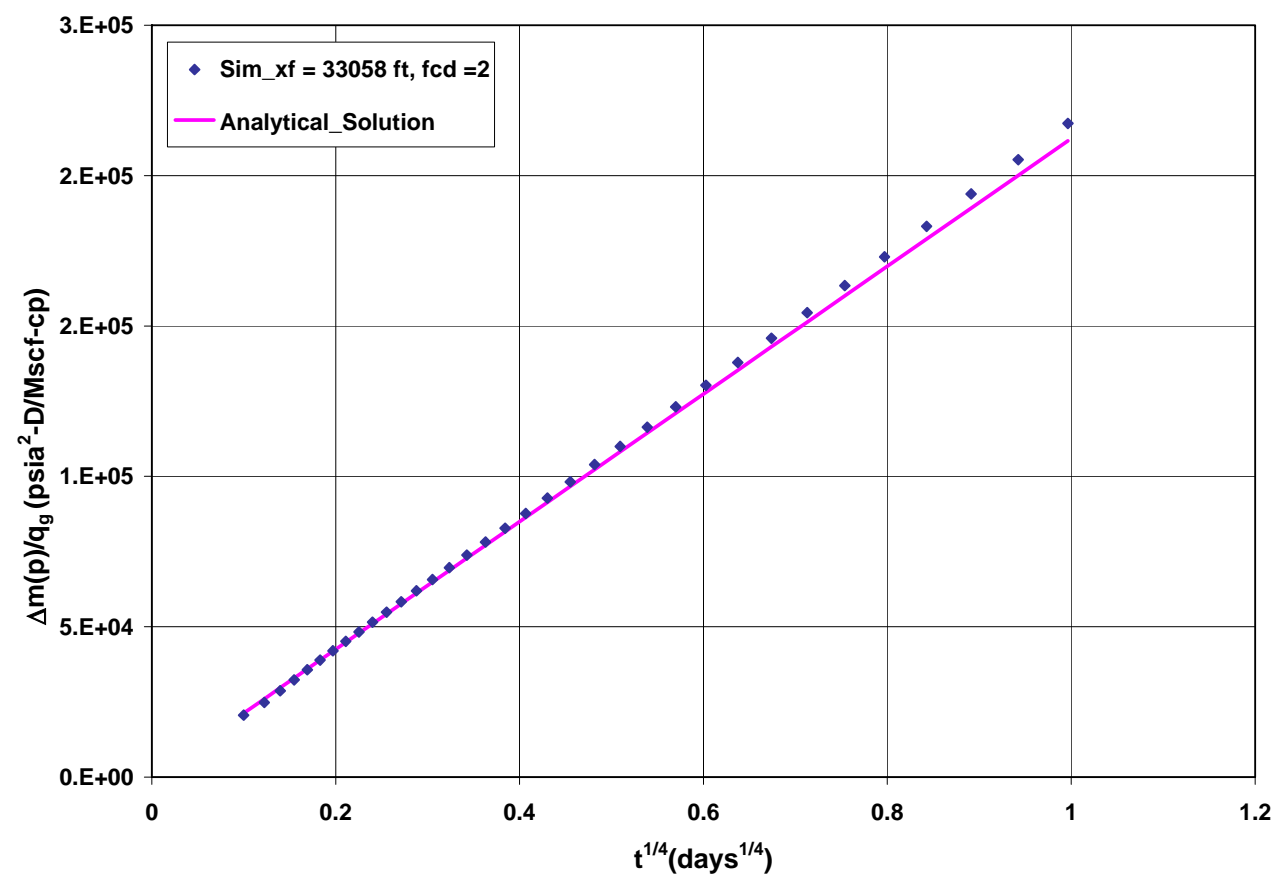

Fig A-4 - Slope under constant $p_{w f}$ solution for case $a / b=32, k_{f}=100 \mathrm{md}$ 


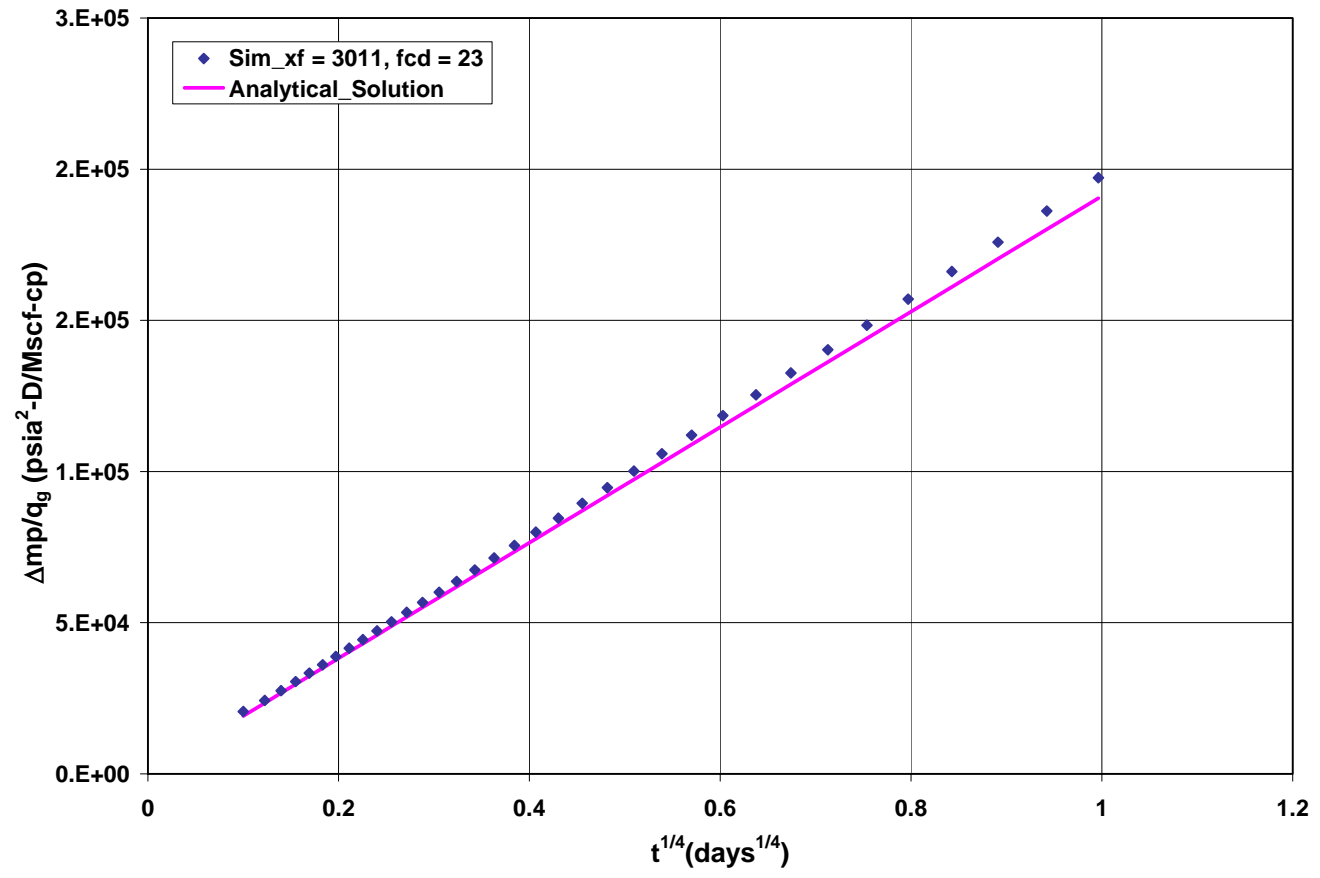

Fig A-5 - Slope under constant rate solution for case $a / b=2, k_{f}=100 \mathrm{md}$

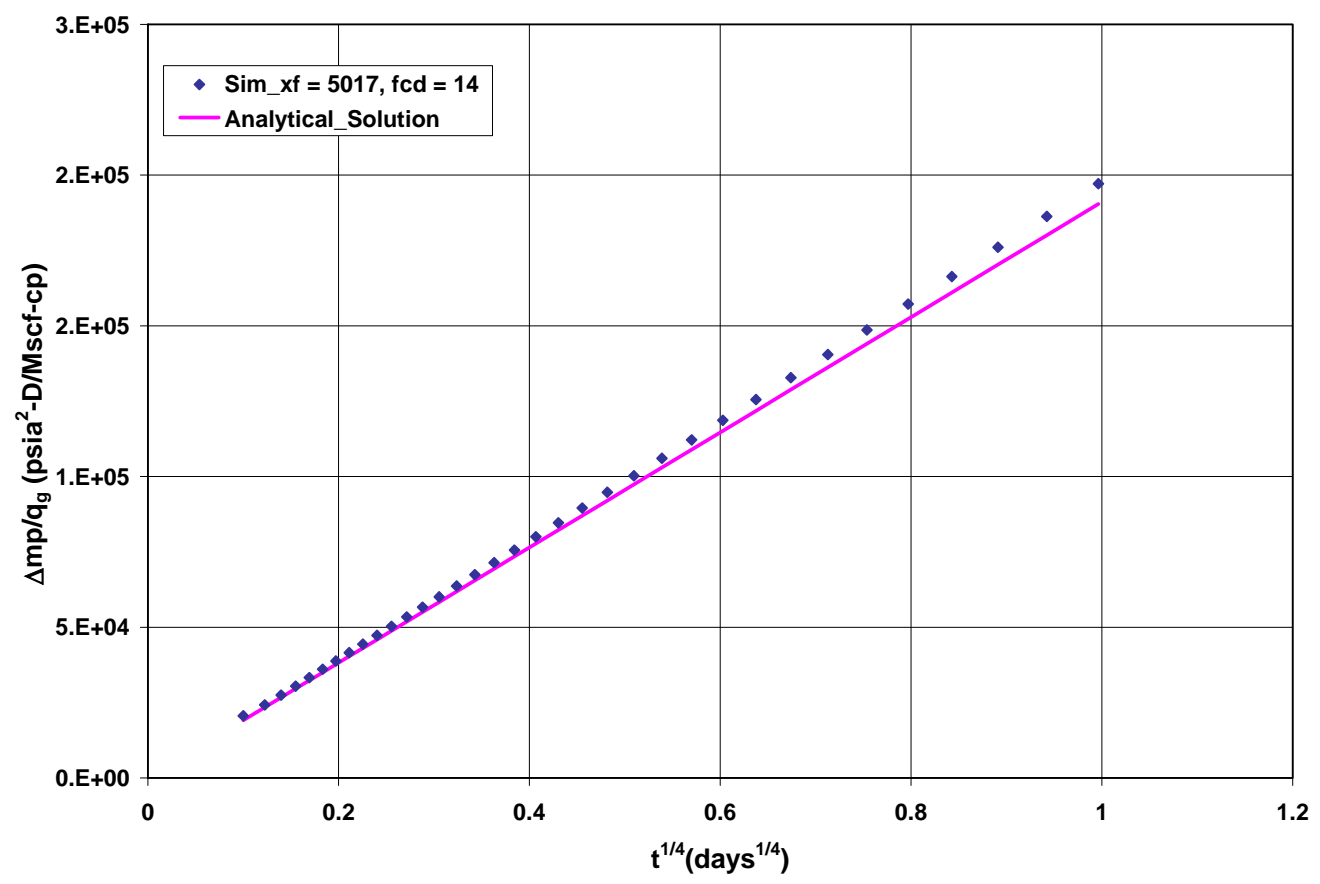

Fig A-6 - Slope under constant rate solution for case $a / b=4, k_{f}=100 \mathrm{md}$ 


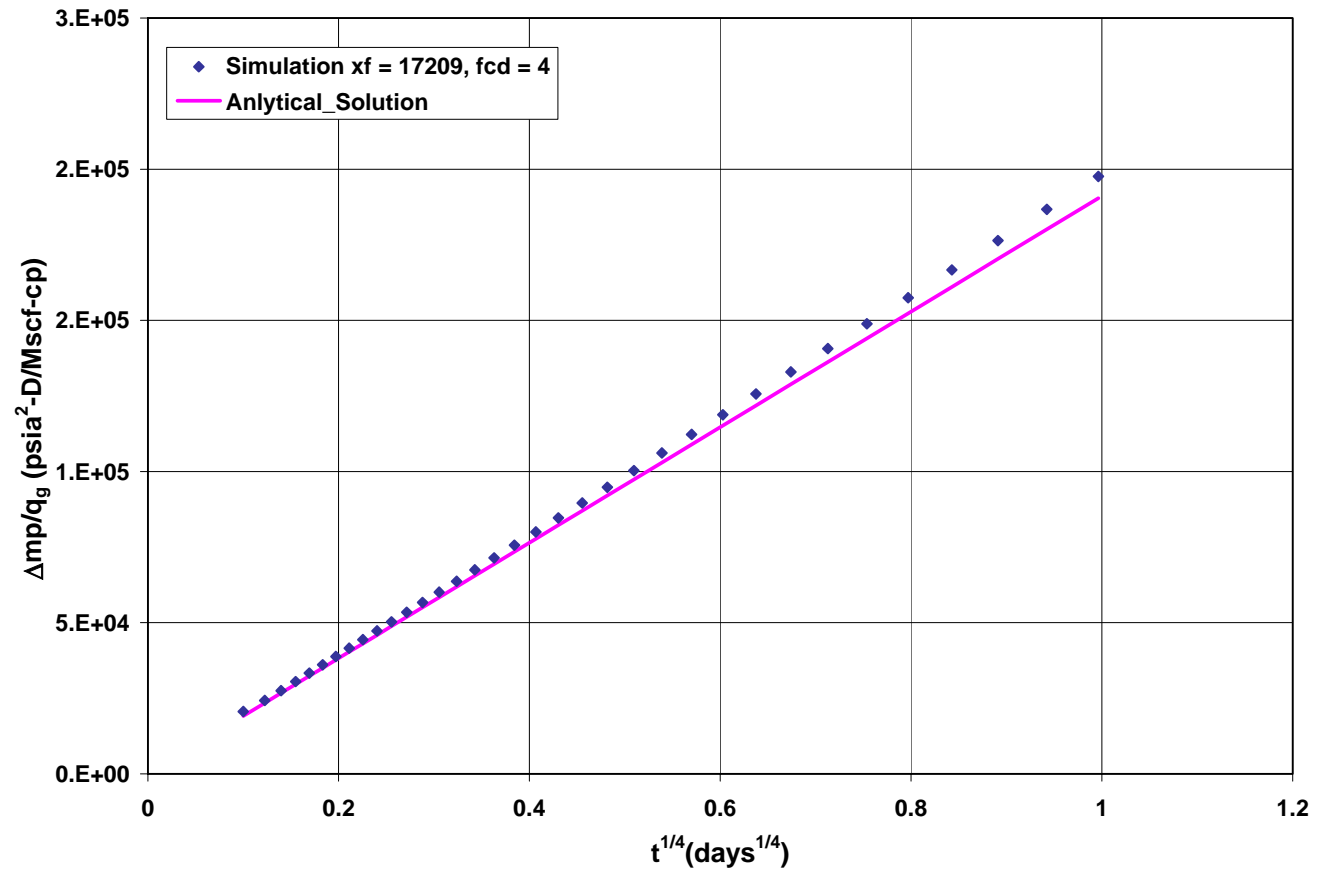

Fig A-7 - Slope under constant rate solution for case $a / b=16, k_{f}=100 \mathrm{md}$

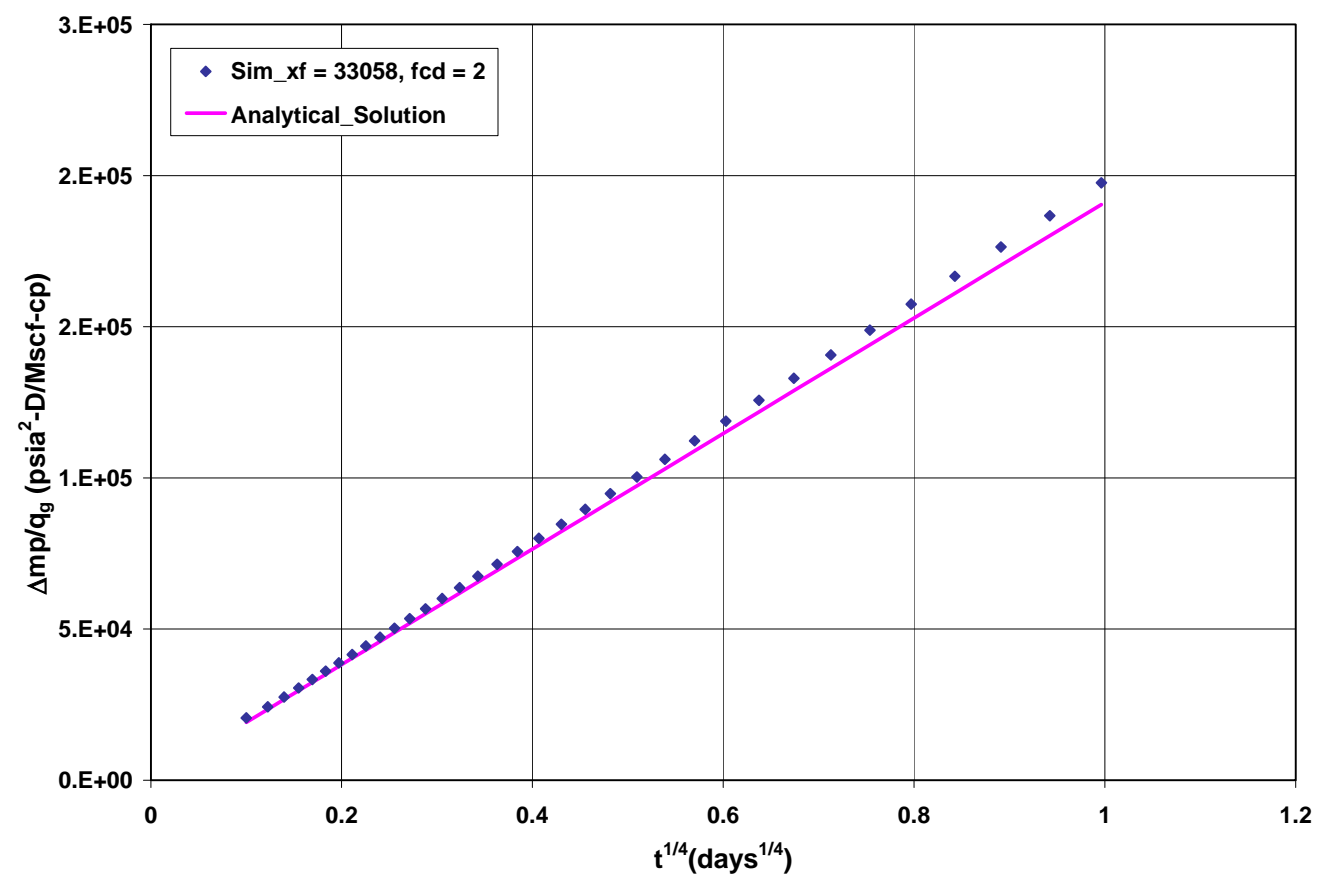

Fig A-8 - Slope under constant rate solution for case $a / b=32, k_{f}=100 \mathrm{md}$ 


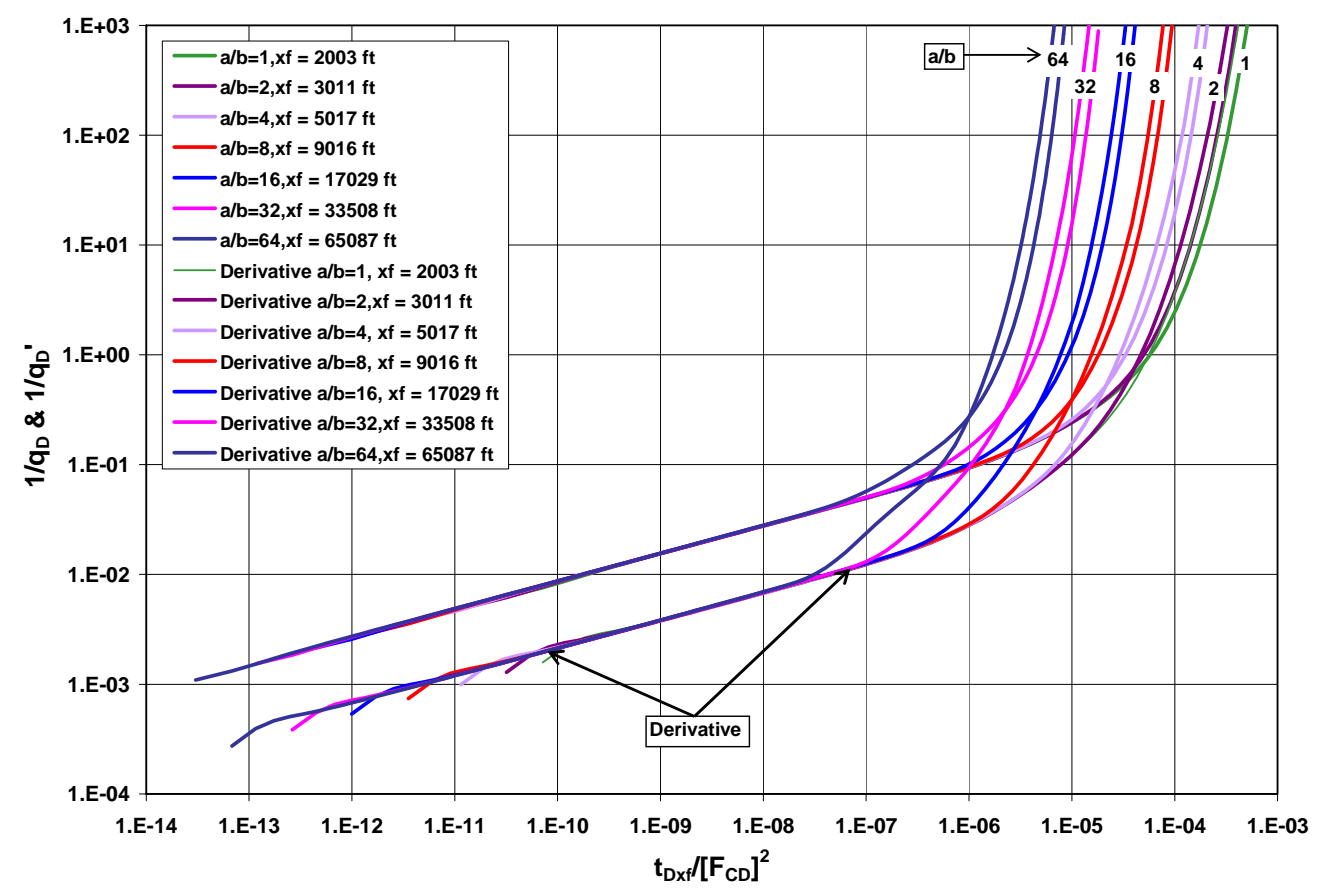

Fig A-9 $-\left(1 / q_{D}\right)$ and $\left(1 / q_{D}^{\prime}\right)$ versus $t_{D x f} f\left(F_{C D}\right)^{2}$, all $a / b$ under constant $p_{w f}$ production, $F C_{D}$ $=20$

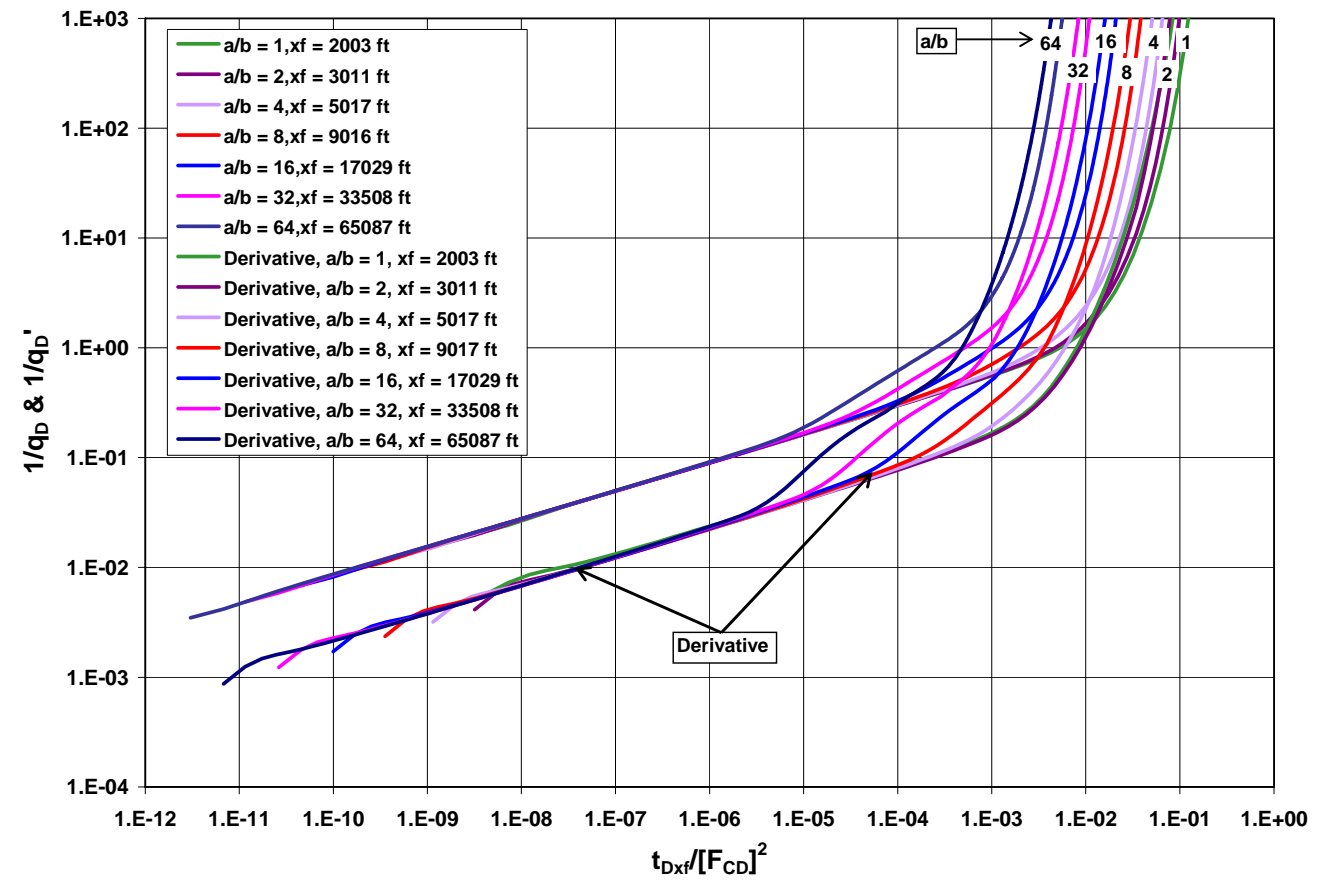

Fig A-10 - $\left(1 / q_{D}\right)$ and $\left(1 / q_{D}{ }^{\prime}\right)$ versus $t_{D x f} f\left(F_{C D}\right)^{2}$, all $a / b$ under constant $p_{w f}$ production, $F C_{D}=2$ 


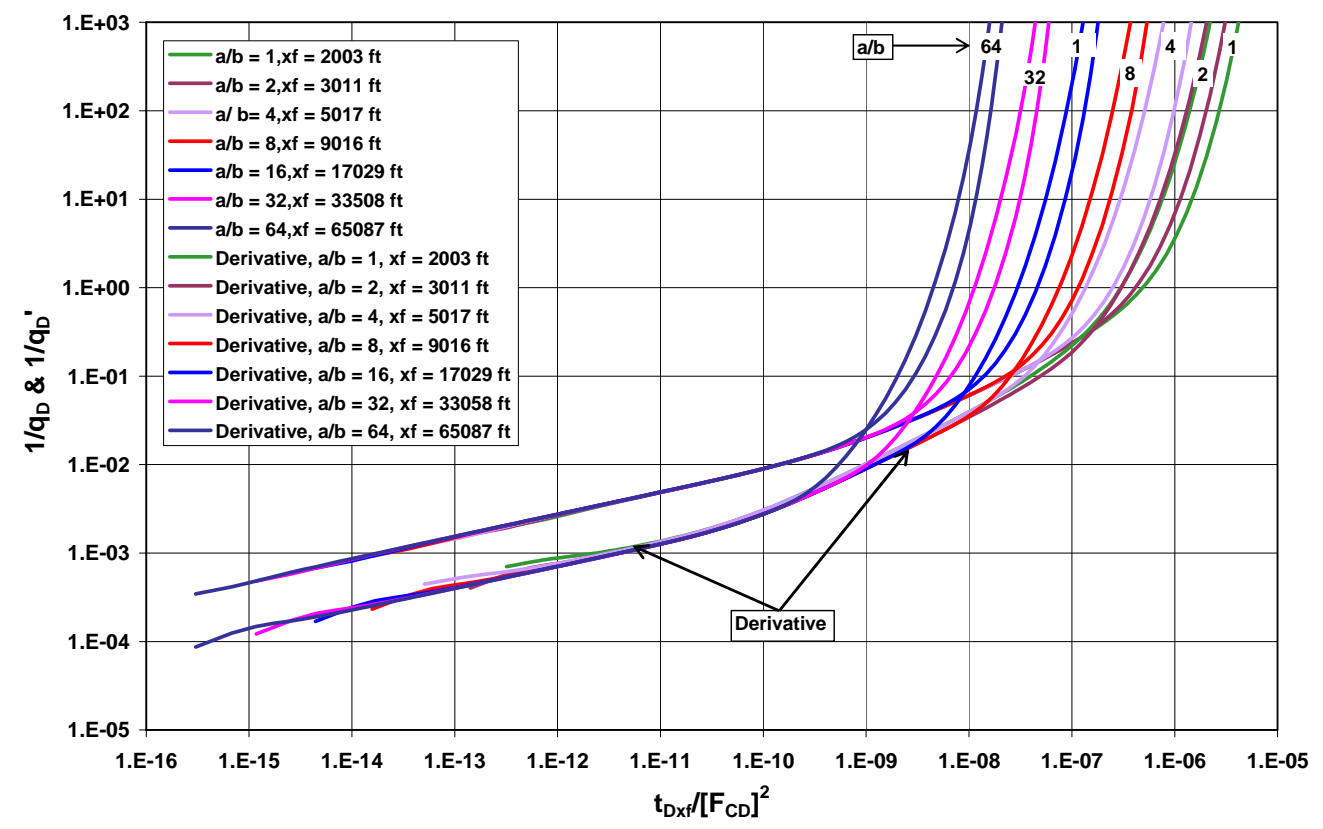

Fig A-11 - $\left(1 / q_{D}\right)$ and $\left(1 / q_{D}\right)$ versus $t_{D x} f\left(F_{C D}\right)^{2}$, all $a / b$ under constant $p_{w f}$ production, $F C_{D}=200$

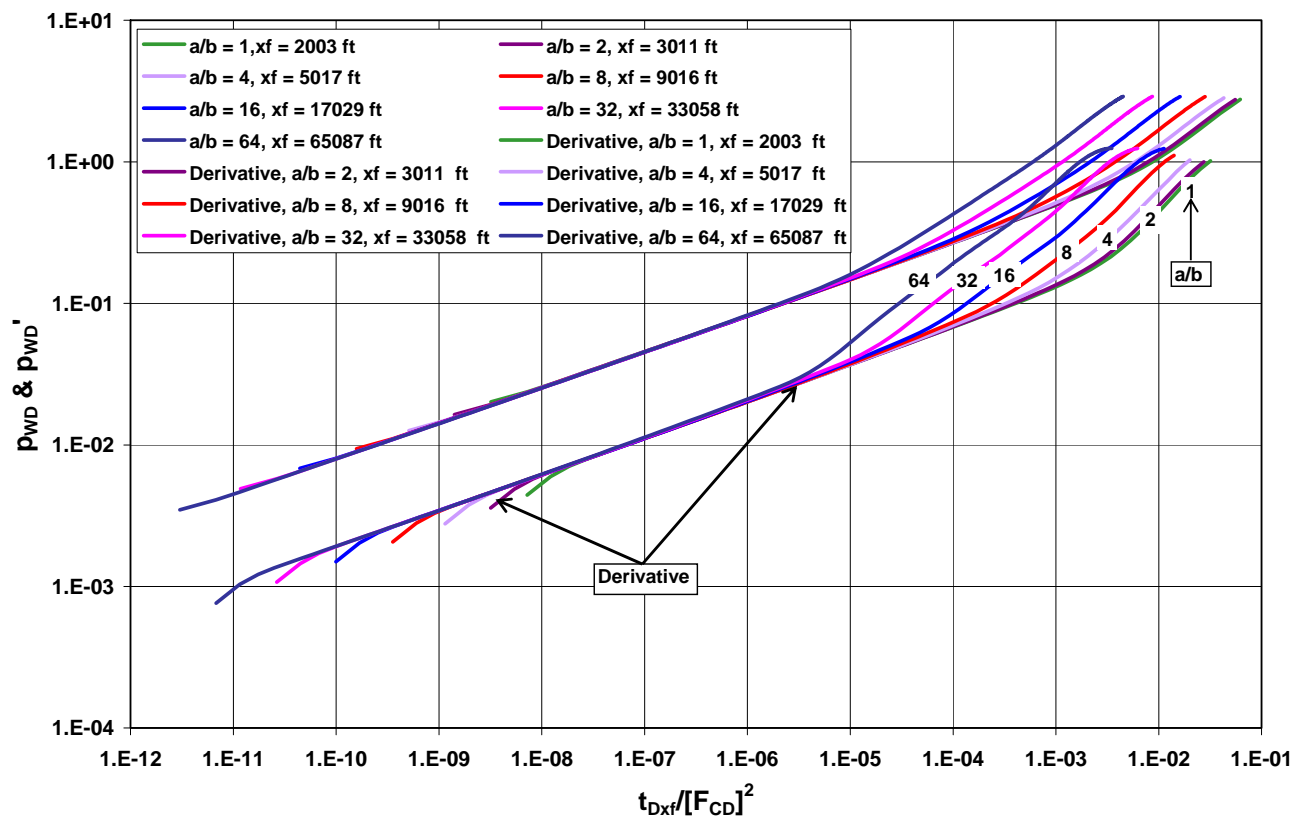

Fig A-12 - $\left(p_{W D}\right)$ and $\left(p_{W D}\right)$ versus $t_{D x} f\left(F_{C D}\right)^{2}$, all $a / b$ under constant rate production,

$$
F C_{D}=2
$$




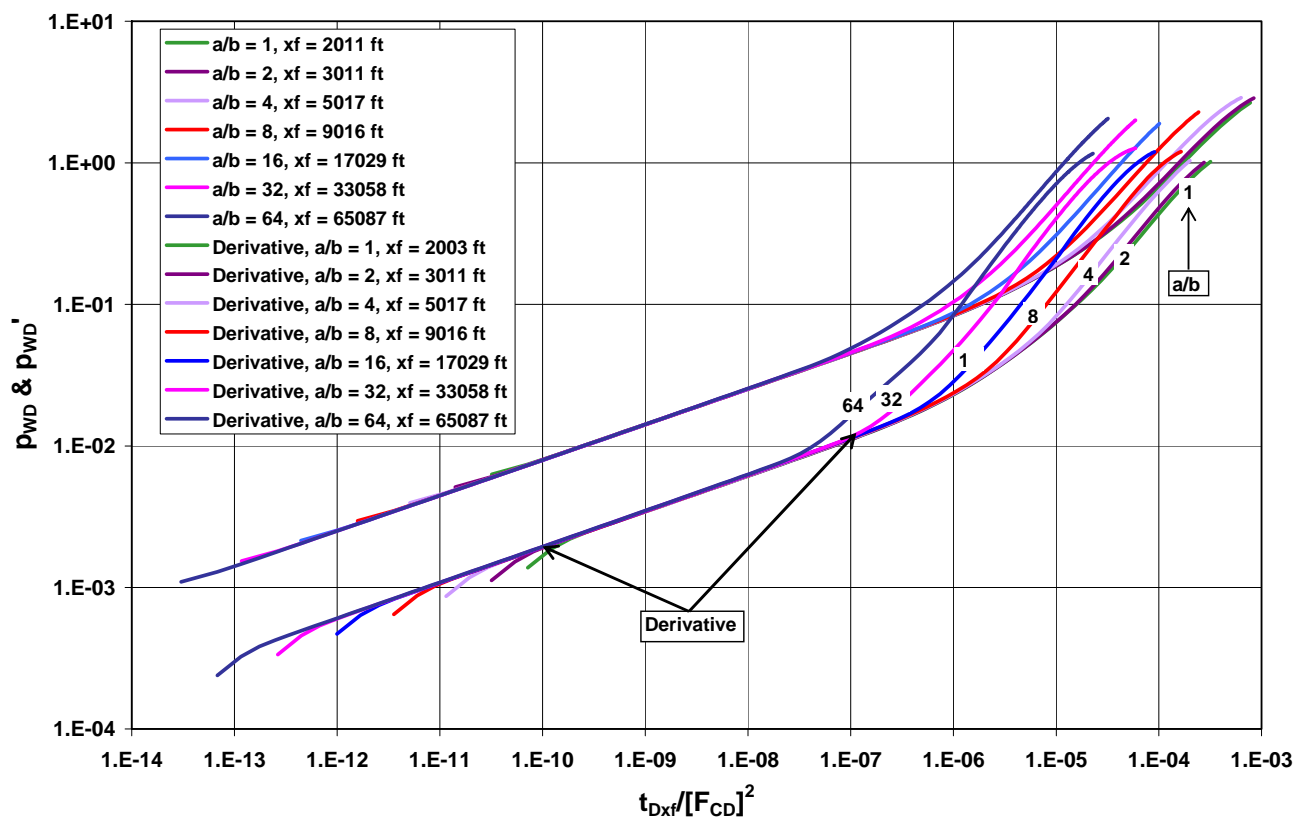

Fig A-12 - $\left(p_{W D}\right)$ and $\left(p_{W D}\right)$ versus $t_{D x} f\left(F_{C D}\right)^{2}$, all $a / b$ under constant rate production, $F C_{D}=20$

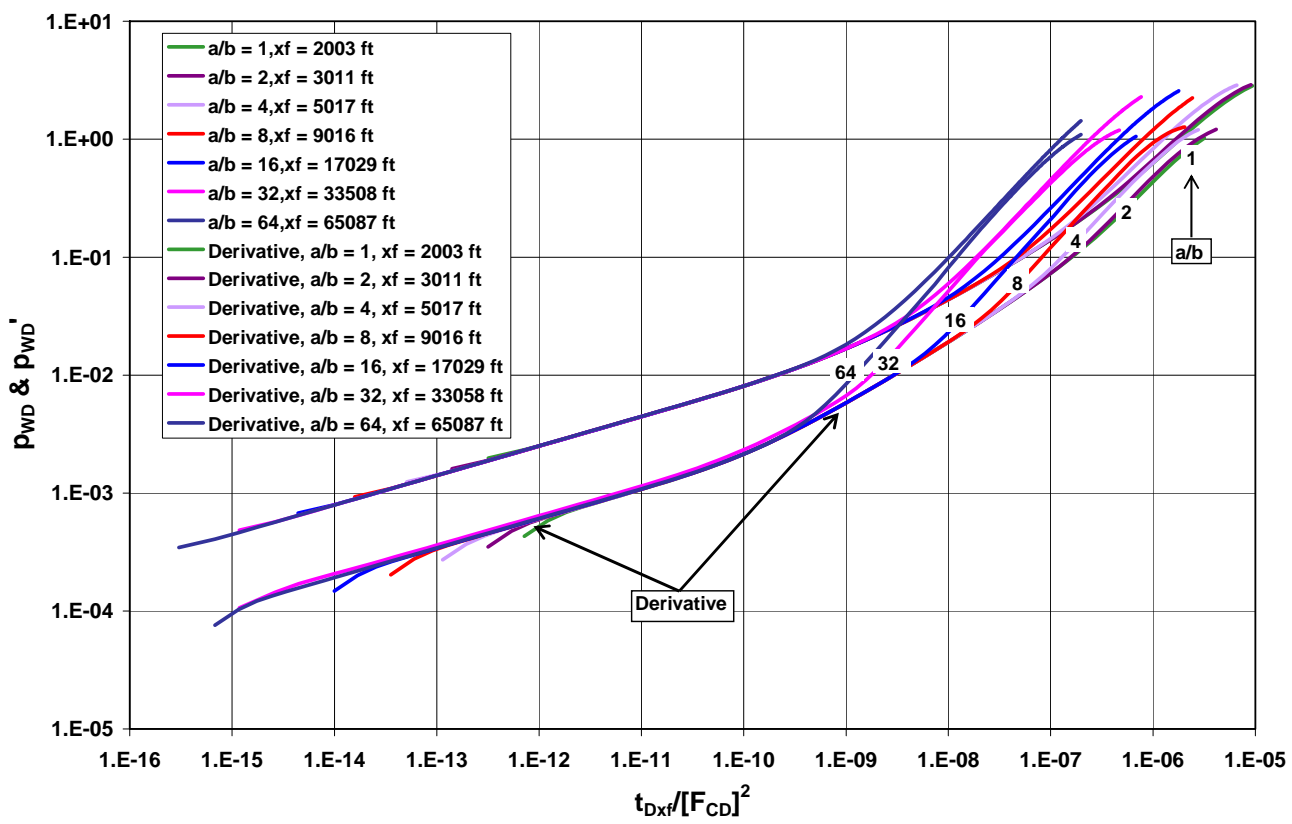

Fig A-13 - $\left(p_{W D}\right)$ and $\left(p_{W D}\right)$ versus $t_{D x} f\left(F_{C D}\right)^{2}$, all $a / b$ under constant rate production, $F C_{D}=200$ 


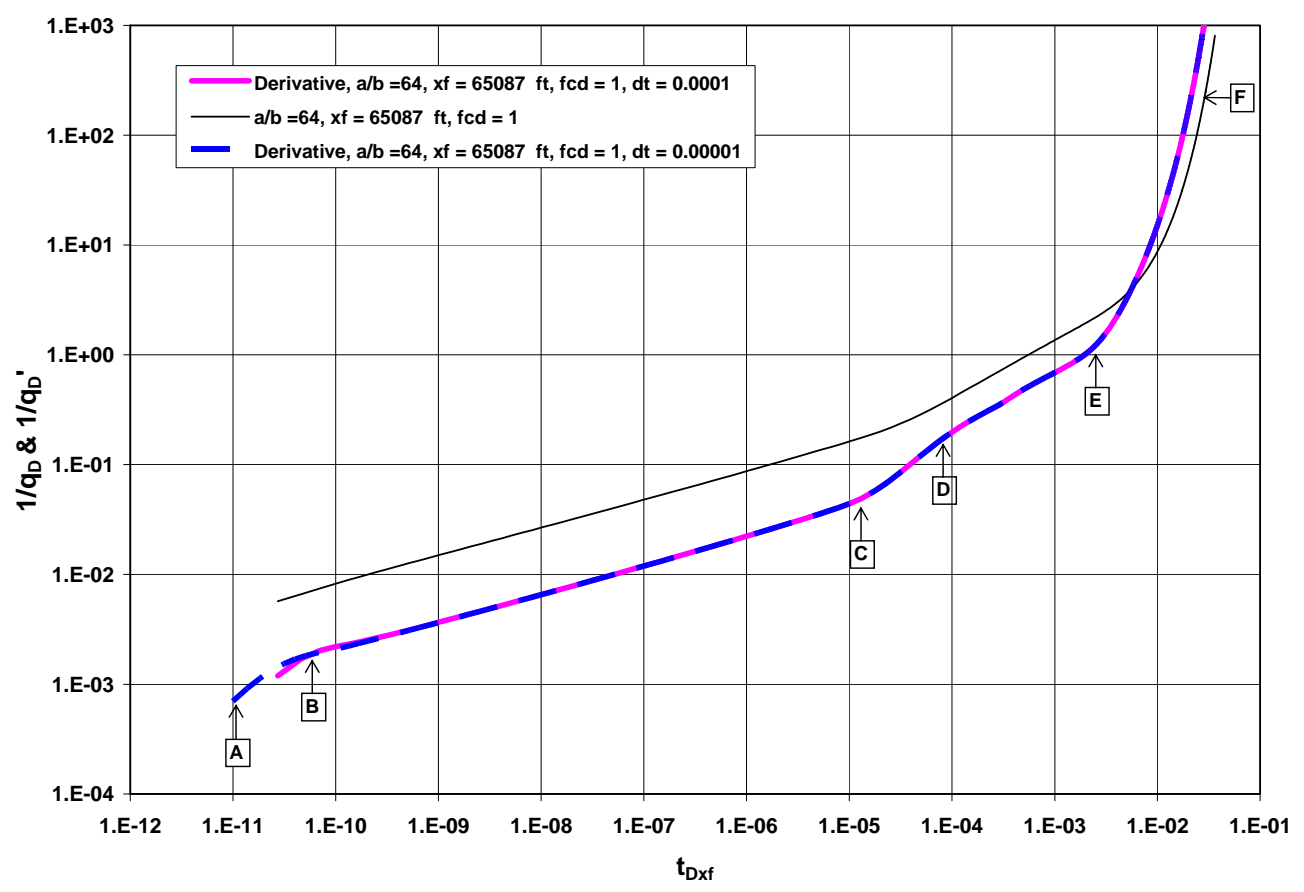

Fig A-14 - $\left(1 / q_{D}\right)$ and $\left(1 / q_{D^{\prime}}\right)$ versus $t_{D x f}, a / b=64$ under constant $p_{w f}$ production, $k_{f}=$ $100 \mathrm{md}, F_{C D}=1$ 


\title{
APPENDIX B \\ SIMULATION DATA SET
}

\author{
B-1 - CMG a/b $=64$, Constant production $p_{w f}$ \\ RESULTS SIMULATOR IMEX \\ RESULTS SECTION INOUT \\ * INUNIT *FIELD \\ *OUTUNIT *FIELD \\ * INTERRUPT * RESTART-STOP \\ ${ }^{*}$ RANGECHECK ${ }^{*} \mathrm{ON}$ \\ ${ }^{*} X D R{ }^{*} \mathrm{ON}$ \\ *MAXERROR 20
}

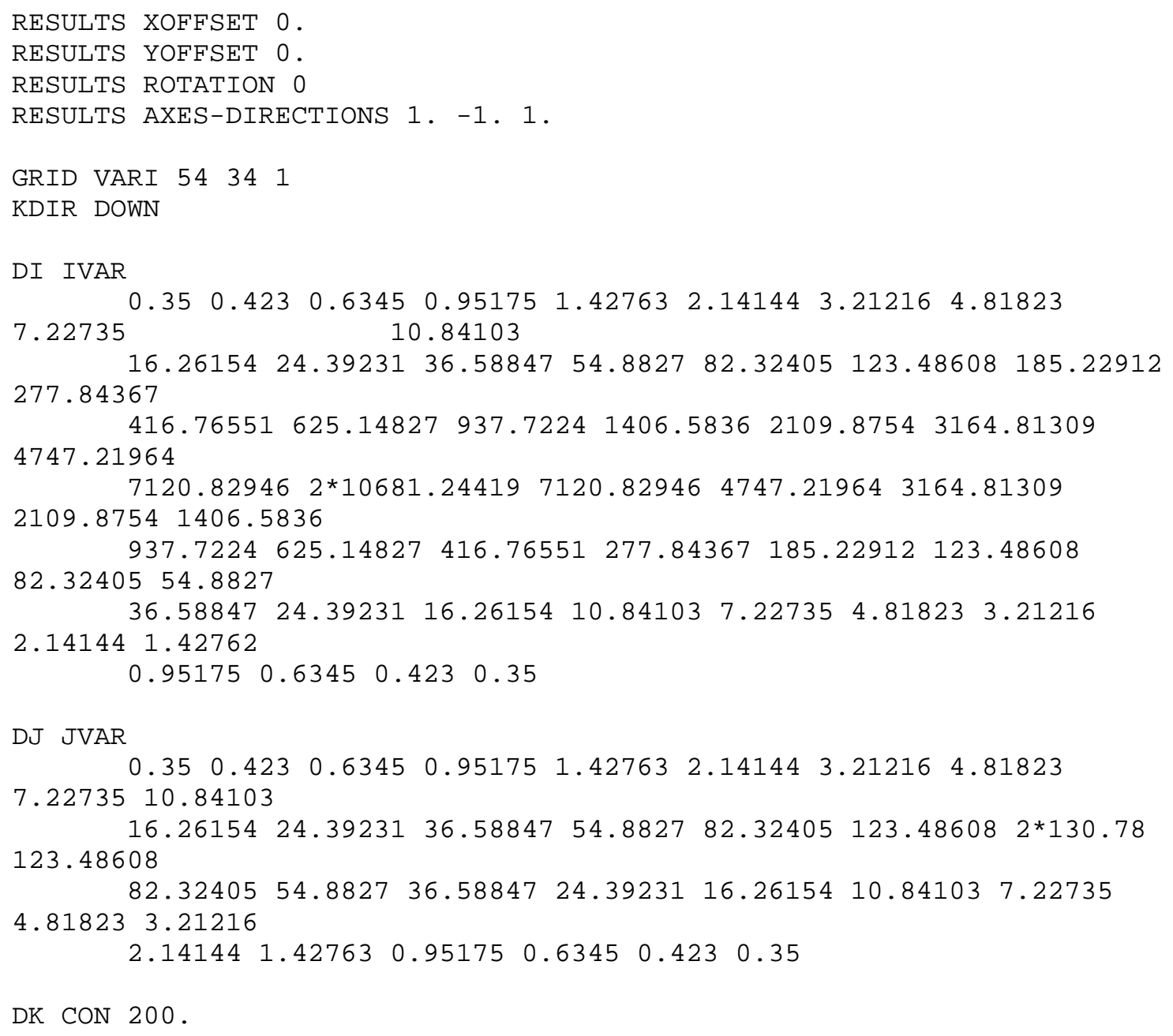




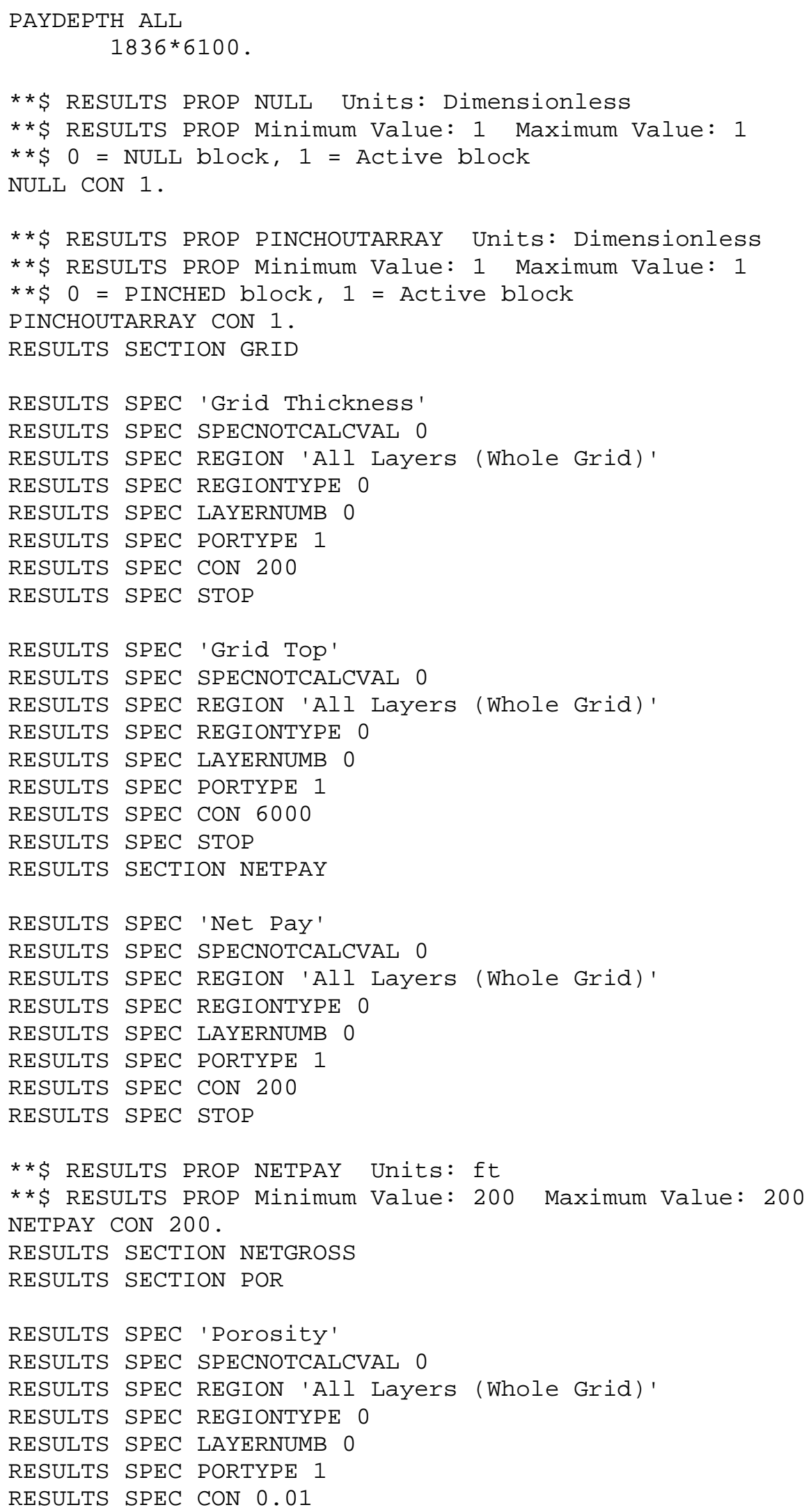




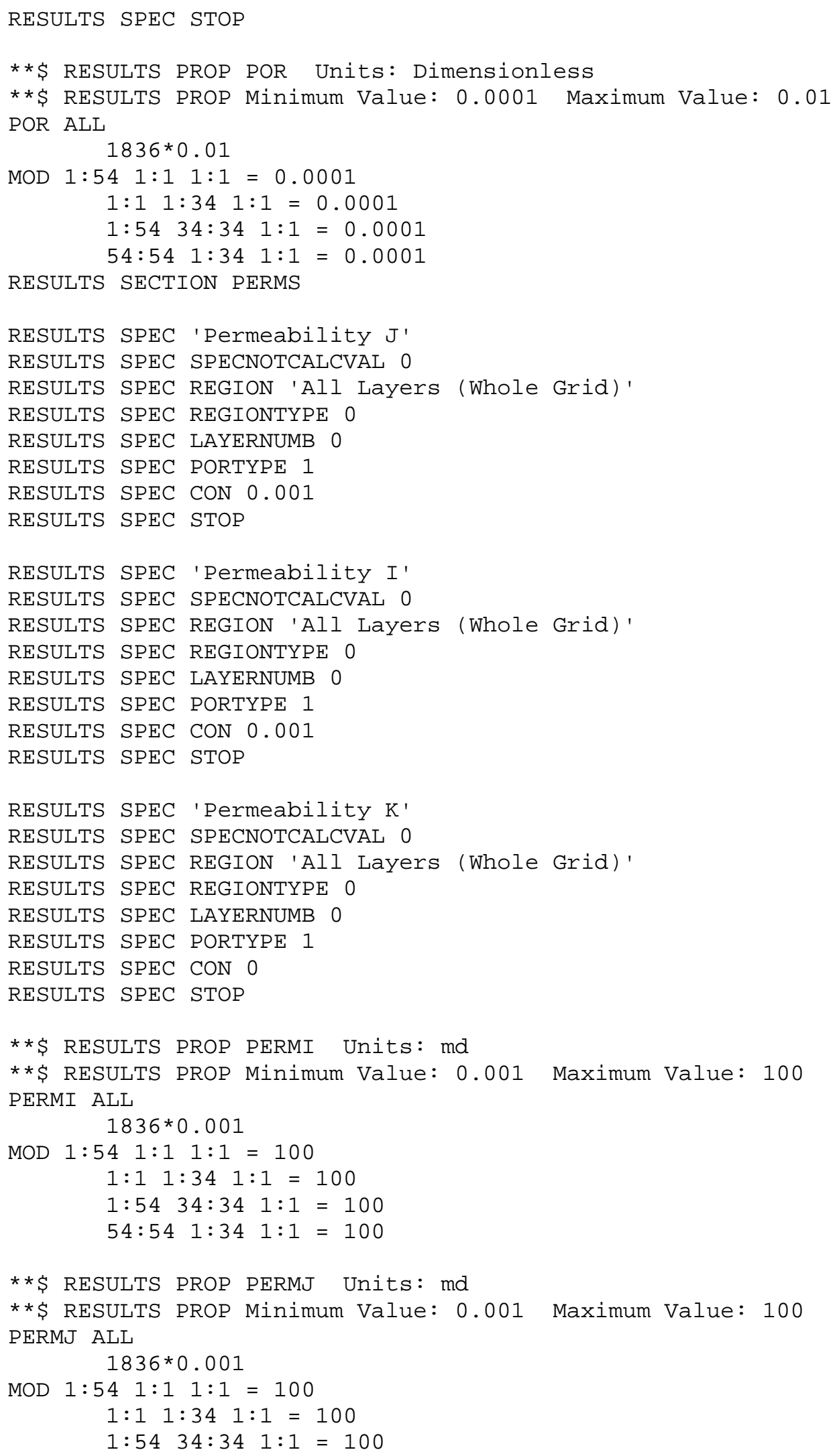


$54: 541: 341: 1=100$

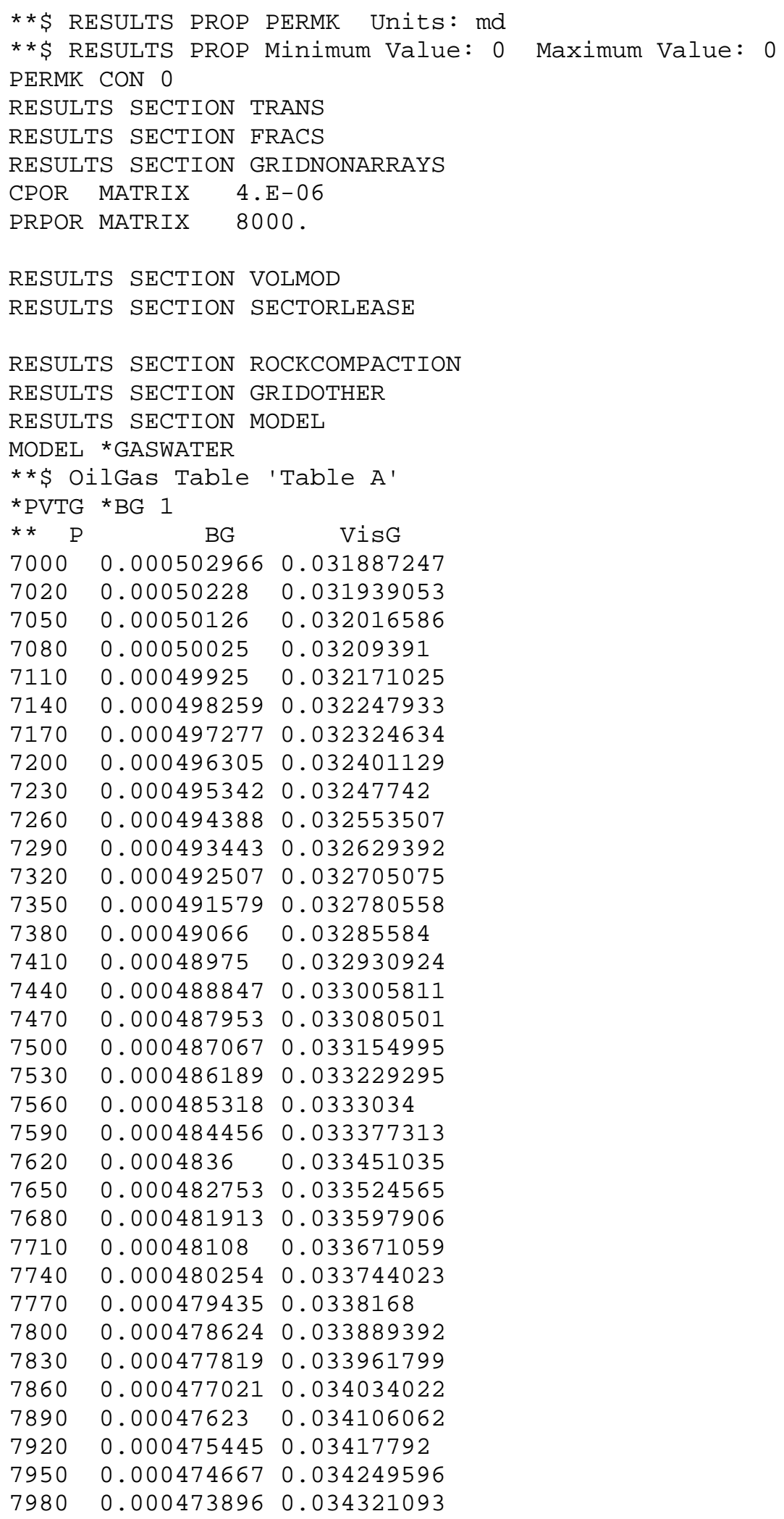




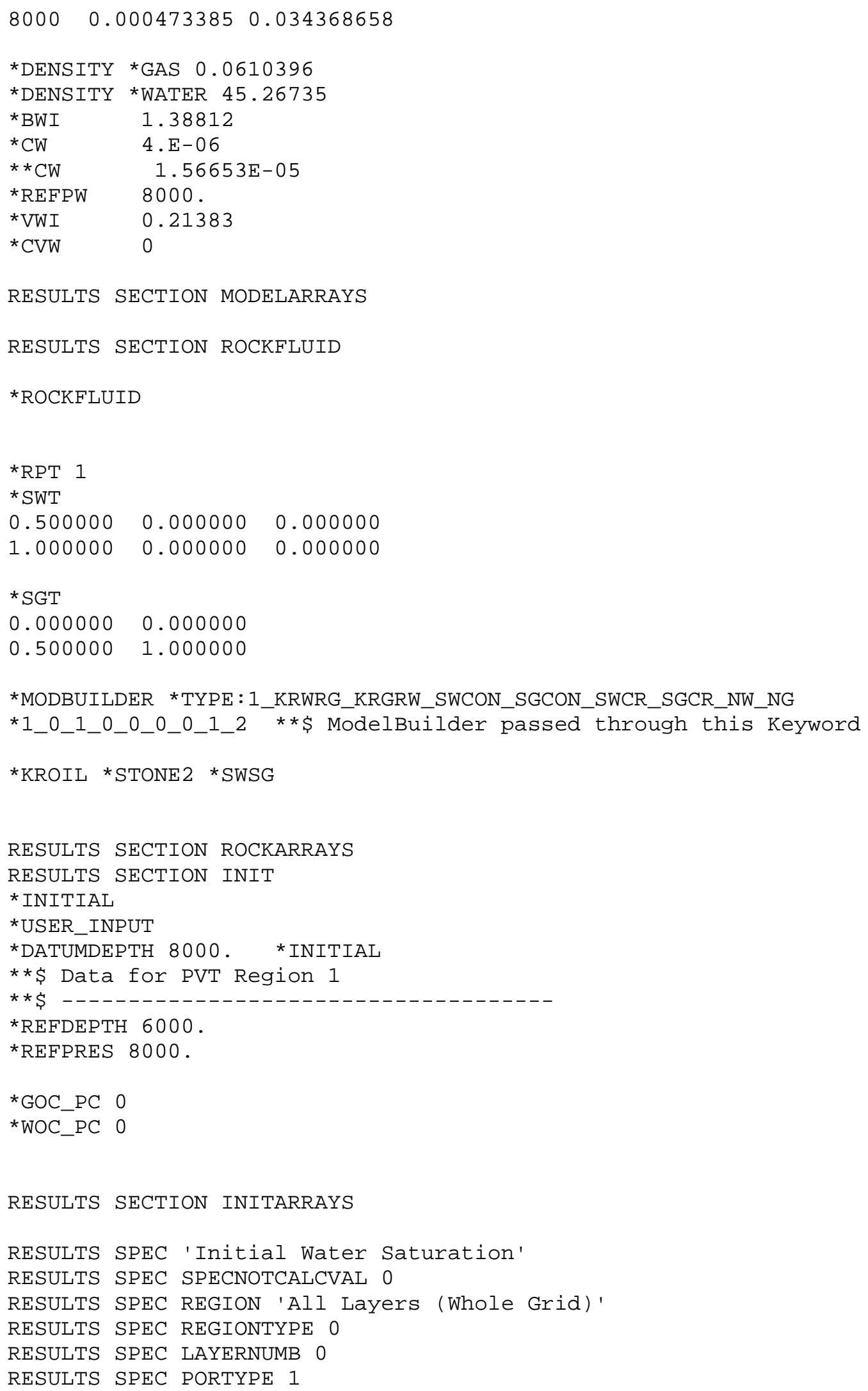




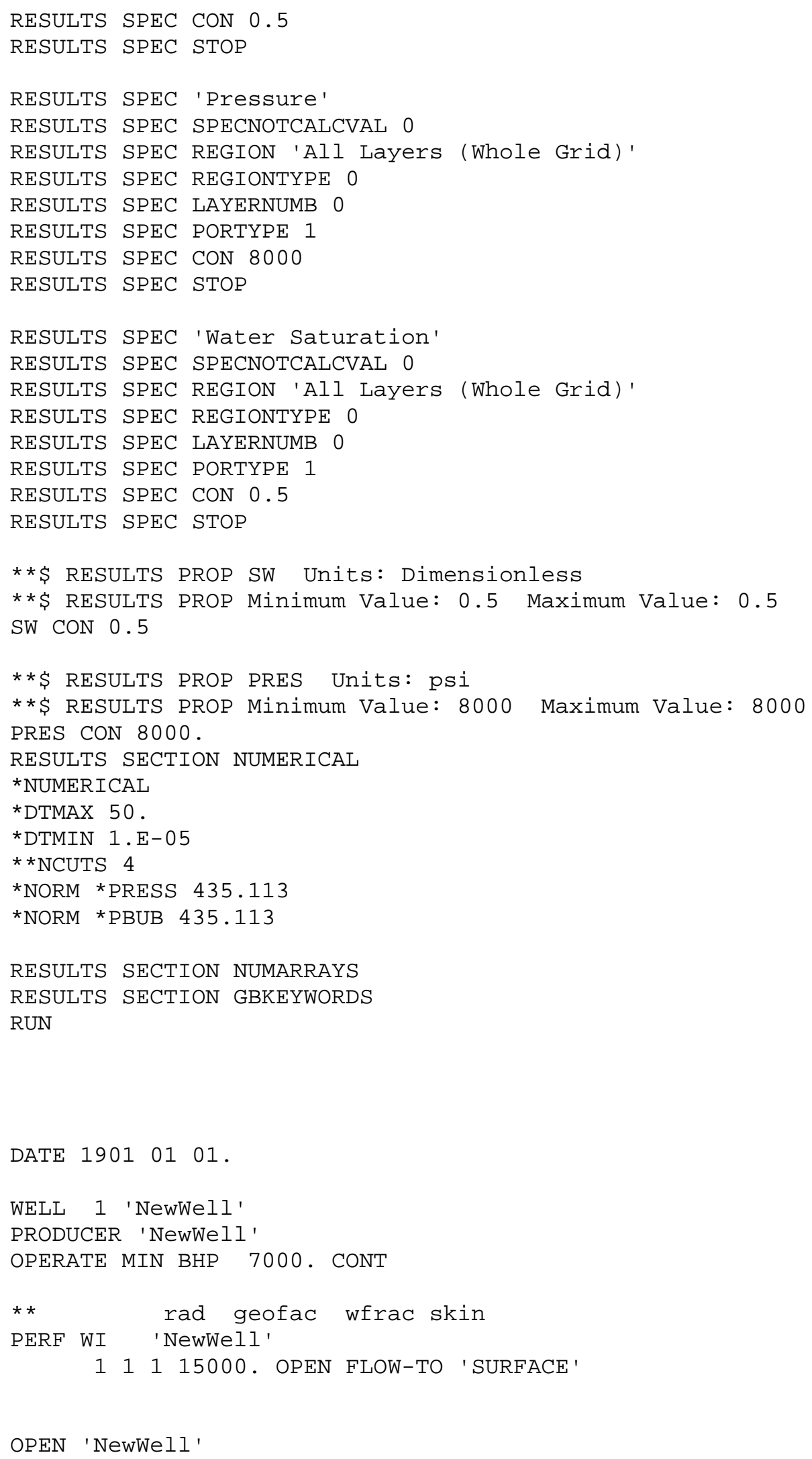


TIME $\odot .000 \odot 925926$

TIME $\odot .0002199074$

TIME 0.000358796

TIME $\odot .00056713$

TIME 7300

TIME $30000 \odot$

STOP

$\star * * * * * * * * * * * * * * * * * * * * * * * * * * * *$ TERMINATE SIMULATION

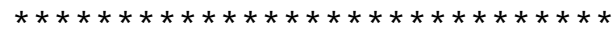




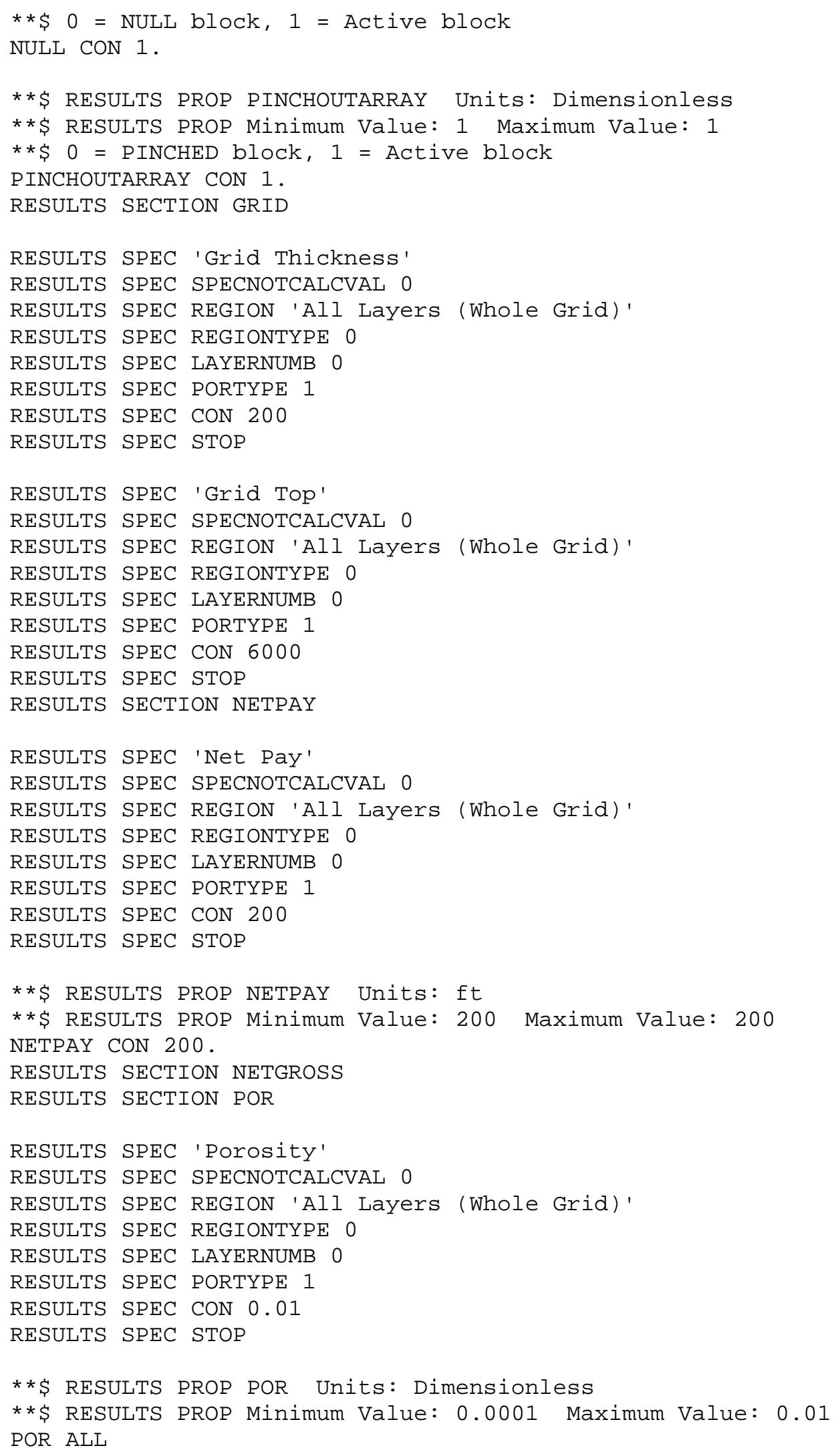




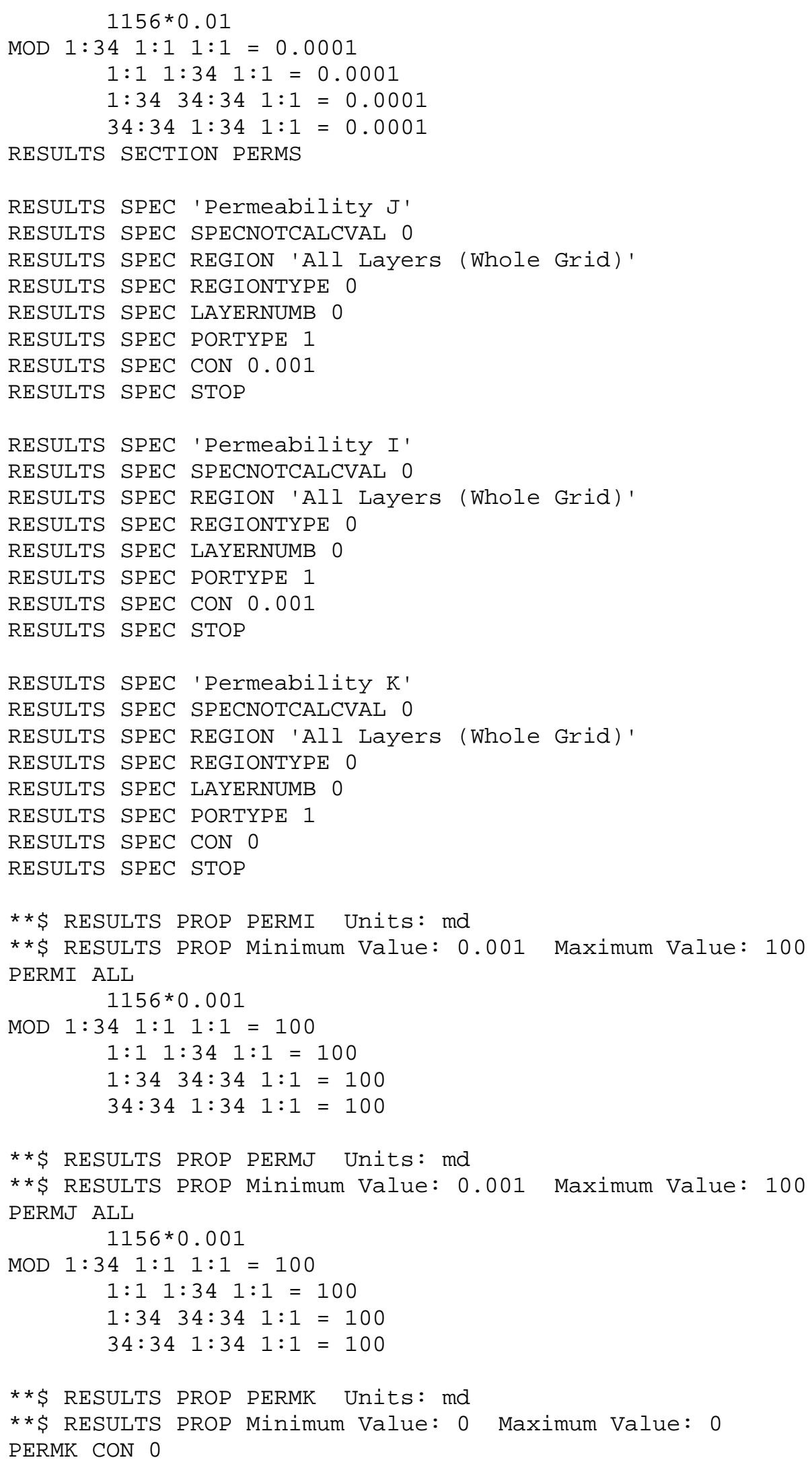




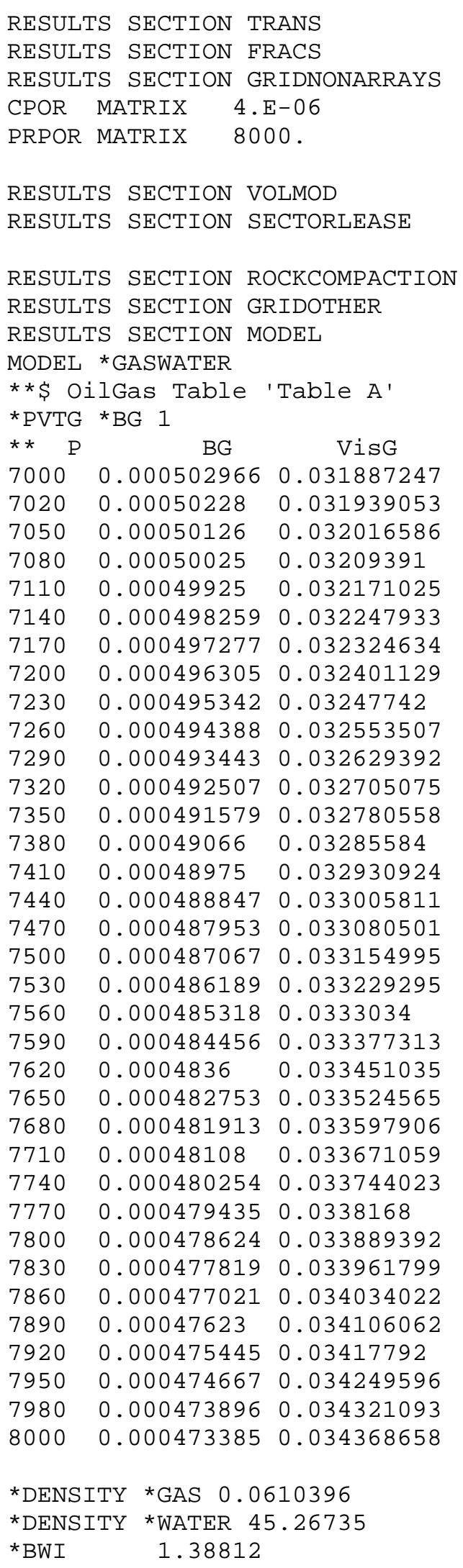




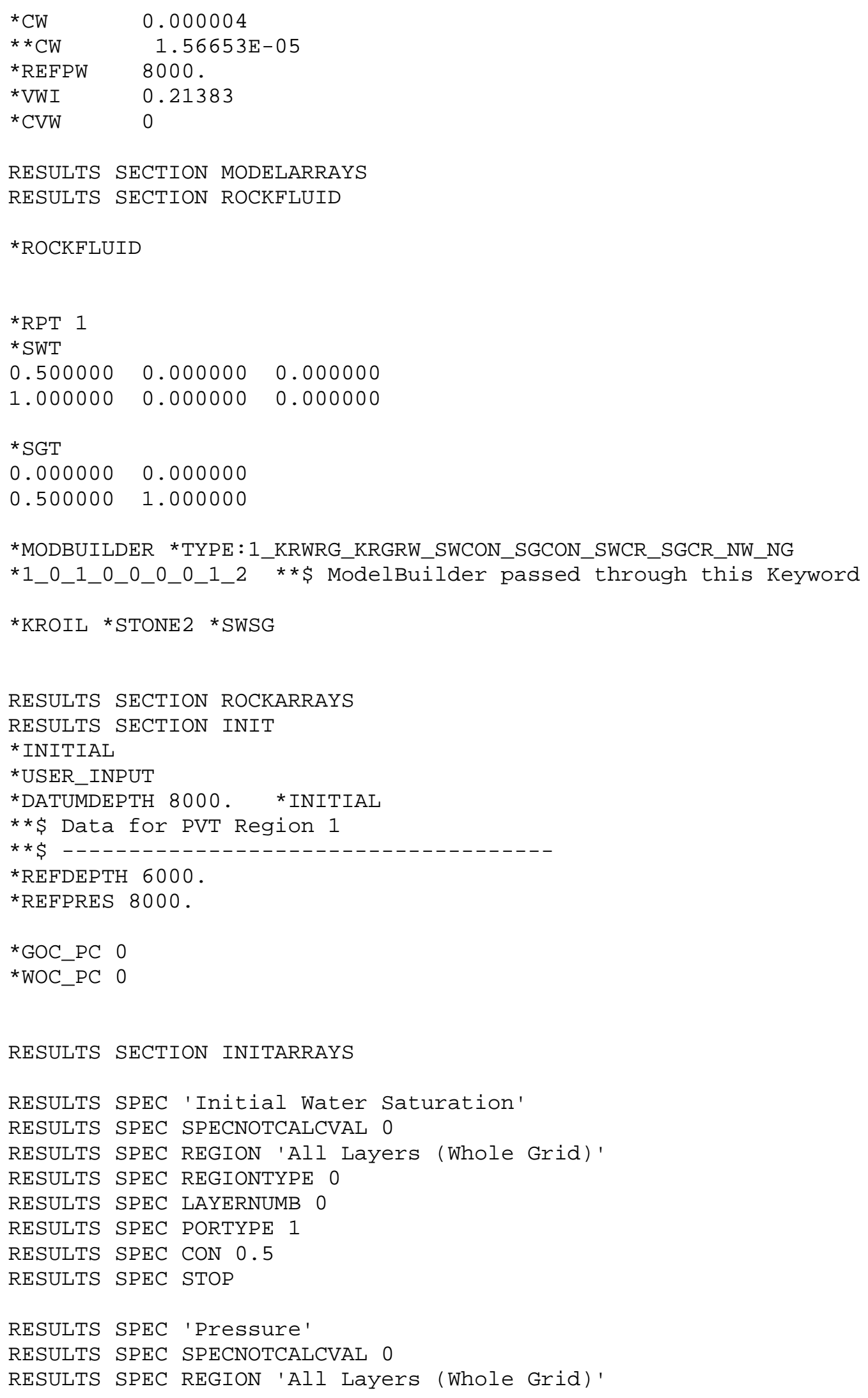




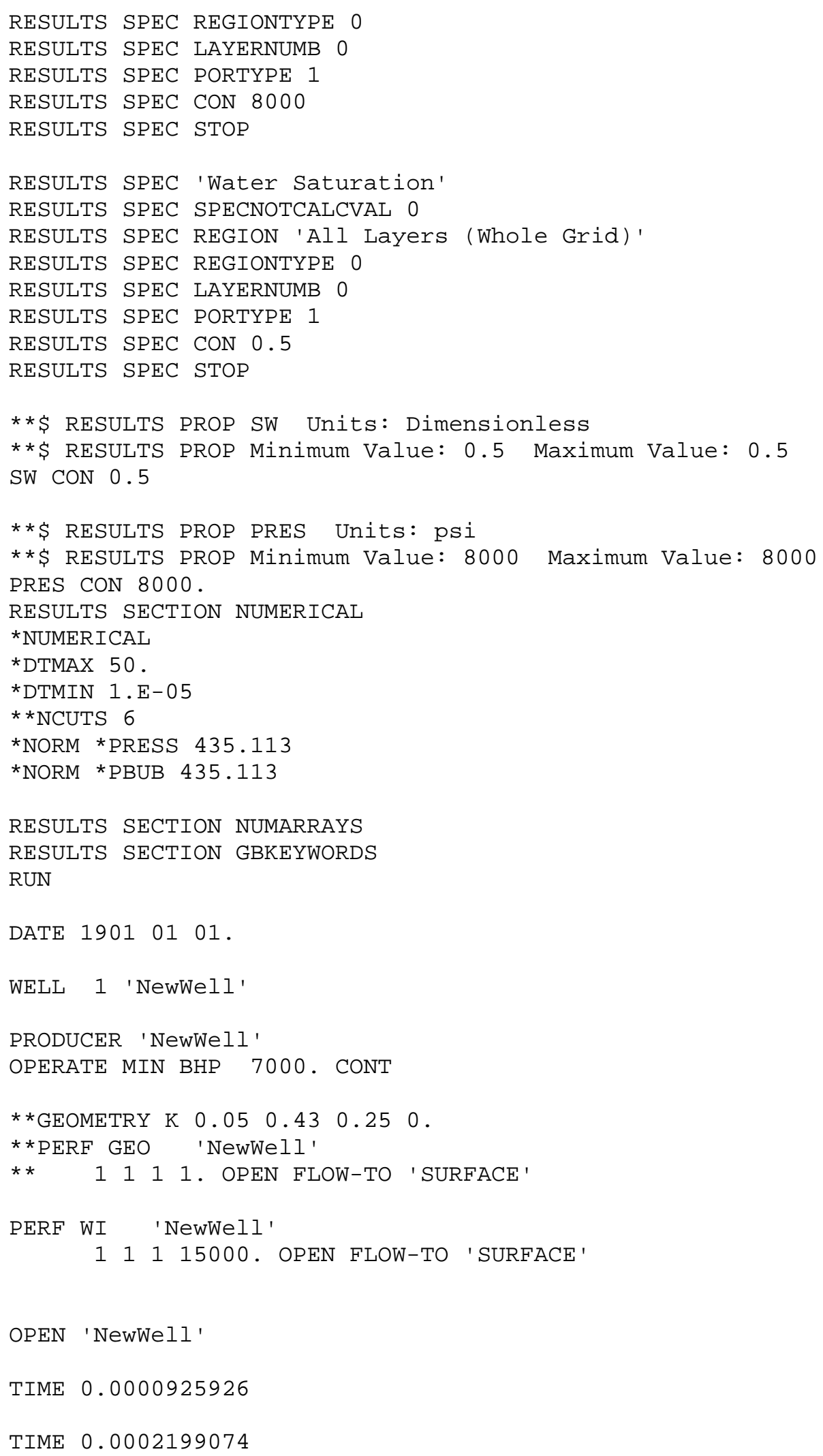


TIME 0.000358796

TIME $\odot .00056713$

TIME 0.000810185

TIME 6865.43

TIME 7300

STOP

$* * * * * * * * * * * * * * * * * * * * * * * * * * * * *$ TERMINATE SIMULATION

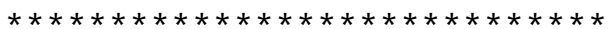

RESULTS SECTION WELLDATA

RESULTS SECTION PERFS 


\section{VITA}

Name: $\quad$ Romi Triaji Branajaya

Permanent Address: Komp. DPRRI Kelapa Dua 20, Kebon Jeruk, Jakarta Barat Jakarta, Indonesia, 11550.

Phone: (62-21)5490986

Email :1_rommy@yahoo.com

Education: $\quad$ B.S., Petroleum Engineering Trisakti University

Jakarta, Indonesia, 2001

Experience: $\quad 2000$ - present Reservoir Engineer, CNOOC Ltd, Indonesia 